\title{
Bioactive compounds and bioactive properties of chaga (Inonotus obliquus) mushroom: a review
}

\author{
Han Peng and Fereidoon Shahidi*
}

\begin{abstract}
Department of Biochemistry, Memorial University of Newfoundland, St. John's, NL, Canada A1B 3X9
*Corresponding author: Fereidoon Shahidi Department of Biochemistry, Memorial University of Newfoundland, St. John's, NL, Canada A1B 3X9. Tel: (709)864-8552; E-mail: fshahidi@mun.ca

DOI: $10.31665 /$ JFB.2020.12245

Received: December 04, 2020; Revised received \& accepted: December 24, 2020

Citation: Peng, H., and Shahidi, F. (2020). Bioactive compounds and bioactive properties of chaga (Inonotus obliquus) mushroom: a review. J. Food Bioact. 12: 9-75.
\end{abstract}

\begin{abstract}
Chaga (Inonotus obliquus) is an edible herbal mushroom extensively distributed in the temperate to frigid regions of the Northern hemisphere, especially the Baltic and Siberian areas. Chaga parasites itself on the trunk of various angiosperms, especially birch tree, for decades and grows to be a shapeless black mass. The medicinal/nutraceutical use of chaga mushroom has been recorded in different ancient cultures of Ainu, Khanty, First Nations, and other Indigenous populations. To date, due to its prevalent use as folk medicine/functional food, a plethora of studies on bioactive compounds and corresponding compositional analysis has been conducted in the past 20 years. In this contribution, various nutraceutical and pharmaceutical potential, including antioxidant, anti-inflammatory, anti-tumor, immunomodulatory, antimutagenic activity, anti-virus, analgesic, antibacterial, antifungal, anti-hyperglycemic, and anti-hyperuricemia activities/effects, as well as main bioactive compounds including phenolics, terpenoids, polysaccharides, fatty acids, and alkaloids of chaga mushroom have been thoroughly reviewed, and tabulated using a total 171 original articles. However, only key bioactivities and bioactives are selectively discussed. Besides, the up-to-date toxicity concerns and risk assessment about the misuse of chaga, which limit its acceptance and use as medicinal/ nutraceutical products, have also been clarified.
\end{abstract}

Keywords: Phenolics; Terpenoids; Polysaccharides; Alkaloids; Nutraceutical/medicinal properties; Bioactives and bioactivities; Toxicity/ safety concerns.

\section{Introduction}

Chaga (Inonotus obliquus) is a terrestrial polypore fungus of $\mathrm{Hy}$ menochaetaceae family, which is mainly distributed in temperate to frigid regions, including North/East Asia, North America, and Central/Eastern/North Europe (Zhong et al., 2009). It is also found in low-latitude areas such as Western/Southern Europe and even Southeast Asia (Thailand) (Glamočlija et al., 2015). Chaga parasites itself on the bark of various boreal broad-leaved deciduous angiosperms such as birch (Betula spp.) and beech (Fagus spp.). However, some other rare hosts such as maple (Acer spp.), alder (Alnus spp.), oak (Quercus spp), and poplar (Populus spp.) may also be available (Lee et al., 2008). The parasitized site on the trunk would finally develop to be a white heart rot in the appearance of shapeless black mass, and these decays typically last for more than ten years and result in the death of the host (Lee et al., 2008). In Northern and Eastern Europe/Asia such as Russia, Poland, Finland, Belarus, and Japan, this wood-destroying fungus has been used as a functional beverage (tea) or folk medicine (decoction, ointment) for the treatment of stomach diseases, intestinal worms, liver/heart ailments, dermatomycoses, joint pains, and different kinds of cancers for centuries (Babitskaya et al., 2002; Koyama, 2017; Lemieszek et al., 2011; Saar, 1991; Shashkina et al., 2006; Shikov et al., 2014). In North America, the historical use for medicinal purposes (including skin irritation and arthritis) by Alaskan, First Nations and other Indigenous tribes such as 
Cree, Chipewyan, Gitxsan, Wet'suwet'en has also been recorded (Cottesfeld, 1992; Kari, 1987; Rogers, 2012; Scerbak et al., 2016).

The binomial name of chaga is known as Inonotus obliquus, but other names including Phaeoporus obliquus, Polyporus obliquus, or Fuscoporia obliqua, have also been sporadically used (He et al., 2001; Reid, 1976). Inonotus is a genus of fungi in the family Hymenochaetaceae that was first described and given by Petter Adolf Karsten and so far is estimated to have 101 species in its wider sense (2005 data) (Ghobad-Nejhad and Kotiranta, 2008; Kirk et al., 2008; Ren and Dai, 2018; Ryvarden, 2005; Wu et al., 2018; Zhou et al., 2016). Interestingly, even though chaga has been clearly defined and classified in nomenclature and taxonomy, the misuse of the original data from the studies of others closely related species rather than the real Inonotus obliquus has frequently happened in some previous reviews (Duru et al., 2019; Zheng et al., 2010). To date, numerous studies have claimed various bioactivities, together with related molecular mechanism of chaga, including antioxidant, antimicrobial, anti-cancer, hypoglycemic, antilipidemic, anti-inflammation, abirritative, immunoregulatory, and cardioprotective effects (Koyama et al., 2008; Patel, 2015; Shashkina et al., 2006; Zhong et al., 2009). Apparently, such a broad spectrum of biological/pharmacological functions implies the complexity of bioactive substances in chaga. However, despite decades of efforts, the full scale of known bioactive components of chaga and corresponding mechanisms of its health effects upon oral ingestion or other administration approaches is still uncertain. Meanwhile, several side effects associated with specific cases are rarely discussed. This contribution intends to fill the existing gap in previous works and to update the secondary metabolites of chaga and their biological properties as well as safety considerations based on the latest available studies.

\section{Health claims for chaga (Inonotus obliquus) extracts}

In East Asian countries, such as China, Japan, and Korea, the use of medicinal mushrooms (e.g., Ganoderma lucidum and Grifola frondosa) and their derived products (e.g., $\beta$-glucan and lentinan) has continued in traditional therapies, but is now also supported by the modern medicinal systems with the verification of phases I, II, or even III clinical trials (Chatterjee et al., 2011; Deng et al., 2009; Deng et al., 2008; Gao, 1993; Gao et al., 2004a; Gao et al., 2004b; Gordon et al., 1998; Kidd, 2000; Ohno et al., 2011; Taguchi et al., 1985; Xu et al., 2012; Zhang et al., 2019). Similarly, chaga is one of the most important and popular medicinal mushrooms which has been extensively used in the East European countries for centuries. As already mentioned, the diversity of its bioactive compounds and effects thereof have been gradually unveiled in the past decades, even though related clinical data are relatively scarce. The recent advancement of health functions as well as the molecular mechanism of chaga extracts is summarized (Table 1) and discussed

\subsection{Anti-tumor effects}

Among various pharmacological properties of crude extracts of chaga, its anti-tumor effects have attracted the most attention. According to World Health Organization (WHO) (2018), cancer, the second leading cause of death, led to an estimated 9.6 million death globally in 2018; thus accounting for around one in six deaths. In the United States, approximately $39.55 \%$ of men and women are diagnosed with cancer at some points during their lifetime (2015-2017 data), and estimated national expenditure for cancer care in 2017 was $\$ 147.3$ billion (NIH, 2020). As shown in Table 1, various extracts of chaga mushroom present broad in vitro anti-proliferation activities on various cancer cells. Baek et al. (2018) reported that the hexane and dichloromethane fractions of methanolic extract of chaga showed significant cytotoxicity on A549, H1264, H1299, and Calu-6 lung cancer cell lines, with $\mathrm{IC}_{50}$ of $95.3-225.1 \mu \mathrm{g} / \mathrm{ml}$. Water and $70 \%$ ethanolic extracts of chaga inhibited the growth of MCF-7 human breast cancer cells, NCI-H460 human non-small cell lung cancer cells, HeLa human cervical uteri tumor cells, and HepG2 human liver cancer cells with $\mathrm{IC}_{50}$ ranging from 80.93 to $318.19 \mu \mathrm{g} / \mathrm{ml}$ (Glamočlija et al., 2015). In in vitro models of PC3 human prostatic carcinoma cells and MDA-MB-231 human breast carcinoma cells, petroleum ether fraction of chaga showed a similar anti-proliferation activity to doxorubicin (Ma et al., 2013). Chaga extracts were found to inhibit the proliferation of cancer cells by inhibiting mitosis and arresting the cell cycle. Jarosz et al. (1990) found that the culture medium of chaga and its lower-molecular weight extracts (fractions from Sephadex G-25 chromatography) block the mitosis of Hela cells with a significant increase of catalase activity and impairment of chromosome and cellular membrane. Later, Mishra et al. (2013) showed that water extract of chaga arrested DLD 1 and HCT116 cells at S phase. While in B16-F10 cells, the water extract arrested cell cycle at $\mathrm{G}_{0} /$ $\mathrm{G}_{1}$ phase with down-regulation of $\mathrm{pRb}, \mathrm{p} 53, \mathrm{p} 27$, cyclin D1/E and CDK 2/4 expression levels (Youn et al., 2009). Likewise, the cell cycle of HepG2 cells was arrested by water extract of chaga at the $\mathrm{G}_{0} /$ $\mathrm{G}_{1}$ phase associated with down-regulation of $\mathrm{p} 53, \mathrm{pRb}, \mathrm{p} 27$, cyclins D1/D2/E, and CDK 2/4/6 expression (Youn et al., 2008). However, in HT-29 cells, the ethanol extract of chaga arrested it in the $\mathrm{G}_{1}$ phase by inhibition of CDK2, CDK4, cyclin D1, and pRb, but with activation of p21, p27, and p53 (Lee et al., 2015a). This vital function of p53 was proven to be unrelated to the pro-apoptotic effect of hexane and dichloromethane fractions of methanolic extracts of chaga on A549, H1264, H1299, and Calu-6 lung cancer cell lines (Baek et al., 2018). Besides, several classic apoptotic pathways were reported to be modulated by chaga extracts. For example, water extract of chaga induced cell apoptosis through downregulation of antiapoptotic protein (Bcl-2) and upregulation of proapoptotic proteins (Bax and caspase-3) in HT-29 cells (Lee et al., 2009). The apoptosis of HepG2 cells induced by water extract of chaga was coupled with the activation of caspase-3 (Youn et al., 2008). Meanwhile, both caspase 3 and 9 were activated in both extract-treated DLD 1 and HCT116 cells, but caspase 8 was only partially activated in HCT116 cells (Mishra et al., 2013). In these two in vitro studies of Youn et al. (2008) and Mishra et al. (2013), water extract inhibited both cytoplasmic and nuclear levels of NK- $\mathrm{BB}$ and $\beta$-catenin, as well as the cytosolic level of a key inflammatory mediator Cox-2 (cyclooxygenase-2). The in vivo anti-tumor effects of chaga extracts were also assessed in various animal models. The intraperitoneal administration of water extract of chaga at a dose of $20 \mathrm{mg} / \mathrm{kg} /$ day for ten days significantly inhibited the growth of tumor mass in B16-F10 cells implanted mice (Youn et al., 2009). A 14-days oral administration of water extract of chaga at a dose of $20-100 \mathrm{mg} / \mathrm{kg}$ body weight/day regressed the tumors in sarcoma 180 implanted mice by inhibiting the sarcoma 180-induced reduction of splenic lymphocytes, stimulating TNF- $\alpha$ release in peritoneal macrophage, and eliciting the over-expression of Bax gene in sarcoma 180 cells of mice (Chen, 2007). In addition, the water extract of chaga showed inhibitory effects on the growth of intestinal polyps in $\mathrm{APC}^{\mathrm{Min} /+}$ mice and colon tumors in AOM/DSS-treated mice. Supplement of the water extract of chaga suppressed the nuclear levels of $\beta$-catenin, inhibited its downstream targets (cyclin D1 and $\mathrm{c}-\mathrm{Myc}$ ), reduced pro-caspase- 3 and cleaved PARP, along with $\mathrm{CRC}$ (colorectal cancer) oncogene CDK8 in $\mathrm{APC}^{\mathrm{Min} /+}$ mice (Mishra et al., 2013). Simultaneously, the inhibition of inflammatory proteins including iNOS and Cox-2 and mRNA levels of pro-inflammatory cytokines (IL-6, IL-1 $\beta$, TNF- $\alpha$ and IFN- $\gamma$ ) was found in the intestine 


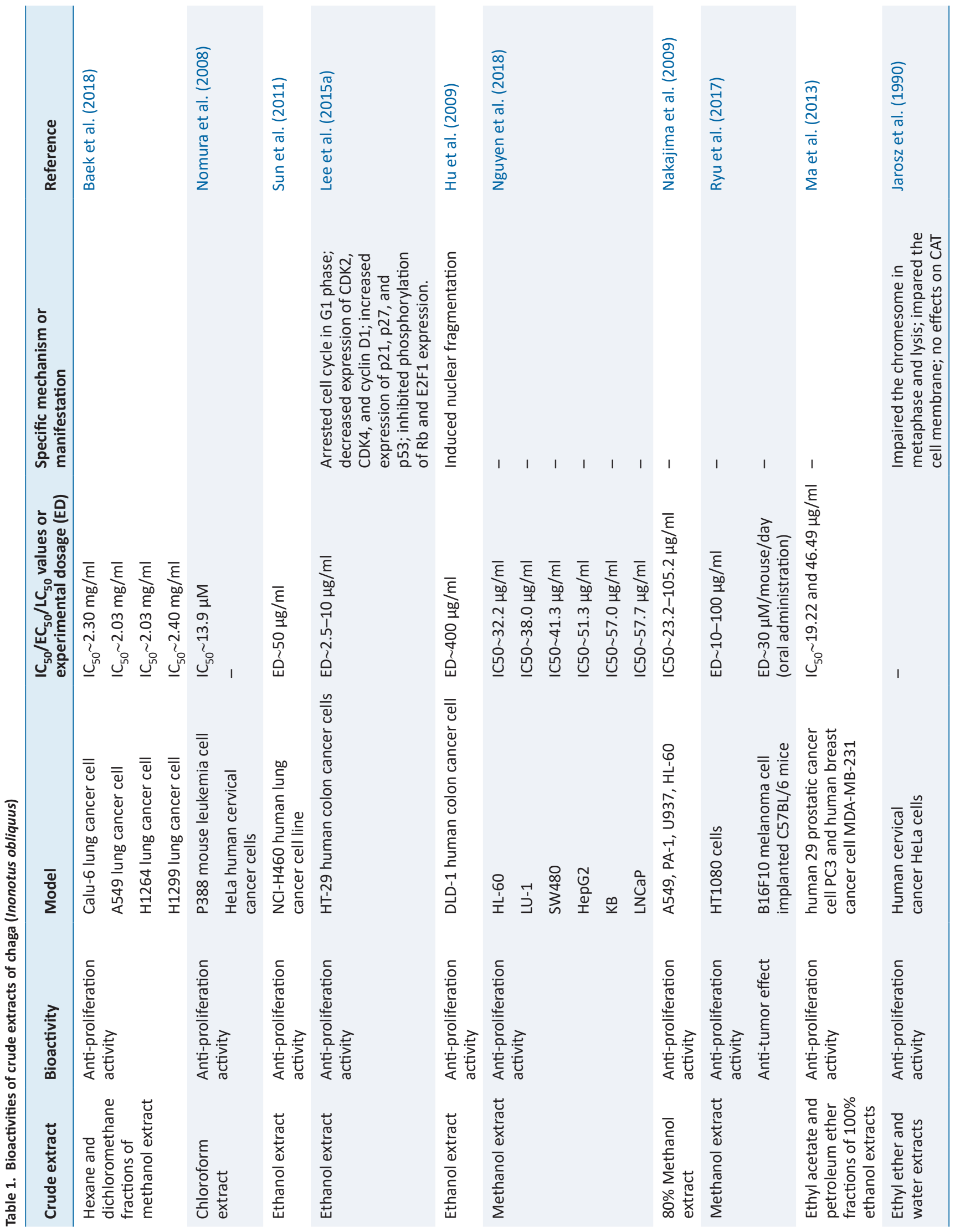




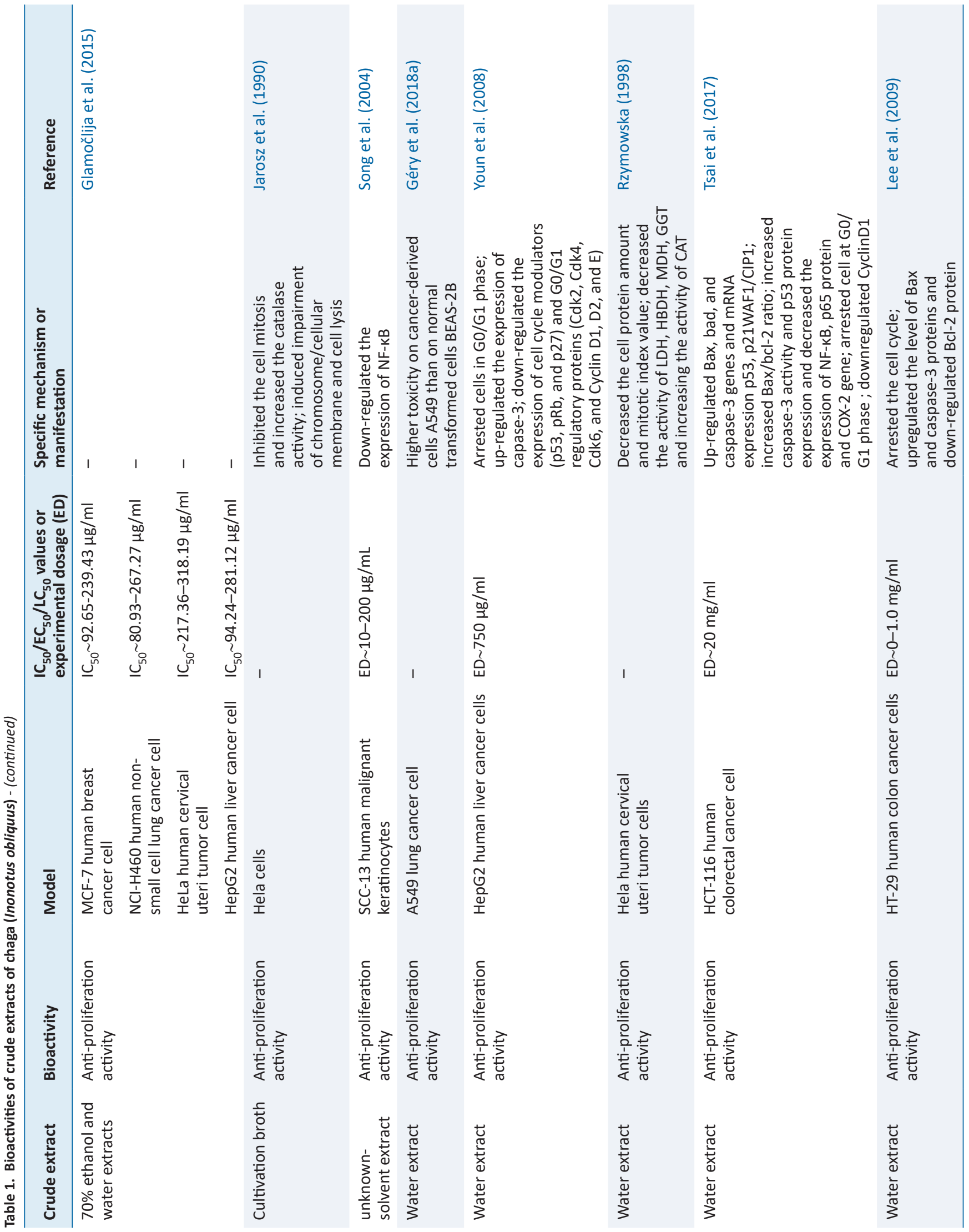




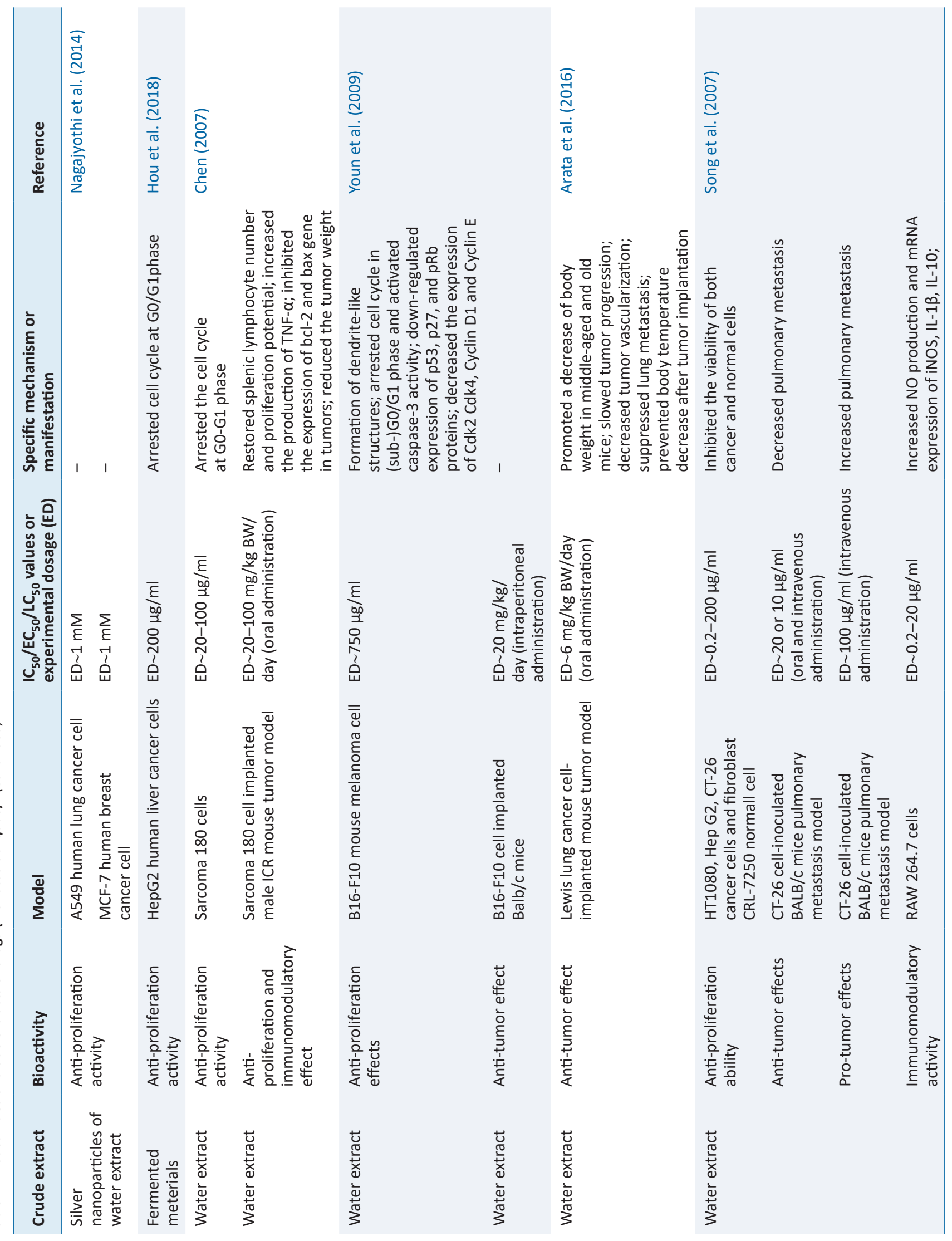




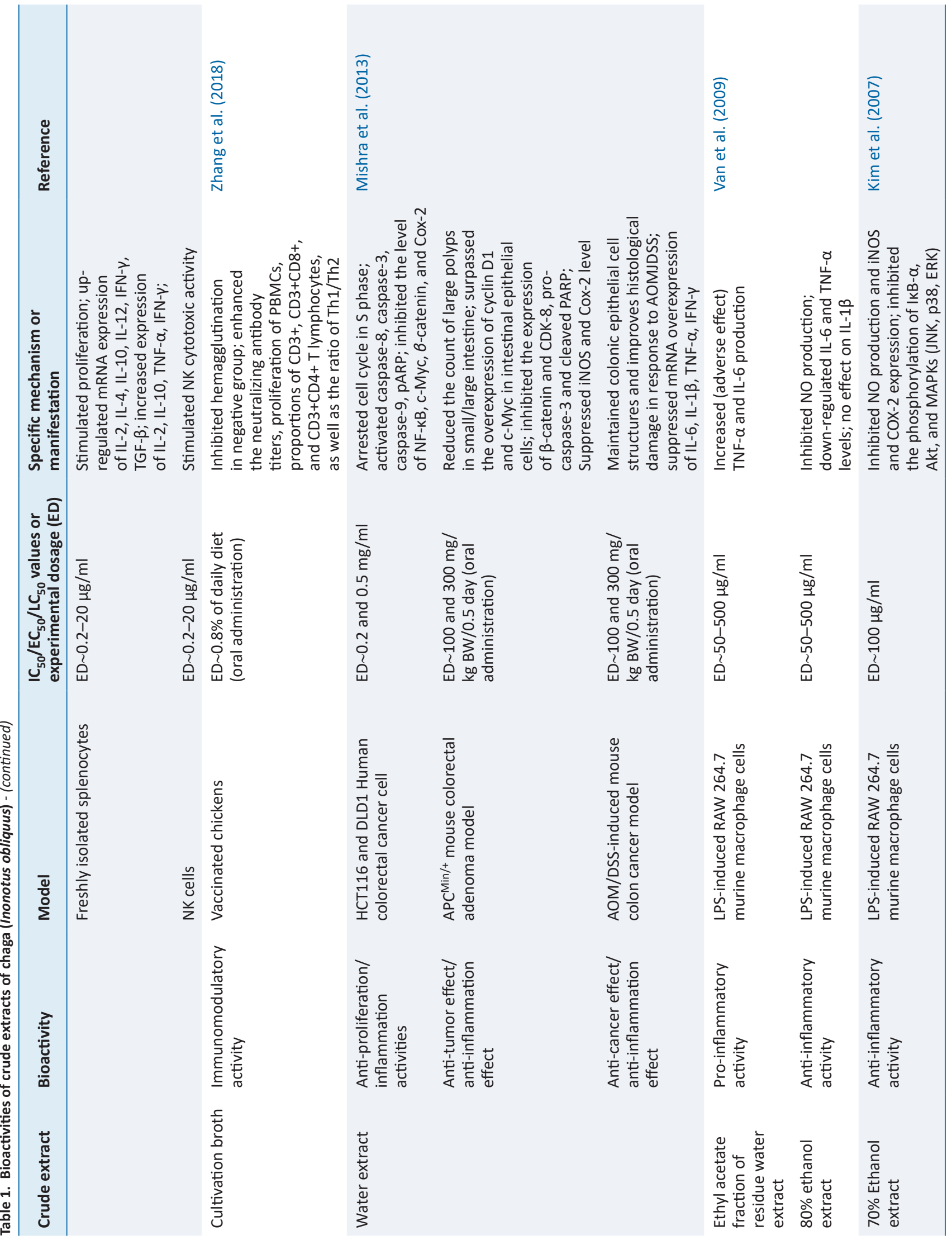




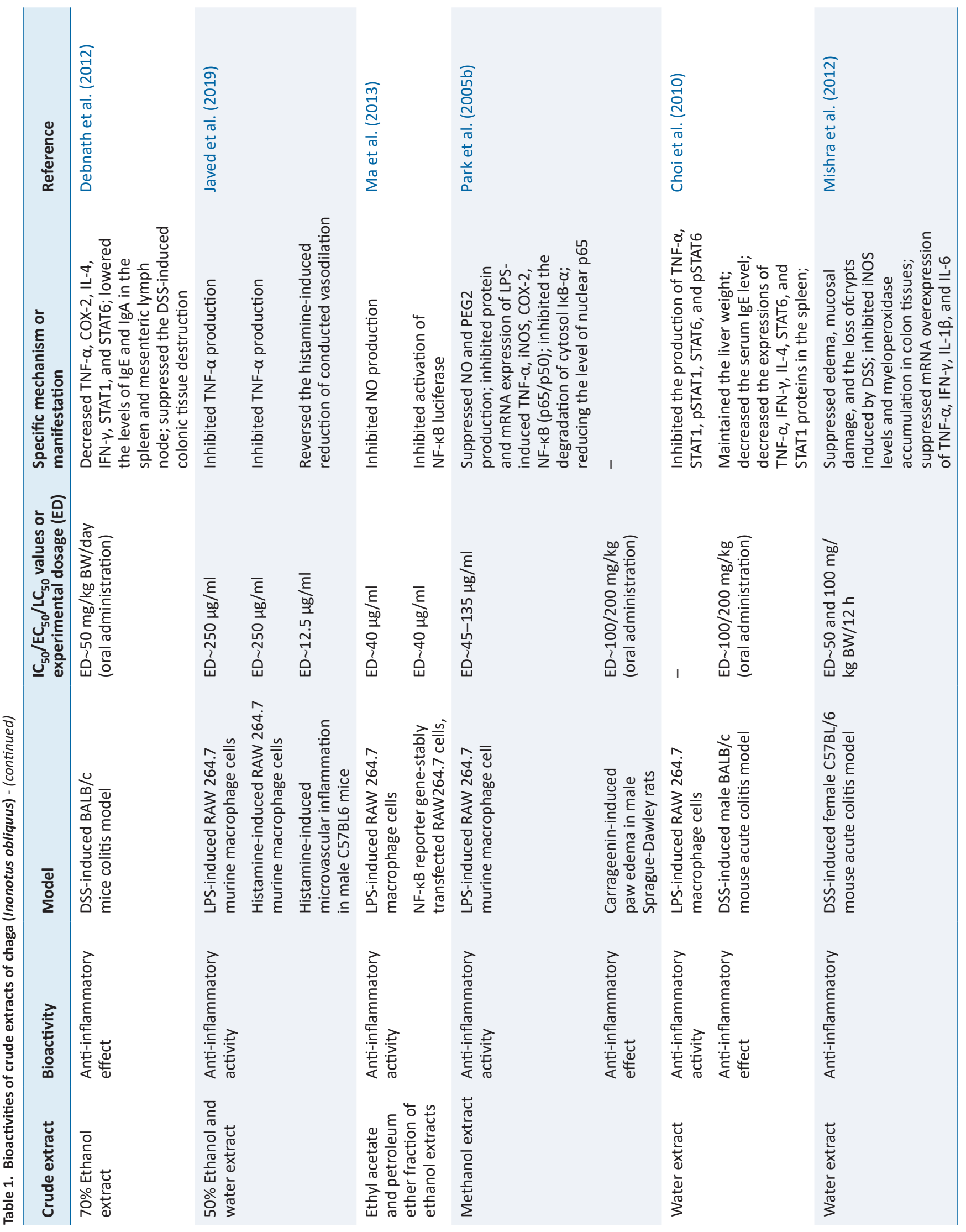




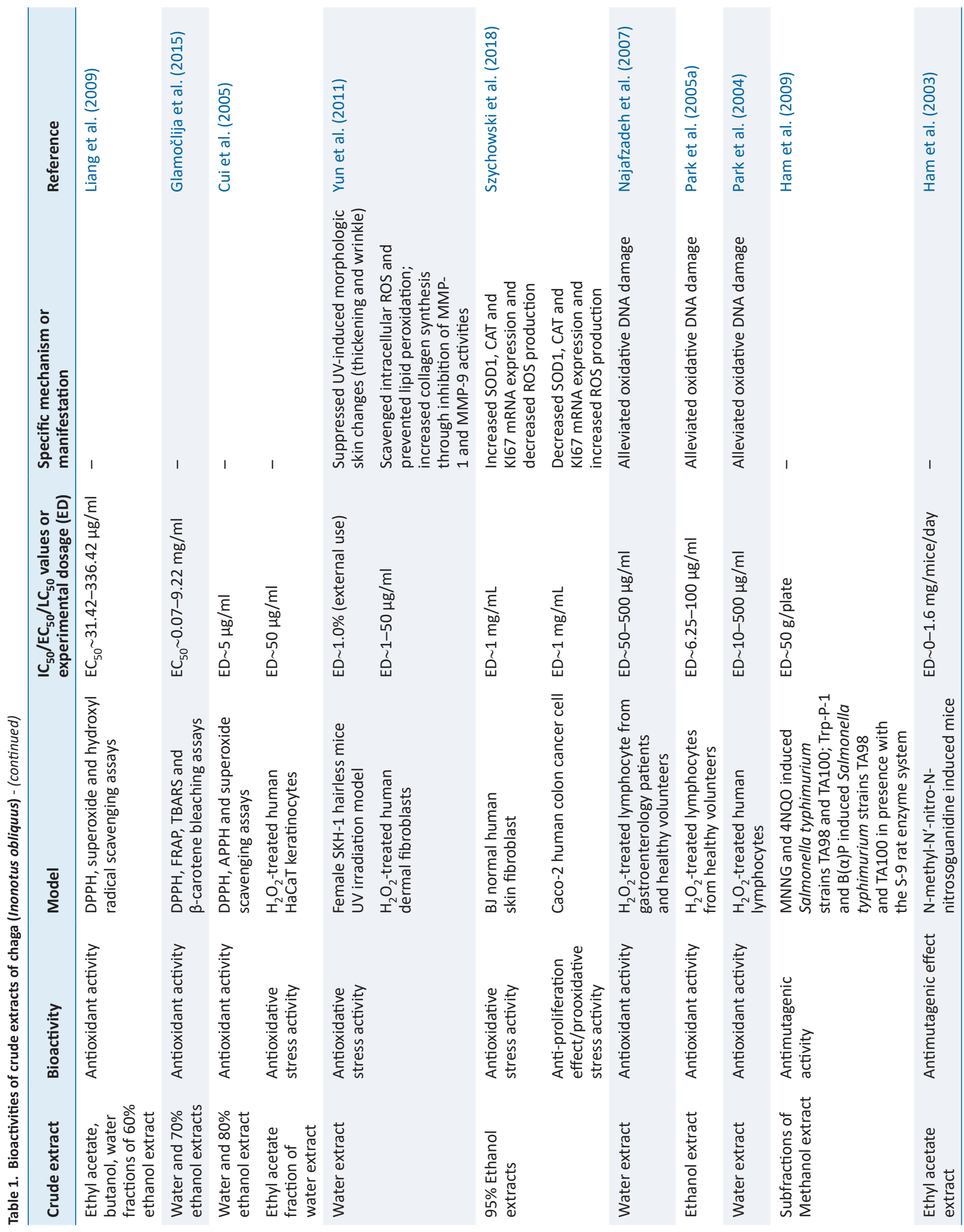




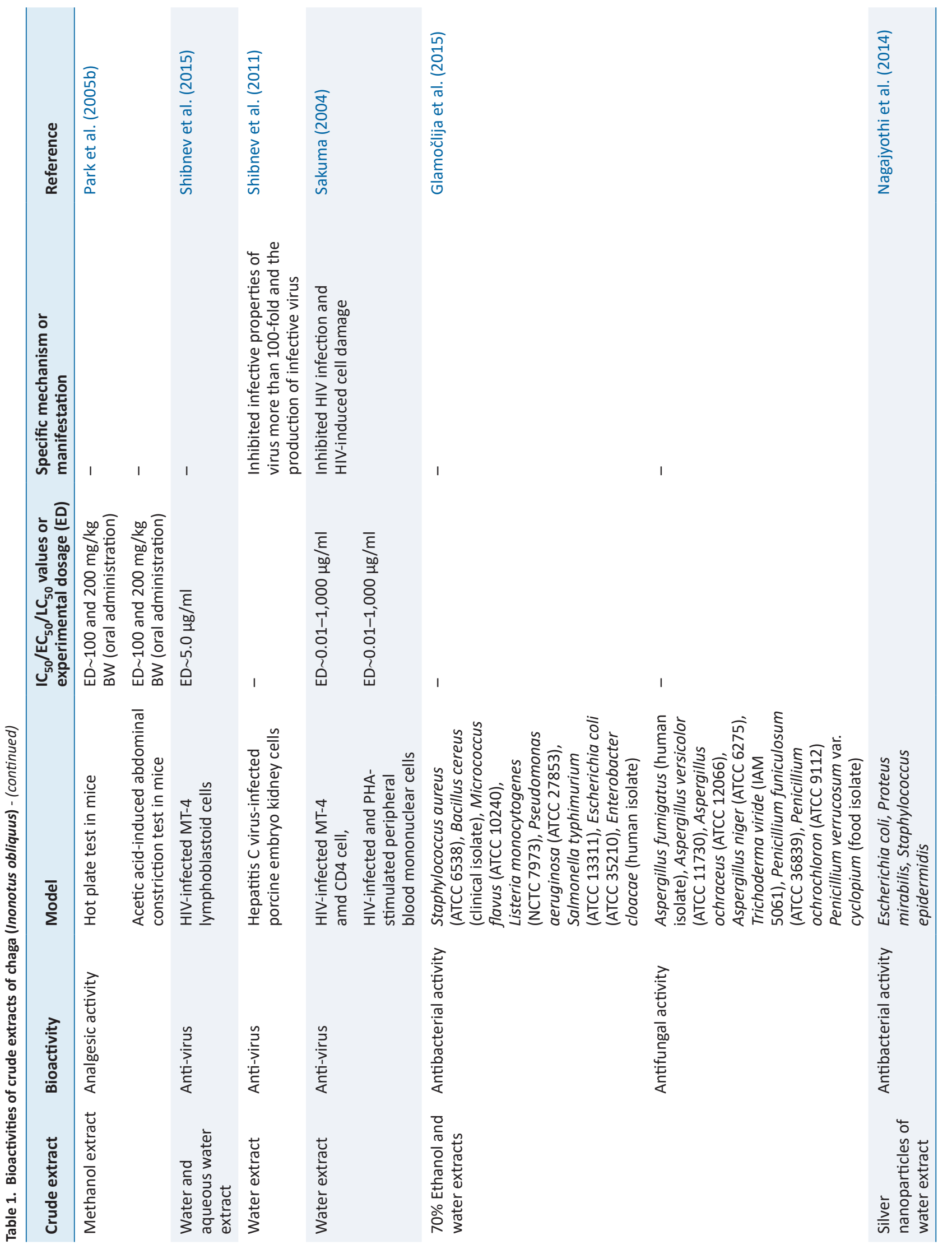




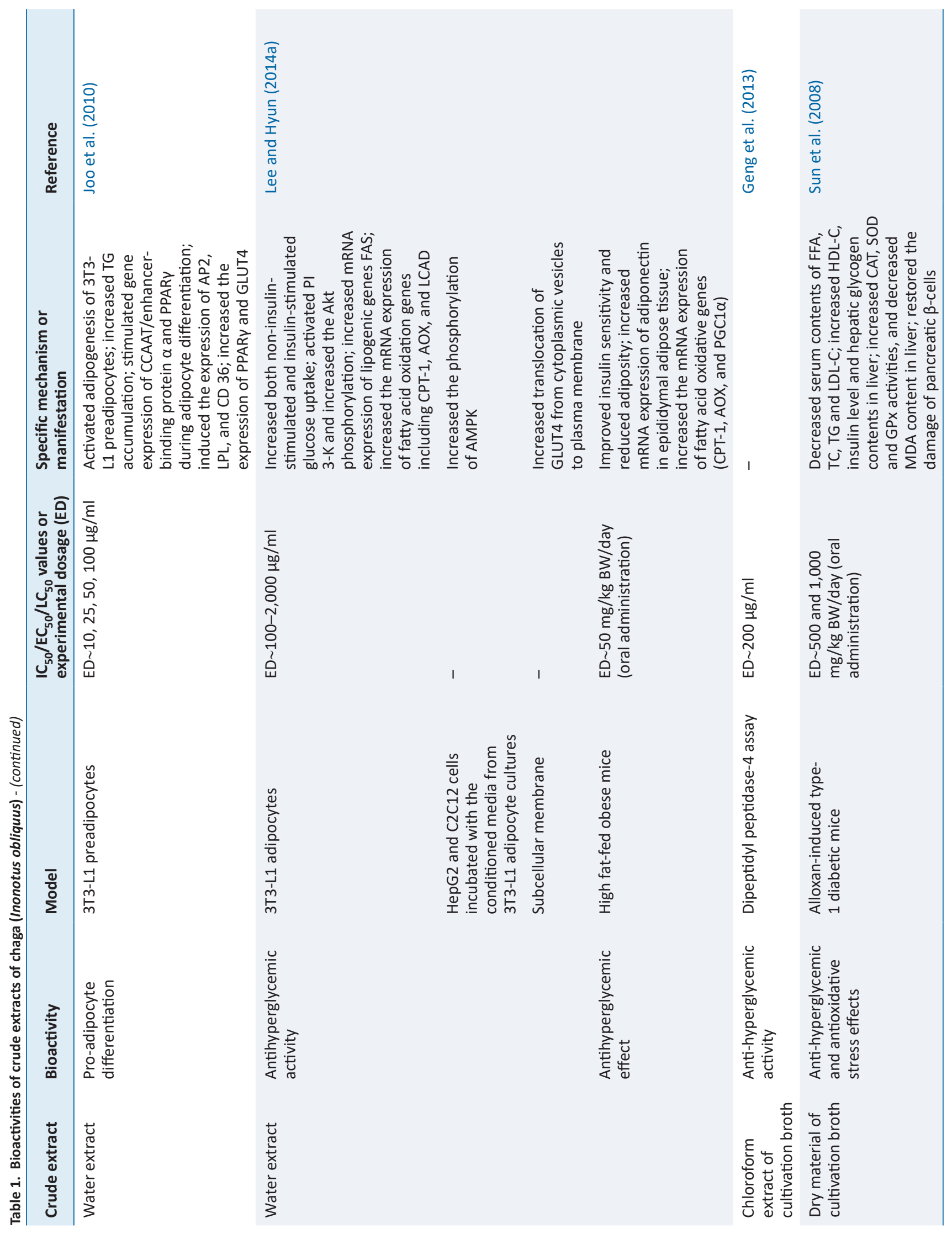




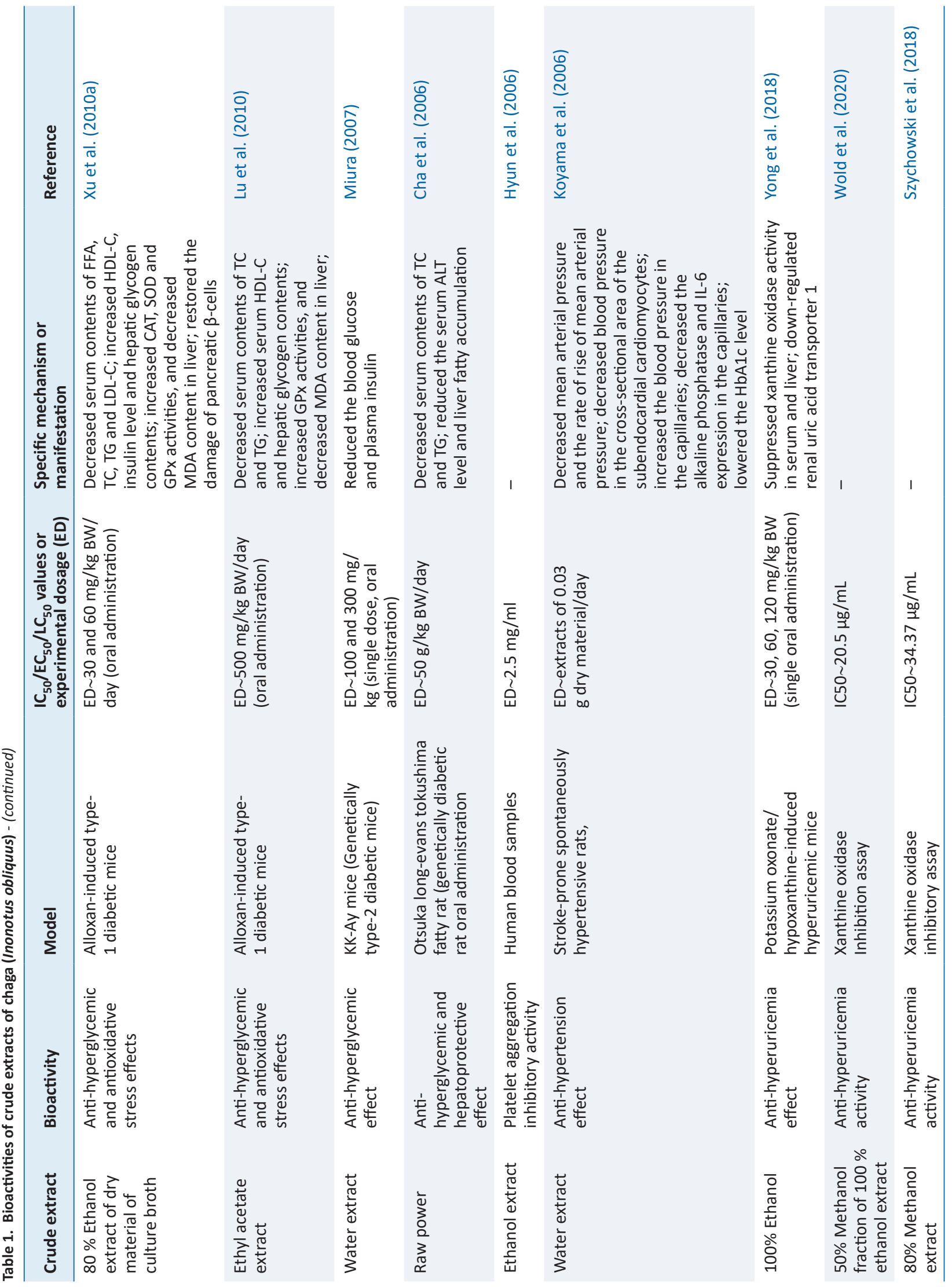




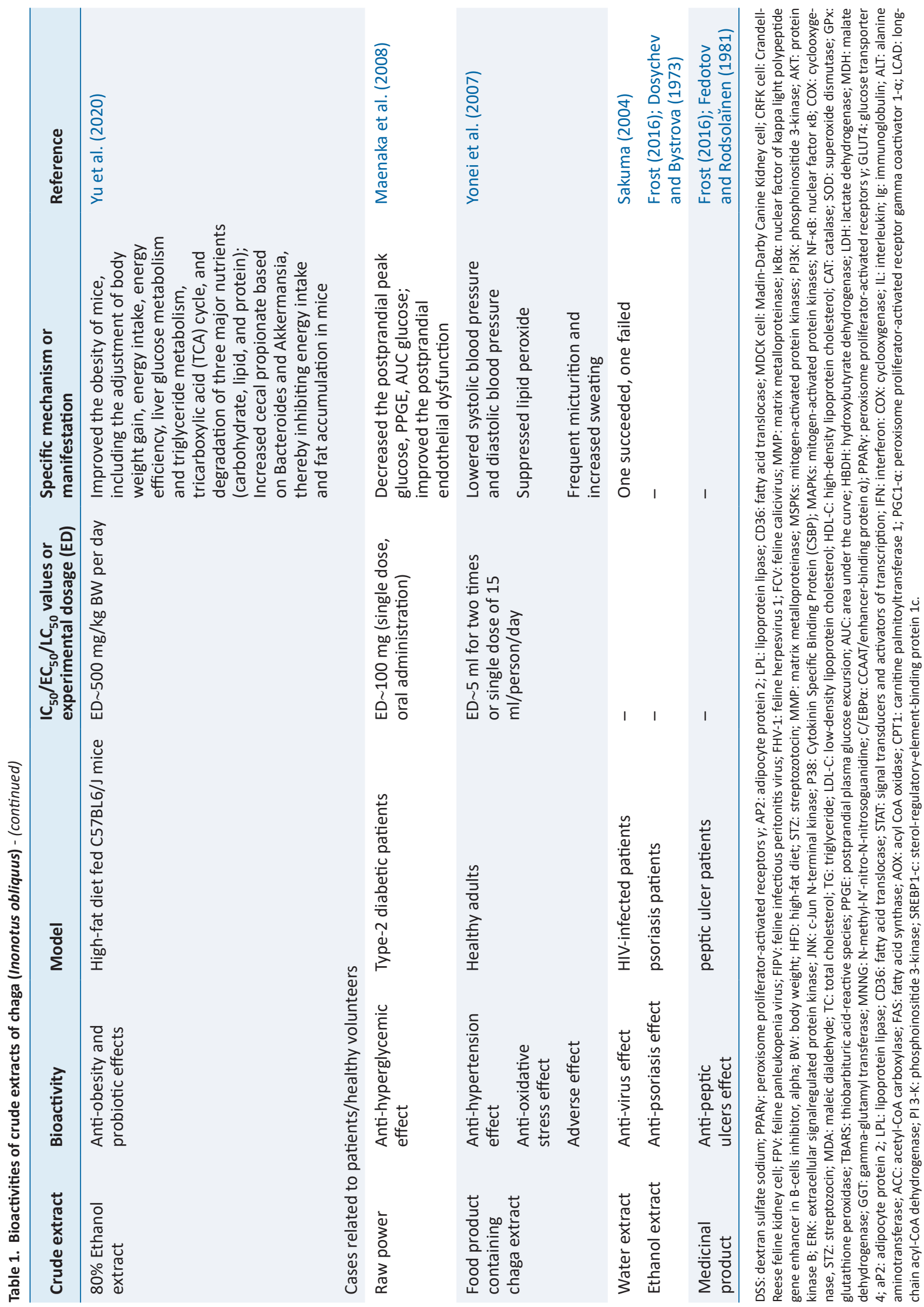


of these two tumor/cancer models, which demonstrated that the antiinflammatory effect might be a key mechanism in anti-cancer effect of chaga extracts (Mishra et al., 2013). Furthermore, a successful cure for triple-negative breast cancer of a 49 years old female patient by combined use of chaga and Ganoderma lucidum has been reported (Tiziana et al., 2020). Even during radiation therapy, the inflammatory markers of this patient were still significantly reduced by administrating low dosages of chaga. On the other hand, Song et al. (2007) thought that the anti-tumor effect of chaga was associated with its immunomodulatory ability. In their study, chaga extract simulated the in vitro immunomodulatory activity of mouse splenocytes but also inhibited the pulmonary metastasis in CT-26 cell-inoculated BALB/c mice (Song et al., 2007). This view was strongly supported by further anti-tumor studies of chaga polysaccharide, as discussed in section 4.3. Hence, these two mechanisms may be involved in inhibiting tumor progression in different stages which are due to different compounds. Particularly, it is noteworthy that either short period (4-days) oral administration (20 or $200 \mathrm{mg} / \mathrm{kg} \mathrm{BW} /$ day; high/low doses,) or short period (4-days)/low dose (10 mg/kg BW/day) intravenous administration of water extract of chaga could significantly inhibit pulmonary metastasis in CT-26 inoculated mice. However, when mice were treated for a long period (14-days) oral administration (20 or $200 \mathrm{mg} / \mathrm{kg} \mathrm{BW} /$ day) or a short period (4-days)/high dose (100 mg/ $\mathrm{kg} \mathrm{BW/day)} \mathrm{intravenous} \mathrm{administration,} \mathrm{their} \mathrm{tumor} \mathrm{metastasis} \mathrm{was}$ significantly stimulated (Song et al., 2007). This contradictory result may imply the adverse effect of long-term/high-dose use of chaga, as discussed in section 3 .

\subsection{Anti-inflammatory effects}

Inflammation is a vital part of the immune system's response to damaged cells, pathogens, and irritants. During inflammation, the cytokines released by injured cells signal the damaged sites for the immune system, which further helps to defend the body against foreign invaders such as pathogens, irritants, and toxins. However, chronic inflammation can contribute to the development of diseases, especially cardiovascular disease and tumor progression (Coussens et al., 2002; Pahwa et al., 2019). On the one hand, inflammation promotes the apoptosis of injured cells and tries to eliminate the cause of inflammation through activating immune cells to release pro-apoptotic cytokines and free radicals (Haanen and Vermes, 1995). On the other hand, to replace the necrotic tissue, it constantly stimulates the proliferation of adjacent cells until repair is completed (Coussens et al., 2002). The abnormal repetition of cell proliferation in microenvironments rich in inflammatory cells (e.g. dendritic cells, macrophages, eosinophils, mast cells, and lymphocytes, but chiefly neutrophils), growth factors (e.g. platelet-derived growth factor, platelet-derived angiogenesis factor (PDGF), transforming growth factor- $\alpha$ (TGF- $\alpha$ ), TGF- $\beta$ and basic fibroblast growth factor), activated stroma (e.g. endothelial cells, nerve cells, immune cells, and extracellular matrix), and DNA-damage-promoting agents (e.g. UV light, gastric acids, silica, reactive oxygen/nitrogen species (ROS/RNS), alcohol, viruses, parasites, and bacteria) potentiates the in vivo DNA damage-induced mutations, in other words, neoplastic risk (Coussens et al., 2002; Kiraly et al., 2015). Therefore, prevention of chronic inflammation may be regarded as an anti-cancer therapeutic opportunity. There are numerous herb/food products containing functional components with proven excellent anti-inflammatory properties, one of them being chaga (Azab et al., 2016; Muszyńska et al., 2018). The aqueous alcohol extracts of chaga can effectively inhibit inflammation by lowering NO (nitrite oxide) production in LPS (lipopolysaccharide)induced RAW 264.7 murine macrophage (Ma et al., 2013; Park et al., 2005b; Van et al., 2009). The NO inhibition ability of methanol or $80 \%$ ethanolic extract of chaga at $50 \mu \mathrm{g} / \mathrm{ml}$ is close to celastrol at $25 \mu \mathrm{g} / \mathrm{ml}$ but better than that of L-N $\mathrm{N}^{6}$-(1-iminoethyl) lysine at 10 $\mathrm{M}$ (Ma et al., 2013; Van et al., 2009). Besides, in an in vitro inflammation model, different inflammation signaling proteins such as MAPKs (mitogen-activated protein kinases), ILs (interleukins), STATs (signal transducer and activator of transcription proteins), IFN- $\gamma$ (interferons), NF- $\kappa \mathrm{B}$ (nuclear factor kappa-light-chain-enhancer of activated B cells), and TNF (tumor necrosis factor) were modulated by chaga extracts. Luciferase has been used as a measure of the activation (high fluorescence incidence) or inhibition (low fluorescence incidence) of NF- $\kappa \mathrm{B}$. A cell line stably expressing luciferase reporter gene under the transcriptional control of the NF- $\mathrm{KB}$ response element, known as NF-kB luciferase reporter cell line, is widely used for screening signaling activators or inhibitors related to TLR (toll-like receptors) signaling pathways and activation of the transcription factor NF- $\mathrm{BB}$ in pharmaceutical studies (Battin et al., 2017). Ma et al. (2013) reported that $70 \%$ ethanolic extract of chaga inhibited the activation of NF- $\mathrm{kB}$-dependent luciferase in (luciferase reporter gene) stably transfected RAW264.7 cells. Meanwhile in LPS-induced RAW 264.7 inflammation model, the 80\% alcohol extract $(100 \mu \mathrm{g} / \mathrm{ml})$ exhibited a similar or higher inhibition activity of pro-inflammatory factors compared with salicin $(500 \mu \mathrm{g} / \mathrm{ml})$, which down-regulated expression of IL- 6 , TNF- $\alpha$, iNOS, COX-2 and inhibited the phosphorylation of IkB- $\alpha$, Akt, and MAPKs (JNK, p38, ERK) (Van et al., 2009). In the same model, pure methanolic extract and water extract of chaga not only decreased the production of PEG2, STAT1, pSTAT1, STAT6, and pSTAT6 but also suppressed the degradation of cytosol I $\mathrm{KB}-\alpha$ and the protein/mRNA levels of TNF- $\alpha$, iNOS, COX-2, NF-kB (p65/p50), and nuclear p65 (Choi et al., 2010; Park et al., 2005b). Most recently, 50\% methanolic and water extracts of chaga were found to inhibit TNF- $\alpha$ production in either LPS- or histamine-induced RAW 264.7 cells. Meanwhile, simultaneous treatment of $50 \%$ methanolic extract and histamine could attenuate histamine-induced microvascular inflammation by reversing the reduction of conducted vasodilation of second-order arterioles in the gluteus maximus muscle of C57BL/6 mice (Javed et al., 2019). Furthermore, anti-inflammatory effects have been further verified in in vivo inflammation models. Park et al. (2005b) examined the anti-inflammatory effect of a methanolic extract of chaga in a carrageenin-induced mouse edema model. They found that this extract exhibited a preventative inhibitory effect on inhibiting carrageenin-induced edema for $2-4 \mathrm{~h}$ if it was administered orally for 7 consecutive days prior to injecting carrageenin, even if effectiveness of extract $(100 / 200 \mathrm{mg} / \mathrm{kg})$ was much lower than that of the positive control (ibuprofen, $100 \mathrm{mg} / \mathrm{kg}$ ). In addition, in DSS (dextran sulfate sodium)-induced mouse acute colitis model, oral administration of water extract of chaga after inducing colitis maintained the liver weight, it decreased the serum level of IgE, decreased the expression of TNF- $\alpha$, IFN- $\gamma$, IL-4, STAT6, and STAT1 proteins in the spleen (Choi et al., 2010). Moreover, in another DSS-induced mouse acute colitis model, both preventative and therapeutic treatment of water extract of chaga suppressed edema, mucosal damage, and the loss of crypts, inhibited iNOS levels and myeloperoxidase accumulation, and suppressed mRNA overexpression of TNF- $\alpha$, IFN- $\gamma$, IL- $1 \beta$, and IL-6 induced by DSS in colon tissues (Mishra et al., 2012).

\subsection{Antioxidant effects}

In aerobic organisms, oxygen consumption is essential for efficient energy metabolism but, paradoxically, produces ROS (reactive oxygen species) and free radicals(Reuter et al., 2010). The detrimental environmental factors, including radiation and toxins as well as adverse physiological/psychological status such as tension, sleep 
deprivation, hyperglycemia, and obesity, can excessively induce free radicals. The overload of free radicals leads to chronic inflammatory reactions and molecular damage in cells, which then progresses to a broad spectrum of diseases, especially type- $1 / 2$ diabetes and cancers (Hapuarachchi et al., 2003; Limón-Pacheco and Gonsebatt, 2009; Tsuboi et al., 2008; Zhang et al., 2013a). Thus, endogenous antioxidant enzymes such as CAT (catalase), SOD (superoxide dismutase), GPx (glutathione peroxidase), thioredoxin and endogenous/exogenous antioxidants such as GSH (glutathione), ascorbic acid, uric acid, tocopherols, bilirubin, phenolics play crucial roles in preventing in vivo free radical-induced oxidative damage. Similar to other medicinal mushrooms and plant-based herbs, polar-solvent extracts of chaga were found to exert intense antioxidant activity. Various antioxidant activities of water/alcohol extracts of chaga have been evaluated in DPPH (2,2-diphenyl-1-picrylhydrazyl), FRAP (ferric reducing antioxidant power), superoxide/hydroxyl radical scavenging, TBARS (thiobarbituric acid reactive substances) formation inhibition, and $\beta$-carotene bleaching assays (Cui et al., 2005; Glamočlija et al., 2015; Liang et al., 2009). The effectiveness of these extracts in scavenging free radicals and reducing transition metal ions is close to that of ascorbic acid at the same concentration (Cui et al., 2005). These antioxidant abilities of chaga mushroom provides the chemical basis in preventing oxidative stress and damage. For instance, water and ethanolic extracts of chaga protected $\mathrm{H}_{2} \mathrm{O}_{2}$-treated human lymphocyte from DNA damage (Najafzadeh et al., 2007; Park et al., 2005a; Park et al., 2004). Besides, water extracts of chaga also prevented $\mathrm{H}_{2} \mathrm{O}_{2}$-induced apoptosis and premature senescence in human fibroblasts, it functioned through scavenging intracellular ROS (reactive oxygen species), preventing lipid peroxidation, and increasing collagen synthesis through inhibition of MMP-1 and MMP-9 activities (Yun et al., 2011). Recently, Szychowski et al. (2018) found that chaga extract enhanced the antioxidative stress ability of normal cells but induced oxidative stress to cancer cells. Thus, treatment of $1 \mathrm{mg} /$ $\mathrm{ml}$ ethanolic extract on BJ normal human skin fibroblast induced increase of SOD1, CAT and KI67 mRNA expression along with decrease of ROS production. However, the same dose gave opposite results in Caco-2 human colon cancer cells, decreased SOD1, CAT and KI67 mRNA expression and increased the ROS production (Szychowski et al., 2018). Apart from the anti-inflammation and antioxidant activities, the antimutagenic activity of chaga could also attenuate cancer initiation and progression processes (Chung et al., 2010). The data of Park et al. (2005a) and Ham et al. (2003) support the protective effects of chaga extracts against oxidative DNA damage in $\mathrm{H}_{2} \mathrm{O}_{2}$-treated human lymphocytes and MNNG-induced genotoxicity in mice. In another study, Ham et al. (2009) later found that two subfractions of methanolic extract mainly contained $3 \beta$-hydroxylanosta8,24-dien-21-al and inotodiol, respectively; these strongly inhibited the mutagenesis of Salmonella typhimurium strain TA100 induced by the directly acting mutagen MNNG (N-methyl-N-nitro-N-nitrosoguanidine) by $77.3-80.0 \%$. At the same concentration, they also inhibited another directly acting mutagens 4NQO (D-biotin, 4-nitroquinoline-1-oxide)-induced mutations in Salmonella typhimurium strain TA98 and TA 100 by $52.6-62.0 \%$. Besides, the mutagenesis in strain TA98 induced by the indirectly acting mutagens Trp-P-1 (tryptophan-P-1) and $\mathrm{B}(\mathrm{a}) \mathrm{P}$ (benzo[a]pyrene) was reduced by $47.0-68.2 \%$ by these subfractions, while the mutagenesis in TA100 induced by Trp-P-1 and $\mathrm{B}(\alpha) \mathrm{P}$ was reduced by $70.5-87.2 \%$.

\subsection{Anti-diabetic effects}

As emphasized in the most recent WHO (2017) statistics report, $8.5 \%$ of global adults had diabetes which resulted in an estimated 1.6 million deaths in 2016. In 2015 in Canada, diabetes and prediabetes rates were $9.3 \%$ (3.4 million) and $22.1 \%$ (5.7 million), respectively (Houlden, 2018). These data in 2018 in the United State of America were around $10.4 \%$ (34.2 million) and $26.8 \%$ (88 million), respectively (Centers-for-Disease-Control-Prevention, 2020). One of the most direct results of pre-diabetes and diabetes is hyperglycemia. Without treatment, hyperglycemia can further cause severe complications, including ketoacidosis, infection (immune dysfunction), and various tissue/organ damage. Chaga and its extracts showed an outstanding anti-hyperglycemic effect in both in vivo type-1 and type-2 diabetic models. The clinical data of Maenaka et al. (2008) showed that prior use of chaga improved postprandial endothelial dysfunction and various indicators of blood sugar in type-2 diabetic patients. Besides, in genetically type-2 diabetes KK-Ay mice, either a single or repeated 6 weeks oral administration of water extract of chaga could significantly reduce blood glucose, as well as plasma insulin, which demonstrate that chaga extract could alleviate insulin resistance (Miura, 2007). In addition, hypoglycemic effects of chaga were confirmed in a type-1 diabetic model. Sun et al. (2008) and Xu et al. (2010a) reported that 2-weeks oral administration of cultured or wild chaga extracts could decrease mice serum contents of FFA (free fatty acids), TC (total cholesterol), TAG (triacylglycerols), LDL-C (low-density lipoprotein-cholesterol), and liver MDA (malondialdehyde) content in alloxan-induced diabetes models. Meanwhile, the treatment also increased mice HDL-C (high-density lipoproteincholesterol), insulin level, and hepatic glycogen contents as well as CAT, SOD and GPx activities in the liver (Sun et al., 2008; Xu et al., 2010a). The histopathological examination of these mice showed that the damage to pancreatic $\beta$-cells was restored in the treated diabetic mice compared to the untreated group, in other words chaga stimulated regeneration of the $\beta$-cells and thus normalized the level of insulin (Sun et al., 2008; Xu et al., 2010a). Later, other potential mechanisms on regulating insulin and blood lipid levels by using chaga were found. For example, alkaloids and terpenoids isolated from chaga extract were found effective in inhibiting the DPP-4 (dipeptidyl peptidase 4), an important enzyme and as a new therapeutic target for diabetes (Geng et al., 2013). The differentiation of 3T3-L1 preadipocytes was induced by chaga extract via signaling pathway of C/EBP $\alpha$ (CCAAT/enhancer-binding protein $\alpha$ ) and PPAR $\gamma$ (peroxisome proliferator-activated receptors $\gamma$ ) (Joo et al., 2010). Water extract of chaga also increased both non-insulin-stimulated and insulin-stimulated glucose uptake of 3T3-L1 adipocytes through activating PI 3-K (phosphoinositide 3-kinase) and phosphorylation of its downstream protein the Akt, and increasing mRNA expression of lipogenic genes FAS (fatty acid synthase) and fatty acid oxidation genes including CPT-1 (carnitine palmitoyltransferase 1), AOX (acyl CoA oxidase), and LCAD (long-chain acyl-CoA dehydrogenase) (Lee and Hyun, 2014a). A similar result was confirmed through high fat-fed obese mice, the oral administration of water extract of chaga at a dose of $50 \mathrm{mg} / \mathrm{kg} \mathrm{BW} /$ day improved insulin sensitivity and reduced adiposity with increasing mRNA expression of adiponectin and fatty acid oxidative genes including CPT-1, AOX, PGC1 $\alpha$ (peroxisome proliferator-activated receptor gamma coactivator $1-\alpha$ ) in epididymal adipose tissue (Lee and Hyun, 2014a).

\subsection{Other health effects and their potential relevance with chemistry of chaga extracts}

Beyond the health effects mentioned above, other bioactivity studies have been carried out as summarized in Table 1. The chaga extract exhibited a broad-spectrum of antiviral, anti-bacterial and anti-fungal activities in various in vitro trials (Glamočlija et al., 2015; Shibnev et al., 2015; Shibnev et al., 2011). The ethanolic extract of chaga showed platelet aggregation inhibitory activity 
in whole blood and platelet-rich plasma, from which Hyun et al. (2006) isolated a novel tripeptide and confirmed its anti-aggregation effect in mice. In addition, the alcohol extracts showed antihyperuricemic effect by inhibiting xanthine oxidase in both in vitro and in vivo trials (Szychowski et al., 2018; Wold et al., 2020; Yong et al., 2018). Yonei et al. (2007) published a clinical study about chaga which verified several health claims of foods containing chaga by a double-blind trial. The parameters including systolic/ diastolic blood pressure, lipid peroxide, and the mental/physical symptoms such as "cold skin" and "inability to sleep because of worries" were significantly improved. However, several adverse effects were also found (see section 3 ).

Normally extraction means concentrating certain groups of functional ingredients from a specific material. Compared to the hypoglycemic efficacy of the materials used in the studies of Sun et al. (2008) and $\mathrm{Xu}$ et al. (2010a), 80\% ethanolic extract of the cultured broth of chaga was almost 100 -fold more efficient than the simple cultured broth of chaga. Regarding different extraction and preliminary purification approaches, variations exist in the composition of extracts. The dry chaga contains around $2-2.76 \%$ protein, $0.04-6.0 \%$ phenolics, $11.63-15 \%$ ash, $0.51-8 \%$ terpenoids, $0.2-2 \%$ melanin, $2.76 \%$ lipid, $25-37.56 \%$ lignin, $2 \%$ cellulose, and $12.5 \%$ hemicellulose (Glamočlija et al., 2015; Ju et al., 2010; Kim et al., 2008b; Koyama et al., 2008; Rhee et al., 2008; Shashkina et al., 2006; Si, 2018). Regardless of the actual proportion of various compounds in chaga, the main bioactive components in various chaga extracts are polysaccharides, terpenoids, phenolics/lignin, melanin, peptides/protein, and their covalent complexes; some compounds such as alkaloids have also been reported. The data of Mishra et al. (2012) revealed significant anti-inflammation ability of water extract $\left(40^{\circ} \mathrm{C}, 3 \mathrm{~h}\right)$ of chaga which contained $57,204,127 \mu \mathrm{g} / \mathrm{mg}$ of phenolics, polysaccharides, and protein, respectively. In another comparative study, the water extract prepared by $2 \mathrm{~h}$ process at 80 ${ }^{\circ} \mathrm{C}$ showed the presence of $247.5 \mu \mathrm{g} / \mathrm{mg}$ extract of polysaccharides and $136.9 \mu \mathrm{g} / \mathrm{mg}$ extract of protein, while these were not detected in the pure-ethanolic extract (Hu et al., 2009). The latter, however, possessed a much stronger pro-apoptotic effect on human colorectal cancer cell line DLD-1 in a time-dependent manner. The presence of higher concentrations of terpenes and/or phenolics is regarded as being the contributor. Along with the anti-proliferation ability, simlilar comparative data between water and organic solvent extracts also corresponded with their in vitro anti-inflammatory and enzyme inhibition activity (Baek et al., 2018; Nomura et al., 2008; Van et al., 2009; Wold et al., 2020). The presence of a high amount of terpenoids and sometimes even alkaloids in organic-solvent extracts was deemed as the main cause (Baek et al., 2018; Geng et al., 2013; Ma et al., 2013; Nomura et al., 2008; Wold et al., 2020). On the other hand, the crude polysaacharide fraction (water fraction) of $80 \%$ ethanolic extract of chaga was found to render stronger anti-inflammatory activity than its crude phenolic/terpene fraction (ethyl acetate fraction) (Van et al., 2009). Meanwhile, Lee et al. (2009) showed that anti-proliferation activity of the $70 \%$ ethanolic extract on HT-29 cells was significantly lower than that of the water extract. Hyun et al. (2006) screened the anti-platelet aggregation activity of water/ethanol extracts from nine chaga samples. The enthanolic extract of one sample showed the highest platelet aggregation inhibitory activity compared to the other ethanol/water extracts but platelet aggregation inhibitory activity of water extracts was found in more samples. The platelet aggregation inhibitory activity was eventually attributed to a tripeptide isolate (Trp-Gly-Cys). In short, the exact efficacies of biactivities of chaga extracts varied with different samples employed. Meanwhile, the combined effects of different pure compounds also needs to be considered although certain compounds may mainly contribute to some specific health effects. To verify the exact contributors and the specific mechanism of these bioactivity differences, further studies of the bioactivity of isolated pure compounds from the extracts are necessary, as discussed further in section 4 .

\section{Safety of chaga products and oxalate-associated side effects of chaga decoction}

Based on their long folk therapy history, the use of chaga and its products is generally deemed safe. Although clinical or animal studies have not sufficiently investigated the acute toxicity, subtoxicity, or chronic toxicity of chaga crude extracts, some preliminary studies have incidentally assessed their toxicity/safety in in vitro cellular assays and murine animal trials. In terms of cellular test, the ethanol and water extracts of chaga were only toxic at concentrations of 100 and $400 \mu \mathrm{g} / \mathrm{ml}$, respectively, to human HaCaT keratinocytes (Cui et al., 2005). Similarly, normal Chang-liver cells and primary porcine liver cells PLP2 were not markedly affected by alcohol and/or water extracts of chaga at a concentration of less than $400 \mu \mathrm{g} / \mathrm{ml}$ (Glamočlija et al., 2015; Youn et al., 2008). There are also studies that show the general cytotoxicity in both the normal and cancer cell lines. Song et al. (2007) reported that the water extract of chaga at high concentrations of over $100 \mu \mathrm{g} / \mathrm{ml}$ inhibited the viability of HT1080, Hep G2, CT-26 as well as CRL-7250 normal human fibroblast after a 6-days culture (much longer than the treating duration in other studies). Nakajima et al. (2009) found the water extract of chaga was more toxic on IMR90 normal human lung cells $\left(\mathrm{IC}_{50} / \mathrm{LD}_{50} \sim 18.7-29.8 \mu \mathrm{g} / \mathrm{ml}\right)$ than on cancer cell lines (A549, PA-1, U937, and HL-60, $\mathrm{IC}_{50} / \mathrm{LD}_{50} \sim 23.2-105.2 \mu \mathrm{g} / \mathrm{ml}$ ). As for in vivo trials, the pro-tumor effect as well as toxic appearance in liver to the naked eye in the CT-26 cells-inoculated mice induced by intravenous administration of water extract of chaga were noticed (Song et al., 2007). In the case of non-intravenous administration, Park et al. (2005b) did not find any toxic syndromes based on the body weight change of male Sprague-Dawley rats which were orally administrated 100 or $200 \mathrm{mg} / \mathrm{kg}$ body weight of chaga methanolic extract for 7 consecutive days. There were also no life-threatening toxic effect and body weight loss in the mice administrated $30 \mathrm{mg} / \mathrm{kg} / \mathrm{day}$, intraperitoneally, or $300 \mathrm{mg} / \mathrm{kg} /$ day, orally, of the extract for 60 consecutive days (Kim et al., 2006). A single dosage of ethanol extract of chaga at $30-120 \mathrm{mg} / \mathrm{kg}$ body weight had no toxic impact on kidney and liver functions of male SPF Kunming mice (Yong et al., 2018). Another anti-tumor study on pathogen-free female ICR mice showed that 20 -weeks consecutive external use of chaga-origin inotodiol had no influence on their body weight (Nakata et al., 2007). The review of Koyama et al. (2008) reported that oral administration of dried raw chaga at 1 g/day for 2-3 weeks did not cause any problem in human subjects.

However, other reports indicated the side effects, including dietary hyperoxaluria, oxalate-induced acute/chronic nephropathy, and liver injury, upon oral administration of chaga over a moderate/long-term and high dose use (Kim et al., 2005; Lee et al., 2020; Lumlertgul et al., 2018; Maenaka et al., 2008; Yonei et al., 2007). The most recent clinical case came from the emergency room of a Korean hospital in 2016. A 49 years-old male without any family medical history and history of kidney stone, diabetes, hypertension, and operation, was confirmed with kidney failure (oxalate nephropathy) and eventually underwent kidney transplantation after 18-months maintenance with hemodialysis. His regular examination result of renal function and urine analysis were both normal until hospitalization. After looking into his drug history, the kidney failure caused by oxalate nephropathy was associated 
with his 5-years continuous use of chaga powder (for treating atopic dermatitis) (Lee et al., 2020). The dosage he took was $3 \mathrm{~g} /$ day (two times/day) in the first 4 years and $9 \mathrm{~g} /$ day in the fifth year. Back to 2014, a 72-year-old Japanese female was diagnosed with liver cancer and had to undergo hepatectomy after 15 months. For alleviating the cancer, she ingested chaga powder (4-5 teaspoons/ day) from the sixth month to the twelfth month after diagnosis, but eventually turned to be oxalate nephropathy with detectable oxalate crystals in her kidney tubules and urinary sediment (Kikuchi et al., 2014). As early as 2007 in Japan, a double-blind study of chaga food product using 60 healthy human volunteers showed unfavorable effects including frequent urination and increased sweating after oral administration at doses of 5 or $15 \mathrm{ml} /$ person/day for 8 weeks even if no specific attention was paid to the concentration of blood/urine oxalate (Yonei et al., 2007). The potential cause of adverse results in these cases was thought to be related to the extremely high quantity of oxalic acid in chaga. Lee et al. (2020) reported a $14.2 \%$ oxalate $(0.142 \mathrm{~g}$ oxalate/g chaga) in chaga powder. Glamočlija et al. (2015) reported oxalic acid content of chaga water extracts at $3.29 \%$ (Thailand), 5.57\% (Finland), and $9.76 \%$ (Russia), while $70 \%$ ethanolic extracts possessed a lower percentage at $0.67 \%$ (Thailand), $0.95 \%$ (Finland), $2.42 \%$ (Russia). It is worth noting that less than $100 \mathrm{mg}$ of oxalate daily is considered safe for preventing kidney stone even if typical diets contain 200 to $300 \mathrm{mg}$ of oxalate daily, and the daily oxalate intake of patient $(9 \mathrm{~g} \times 3-14 \%)$ in the first case is close to its lethal dose of $2-30 \mathrm{~g} /$ day (Lee et al., 2020). On the other hand, there is no related study about the oxalate levels in cultured chaga materials.

The above cases should make people consider the susceptibility of Asians to chaga-origin oxalate nephropathy because potential racial difference in handling dietary oxalate truly exists (Lewandowski et al., 2001; Lewandowski et al., 2005). However, around 12 other chaga-related cases including two nephropathy cases have also been noted by British Columbia, Drug and Poison Information Centre (BC-DPIC), as reported by Toxicology Committee chair of NAMA (North American Mycological Association) (BC-DPIC, 2016; Beug, 2019; Takikawa, 2006). In the nephropathy case of BC-DPIC, hepatitis as well as renal failure happened in patient at the same time and dialysis was still required on last follow-up 2 months later but fortunately the patient was recovered. Another case is an unofficial personal narrative from NAMA, the patient was a regular chaga user (a cup of chaga decoction daily) for over 10 years, nothing wrong happened to him until the resumption of using chaga after a prostate surgery. Then he had quite heavy hematuria, followed by excruciatingly painful bladder spasms which was suspected to be due to using chaga, even 3 weeks post surgery (Beug, 2019). Therefore, even though the content of oxalic acid in chaga and excretion capacity of absorbed oxalate is circumstantial, long-term administration of chaga or its decoctions/tincture will undoubtedly increase the plasma concentration of oxalate and corresponding risk of oxalate nephropathy.

In addition, liver damage induced by the arbitrary use of traditional herbs as well as chaga has become a worldwide medical issue (Douros et al., 2016; Jing and Teschke, 2018; Lee et al., 2015b; Lin et al., 2019; Takikawa, 2006). It is understandable that conducting expensive clinical studies are impractical for every herb especially for niche market products. However, specific safe guideline and healthy limitation for the use of non-mainstream herbal products should be followed. Regardless of clinical studies, the scientific basis of the safety assumption including acute/chronic animal trials and subsequent blood/urine/histoanatomy analysis is reasonable to be requested before their commercialization. Furthermore, sufficient chemical analysis not only helps demonstrating the bioactive sources of natural herb products but would also reveal their risk factors before tragedies happen to vulnerable individuals. Sometimes the so-called bioactive compound is the risk itself as it is the dose that makes the poison. Meanwhile, the safety and chemical composition of wild mushroom supplements are largely influenced by their nutritional host. In the following section, a retrospect of the known organic constituents especially the bioactive compounds of chaga and their potential safety concerns are discussed.

\section{Main bioactives/medicinal constituents of chaga and their bioactivities}

\subsection{Terpenoids}

Based on numerous comparative studies of the structure-function relationship of different components in chaga, it was found that the anti-cancer effect of chaga extracts is remarkably influenced by their content of terpenoid/terpene derivatives (Kim et al., 2011; Liu et al., 2014; Zhao et al., 2016a; Zheng et al., 2011b). Terpenoid/terpene derivatives are a major class of chemical compounds found in natural plants which normally function as signaling chemicals (e.g. gibberellin and abscisic acid), attractants (e.g. carotenoids, caryophyllene, limonene), repellents (e.g. linalool, farnesene), as well as crucial structural components of biomembranes (e.g. phytosterols) (Sharma et al., 2017; Theis and Lerdau, 2003). Terpenes are a plentiful and diverse group of hydrocarbon compounds categorized by their number of isoprene units and include hemiterpene, monoterpene, sesquiterpene, and diterpene, among others. Even if the mixed-use of terpenoids and terpenes is common, the term "terpenoids" is different from "terpenes", the latter compounds are simply unsaturated hydrocarbons polymerized by isoprene units while the former belongs to terpene derivatives structured with various elements or functional groups such as oxygenated and nitrogenated branches. According to the number of cyclic structures, the triterpenoids can be divided into linear triterpenoids (squalene), monocyclic triterpenoids (e.g. achilleol A and camelliol C), bicyclic triterpenoids (e.g. myrrhanol C and myrrhanone A), tricyclic triterpenoids (e.g. arabidiol and achilleol B), pentacyclic triterpenoids (ceanothanolic and rosamultic acid), as well as the two most common categories in the study of chaga terpenoids, namely tetracyclic triterpenoids and steroids (Daniel and Mammen, 2016; Grishko et al., 2015; Kimura et al., 2001; Perveen, 2018; Xiang et al., 2006; Xu et al., 2018). The steroids and tetracyclic triterpenoids both contain four cycloalkane rings joined mutually, therefore it is sometimes difficult to conceptually separate them from each other. Some structural characteristics such as methyl groups on the C-4 and 14 positions may help to distinguish some steroids from terpenoids (Tong, 2013). Biosynthetic routes can also help to differentiate them. The tetracyclic triterpenoids derivate from 2,3-oxidosqualene or/and squalene involving various synthetic reactions such as hydroxylation, cyclization, hydrogenation/ dehydrogenation, epoxidation/peroxidation, and hydride/methyl shift (Rascon-Valenzuela et al., 2017). Then the produced lanosterol (animals/yeast) or cycloartenol (plants) can further be metabolized into steroids. The derivation of steroids involves demethylation, ketonization, and hydrogenation/dehydrogenation (Bishop and Yokota, 2001). Therefore, some tetracyclic triterpenoids, including lanosterol and cycloartenol, can also be classified as steroids. Figure 1 displays various core skeletons of tetracyclic and pentacyclic triterpenoids (Bishop and Yokota, 2001; Biswas and Dwivedi, 2019; Hamid et al., 2015; Rascon-Valenzuela et al., 2017; Stanczyk, 2009; Xiao et al., 2018). The lanostane-type terpenoids are main triterpenoids/steroids isolated from mushrooms which also apply to terpenoid composition of chaga. As summarized in Table 2, 57 out of 108 known triterpenoids/steroids are lanostane-type tetracy- 
clic terpenoids/steroids. Some triterpenoids such as fuscoporianols A-D, inoterpene A-F, inonotsuoxodiol A, spiroinonotsuoxodiol, inonotsudiol A, inonotusane A-G, inotolactone A-C, inonotsuoxide A and B, inonotsutriol A-E, fuscoporianol A-C, obliquic acid, and inotodiol are exclusive and can only be found in chaga (Figure 2). The isolation and identification methods of these compounds are also briefly given in Table 2. Moreover, the review of Nikitina et al. (2016), which summarized the original Russian articles, may provide different structural information about chaga terpenoids from those given in this contribution that is built upon using the English source.

Lanostane-type terpenoids are well known for their potential in cancer treatment (Duru and Çayan, 2015). As Table 3 summarizes, numerous in vitro anti-proliferation studies of lanostane-type terpenoids isolated from chaga extracts have been published. In this table, only the results with significant inhibitory ability at the experimental dosage (ED) employed or the results with $\mathrm{IC}_{50}$ (half maximal inhibitory concentration) less than $40 \mu \mathrm{M}$ are shown. For example, the ergosterol peroxide purified from chaga exerted moderate-high cytotoxicity on various cancer cell lines such as PC3, MDA-MB-231, A549, L1210, HepG2, MCF-7, HCT116, HT-29, SW620, DLD-1 cells (Kang et al., 2015; Kim et al., 2011; Ma et al., 2013). In HT-29 and HCT116 colorectal cancer cell models, ergosterol peroxide could induce subG1 arresting, inhibiting the nuclear levels of of $\beta$-catenin, and ultimately resulting in reduced transcription of c-Myc, cyclin D1, and CDK-8 (Kang et al., 2015). The inotodiol also showed cytotoxicity on many cancer cell lines including L1210, A549, P388, AGS, MCF-7, and Hela cells (Chung et al., 2010; Nomura et al., 2008; Tanaka et al., 2011; Zhong et al., 2011). In A549 lung cancer cell model, inotodiol arrested cell cycle in $\mathrm{S}$ phase, decreased expression of $\mathrm{Ki}-67$ and Bcl-2 proteins, and increased expression of $\mathrm{p} 53$ and bax proteins (Zhong et al., 2011). Furthermore, the in vivo anti-cancer effect of chaga terpenoids has been confirmed in animal trials. Taking ergosterol peroxide (isolated from chaga), as an example, the oral administration of ergosterol peroxide at $15 \mathrm{mg} / \mathrm{kg}$ body weight $/ 12$ h for 8 or 14 weeks helped maintaining colonic epithelial cell structures, improving histological damage in response to AOM/ DSS, and suppressing tumor growth in the colon colorectal cancer in mice (Kang et al., 2015). More in vivo anti-cancer trials can be found in the studies of chaga-origin triterpenoids such as lanosterol, inotodiol, and 33-hydroxylanos-8,24-dien-21-al (Table 3). Other bioactivities of chaga-origin terpenoids including $\alpha$-glucosidase inhibitory activity, EBV-EA activation inhibitory activity, PTKs (protein tyrosine kinases) inhibitory activity, hepatoprotective activity, antioxidant, and anti-inflammatory activity have also been reported (Table 3). Intriguingly, chaga ethanolic extract was found to have significant in vivo anti-hyperuricemic effect, and the triterpenoids such as 3 $\beta$-hydroxylanosta-7,9(11),24-trien-21-oic acid, inonotusic acid, trametenolic acid, and betulin were considered as the main contributors due to their efficient xanthine oxidase inhibitory activity (Yong et al., 2018). However, this standpoint was challenged later due to the failed repetition in the study of Wold et al. (2020) who suggested the non-terpenoid compounds inhibit the xanthine oxidase activity. This property was therefore not included in Table 3. Besides, a quantity of medicinal potential of common triterpenoids such as ergosterol peroxide, $\beta$-sitosterol, betulinic acid, and oleanolic acid, which are extractable from not only chaga but also various other fungi/plants, have been prevalently reported (Chhikara et al., 2018; Merdivan and Lindequist, 2017; Moghaddam et al., 2012; Yogeeswari and Sriram, 2005). Such bioactivity studies may provide additional information in investigating pharmaceutical properties of chaga products. Apart from the various bioactivities published, the terpenoids also attract the toxicity concerns. Some terpenoids are known to cause detrimental effects on skin, digestive tract and even central nervous system with various adverse syndrome such as irritation, gastrointestinal disorders, hallucination, seizure, and coma (Mbaveng et al., 2014). However, to date, there is no specific toxicity studies on the unique terpenoids of chaga.

The growth rate of wild chaga is extremely slow. To satisfy the increased commercial requirement of chaga products, the artificial culture of chaga has attracted much attention. However, the diversity and content of chaga terpenoids are quite distinct between wild and cultured types. For example, instead of the two dominant sterols in wild chaga, namely lanosterol and inotodiol, ergosterol becomes the main sterol in the cultured mycelium. Meanwhile, other trace sterols in wild chaga such as episterol, 24-methylene dihydrolanosterol, and ergosterol peroxide can not be found in cultured mycelium (Zheng et al., 2007a). A similar phenonmenon was found for the terpenoids composition of chaga among different wild types. Géry et al. (2018a) compared chaga samples collected from Canada, Ukraine, and France. The betulin and betulinic acid contents of French chaga were almost 100-fold and 10-fold higher than the Canadian/Ukrainian ones, respectively. Furthermore, the collected raw materials of wild chaga were sometimes divided into sclerotium and fruits/mycelia parts. The simliarity or difference of the composition of these two parts have frequently been reported but are beyond the scope of this review and hence are not described here (Kim et al., 2005; Song et al., 2008; Sun et al., 2011). These results directly implicate that the growth environment is one of the critical factors determining the composition and proportion of chaga terpenoids. Optimizing the nutritional condition of artificial medium, including $\mathrm{pH}$, the concentration of minerals, carbon, and nitrogen sources, or even nitrogen to oxygen ratio, could effectively enhance terpenoids' production such as betulin, inotodiol and betulinic acid in cultured chaga (Bai et al., 2012; Chen et al., 2020a; Wei et al., 2018). Meanwhile, supplementing $\mathrm{Ag}^{+}, \mathrm{Cu}^{2+}$ and $\mathrm{Ca}^{2+}$ could stimulate accumulation of lanosterol and ergosterol (Zheng et al., 2008a). Adding methyl jasmonate or linoleic acid could enhance more than $50 \%$ of the total triterpenoid production as well as its phenolic content and diversity (Xu et al., 2015b; Xu et al., 2016a). Besides, cultivating the mycelium with the aqueous extracts or methanolic extracts of birch bark, birch core or chitosan could significantly enhance the steroid production of inotodiol, ergosterol peroxide, betulin, ergosterol, cholesterol, lanosterol, stigmasterol, and sitosterol (Kahlos, 1994; Wang et al., 2014). Similarly, the addition of betulin, or various spent substrates such as bark residues of white birch, birch extracts, corn grain and mulberry powder in the medium, or exposing into light at certain wavelengthes to mimic the wild nutritional or host condition could efficiently stimulate the growth of chaga mycelium as well as its polysaccharide yield (Chen et al., 2020b; Fradj et al., 2019; Poyedinok et al., 2015; Wang et al., 2019). Other stimulants such as colloidal metal nanoparticles, AgNPs (silver nanonparticles), could inhibit polysaccharide and flavonoid synthesis but may stimulate melanin synthesis while MgNPs (magnesium nanonparticles) colloid was effective in stimulating the accumulation of endopolysaccharides, flavonoids, and melanin pigments (Poyedinok et al., 2020).

\subsection{Phenolic compounds in chaga}

Naturally occurring phenolics could be found in most plant and other sources. They play vital roles in chemical defense, pigmentation, signals delivery, and even structure building in the organisms especially the plants and microorganisms (Mandal et al., 2010; Zhang et al., 2016). In our daily diet, natural phenolics have been 

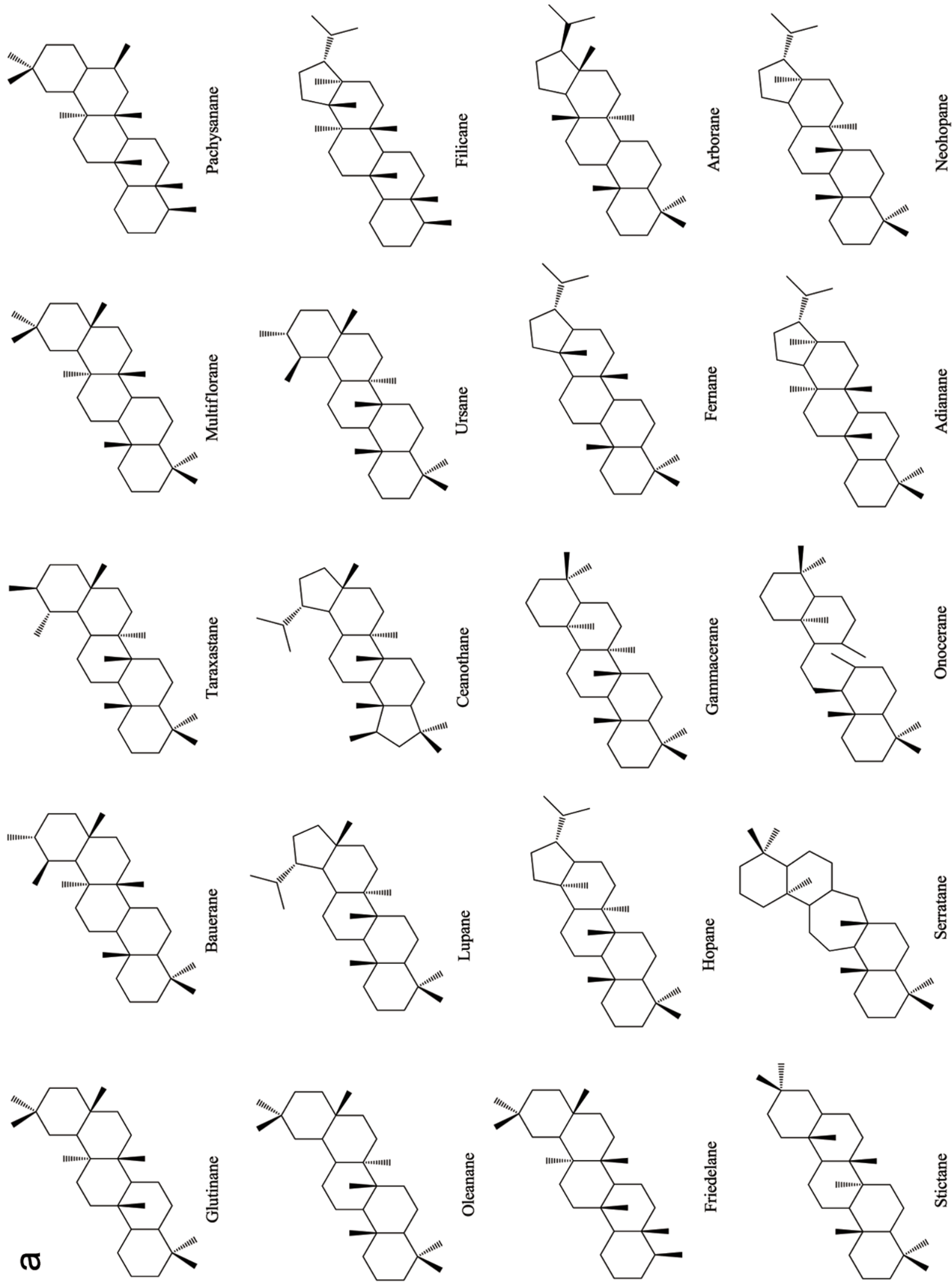


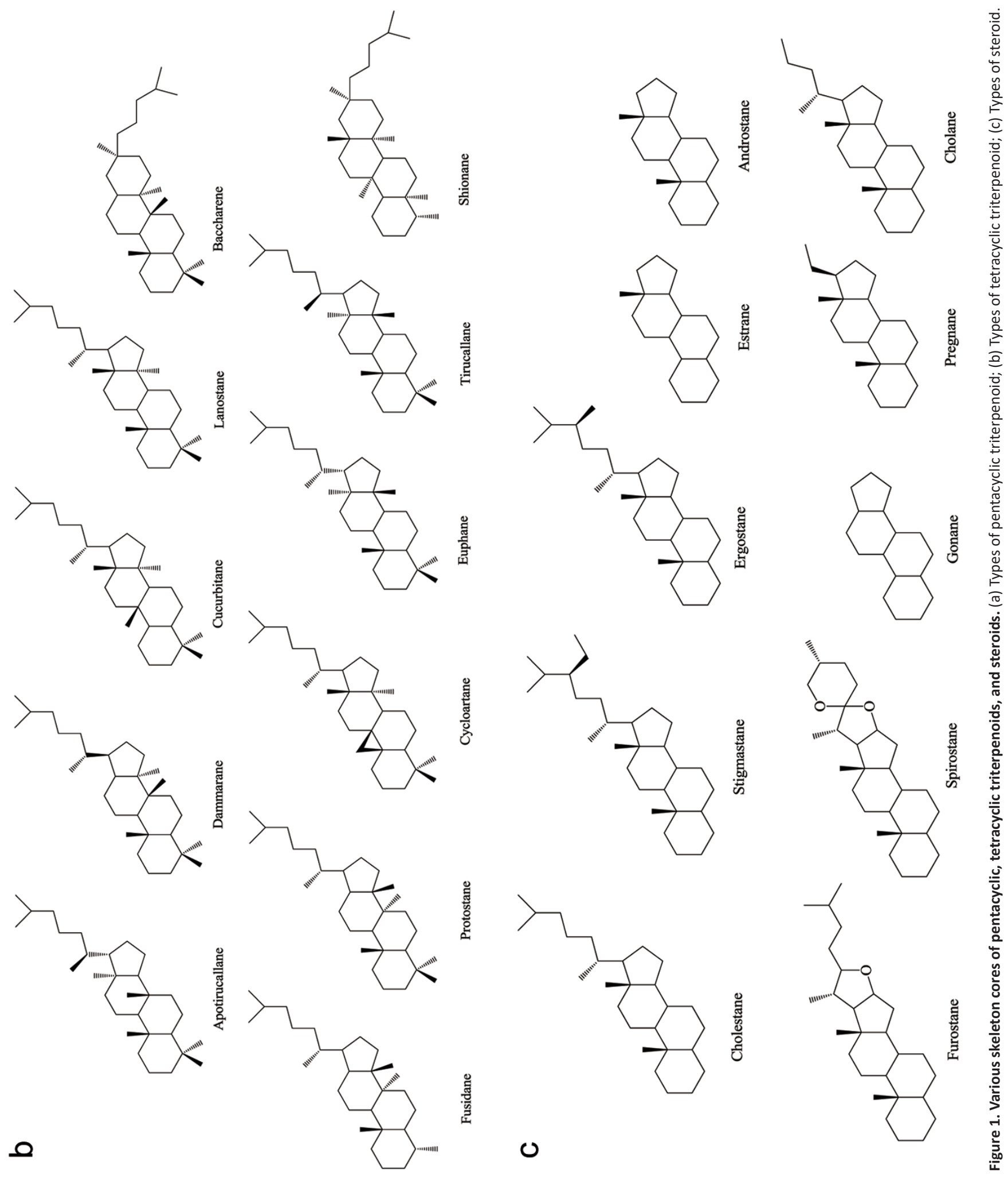




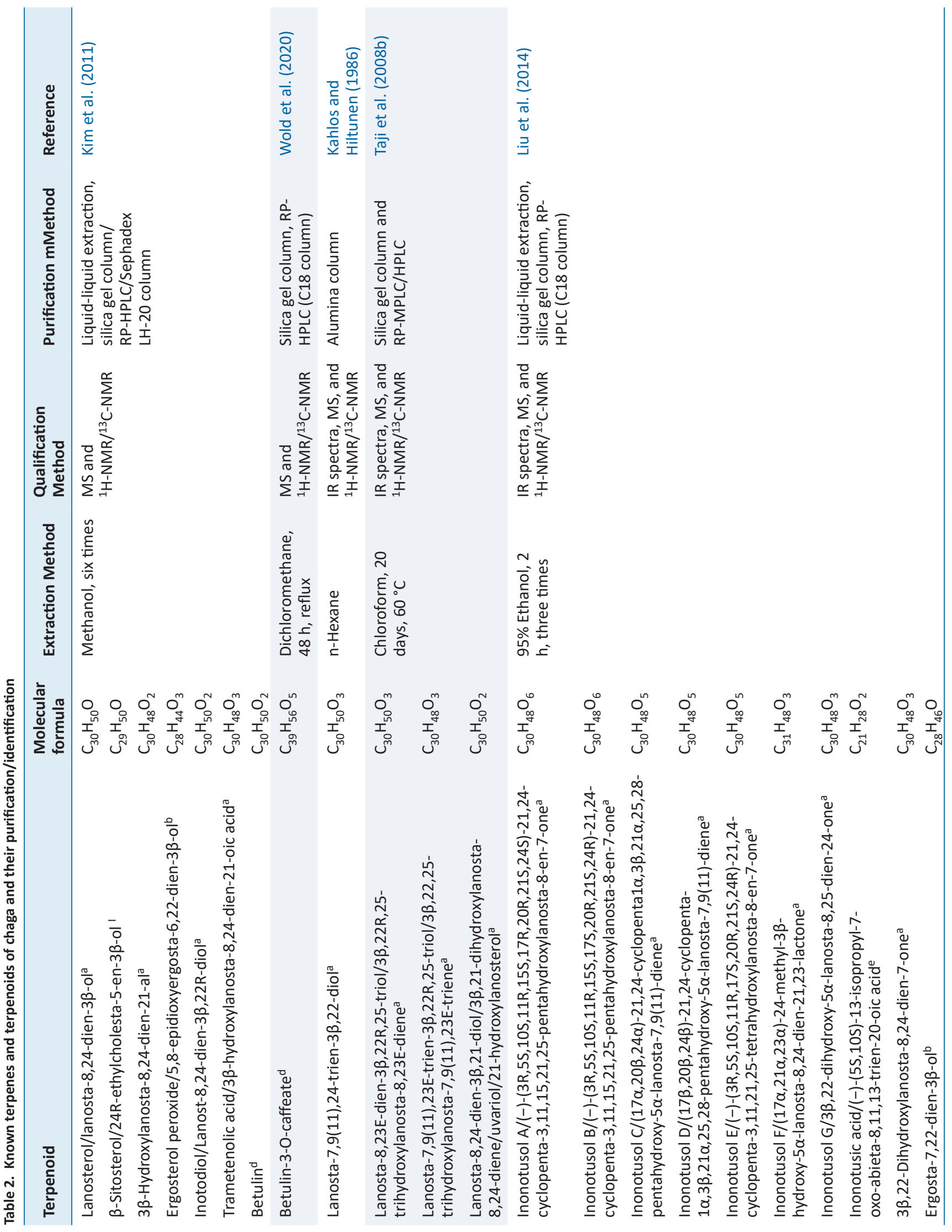




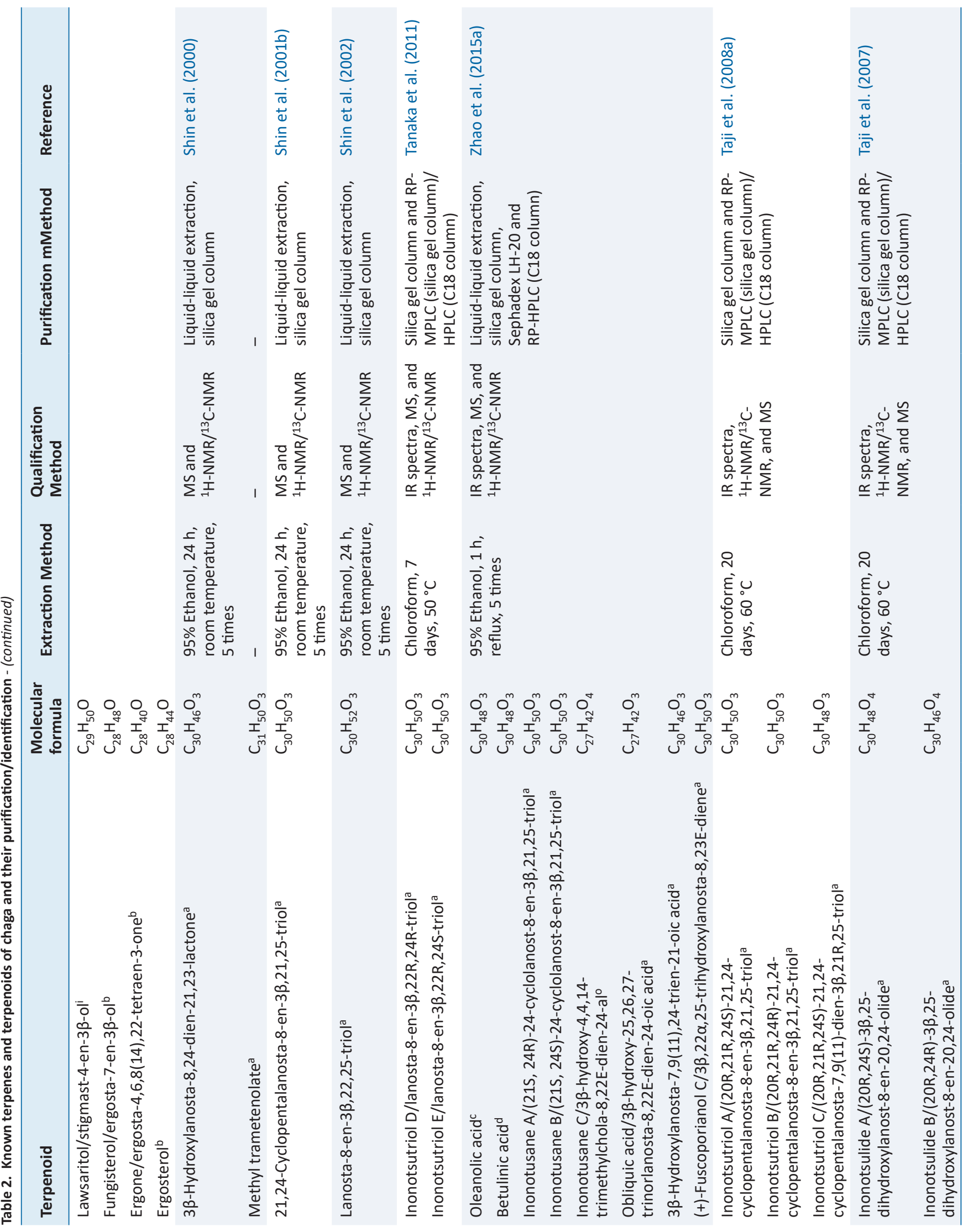




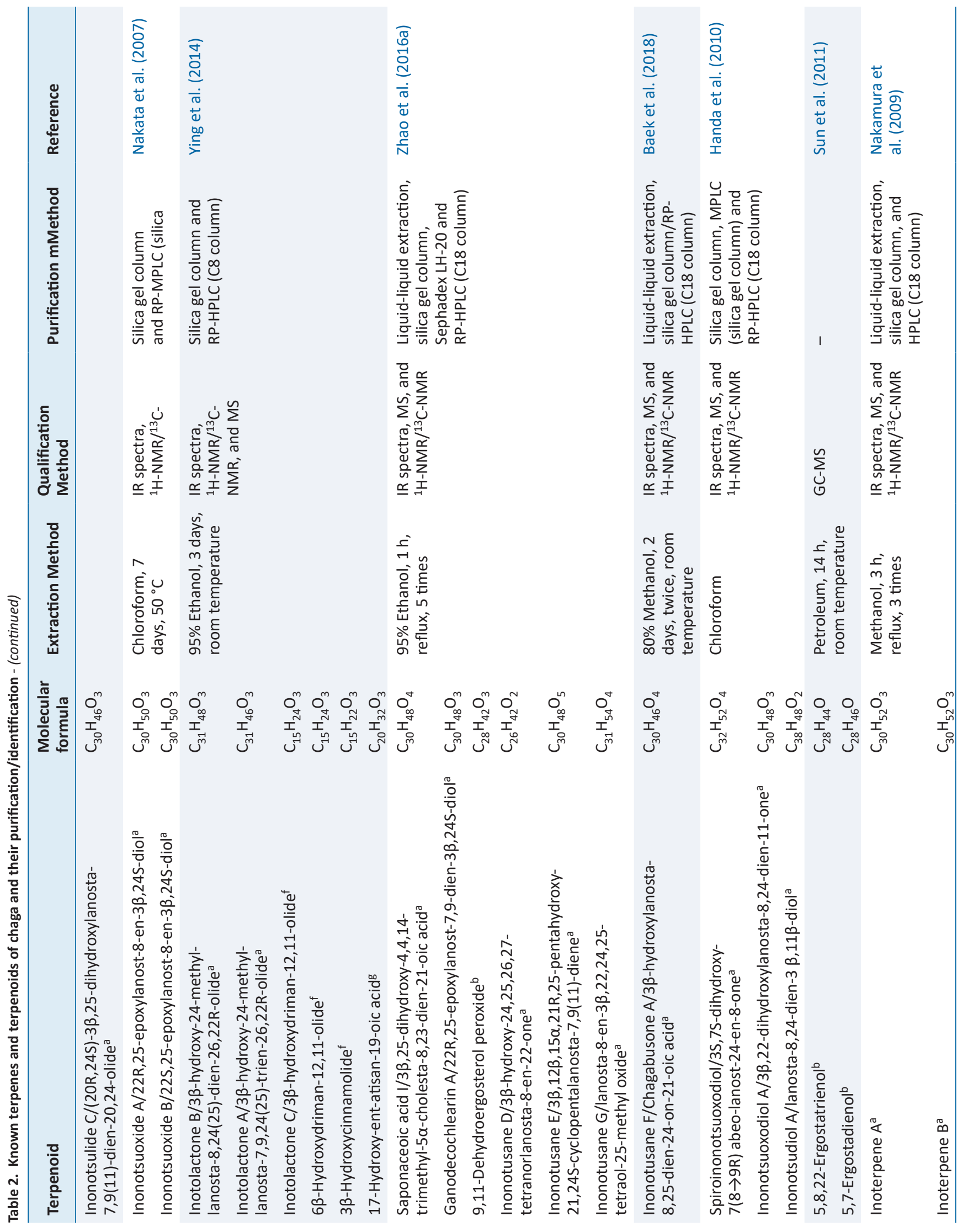




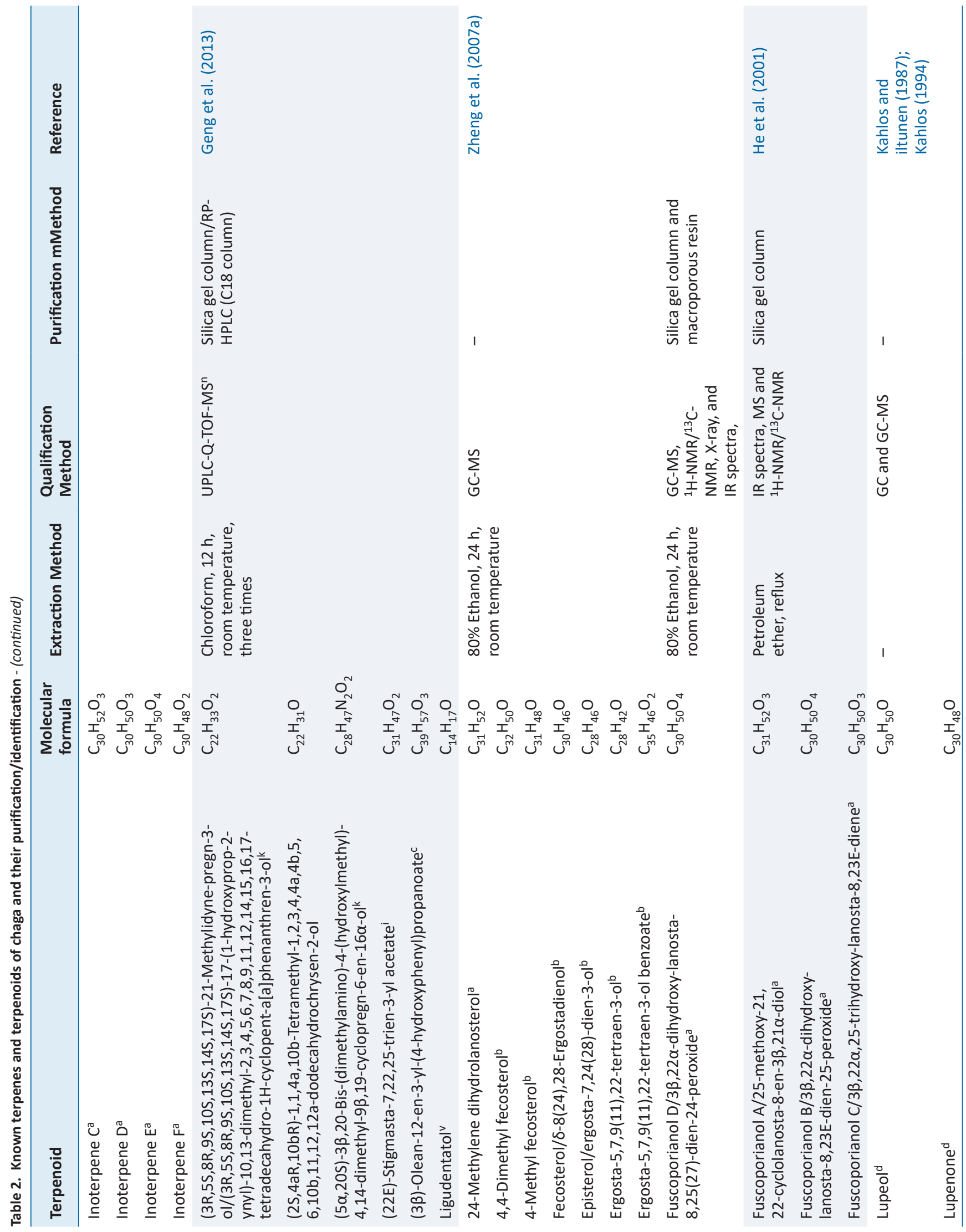




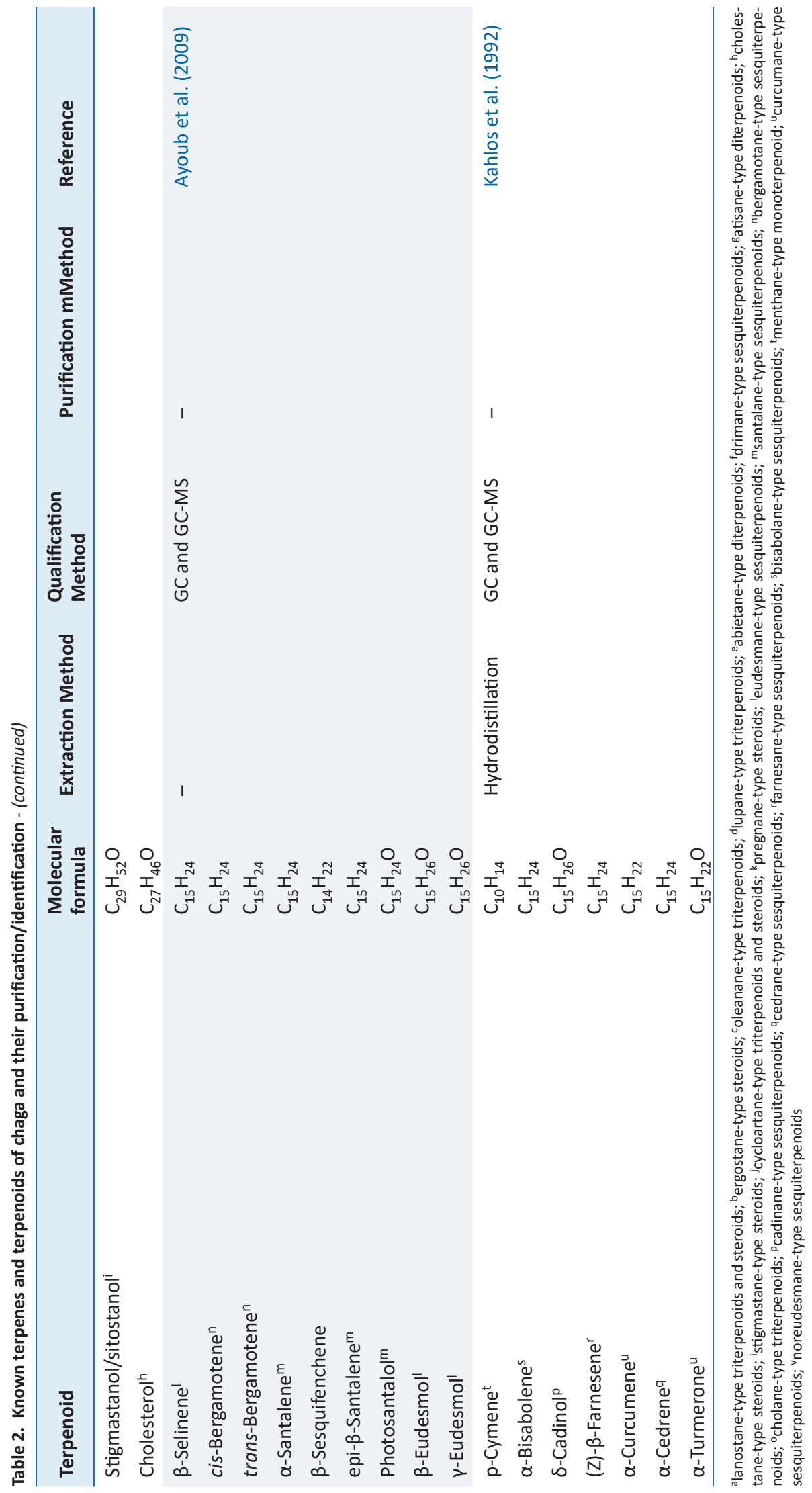




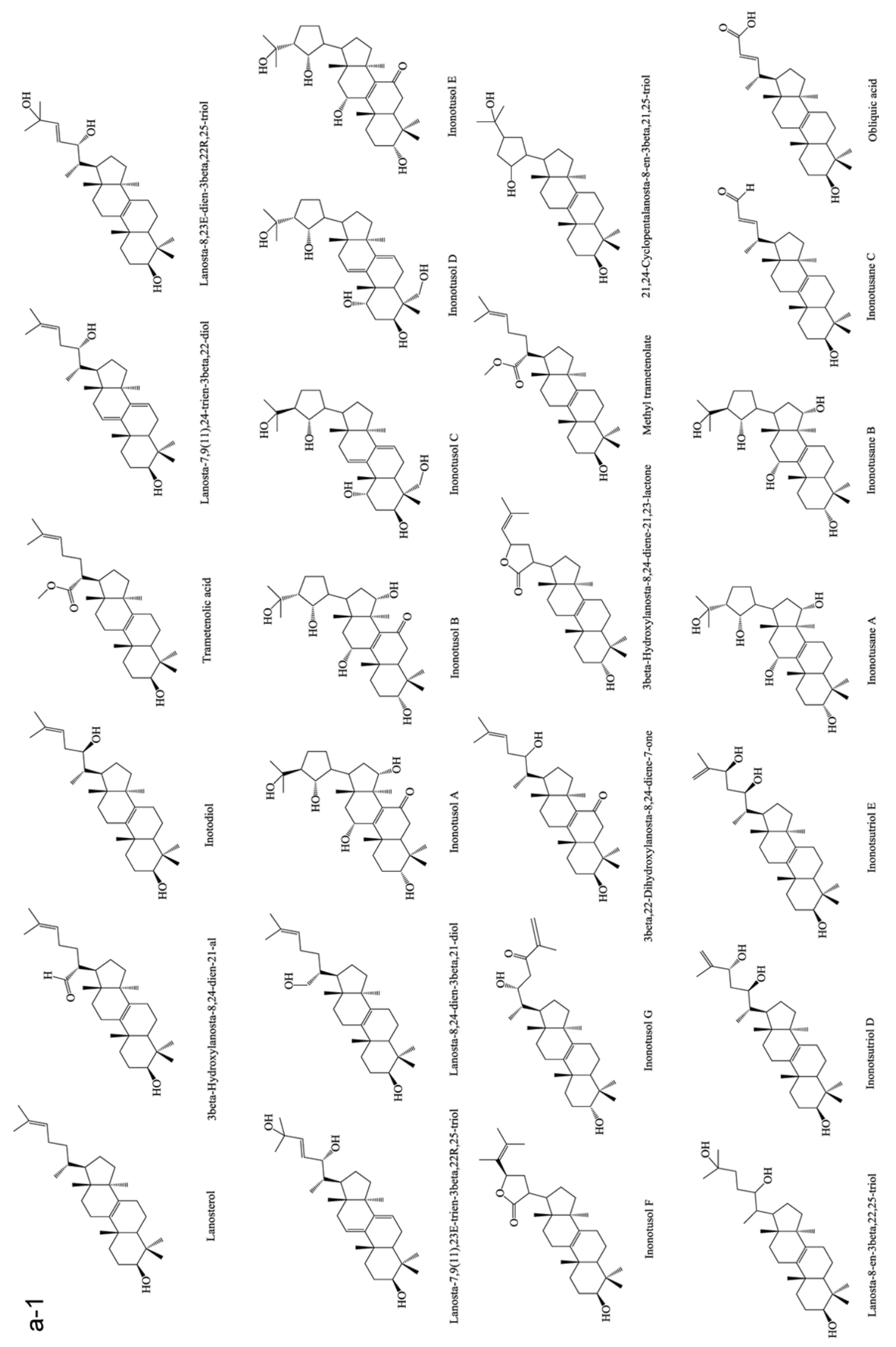




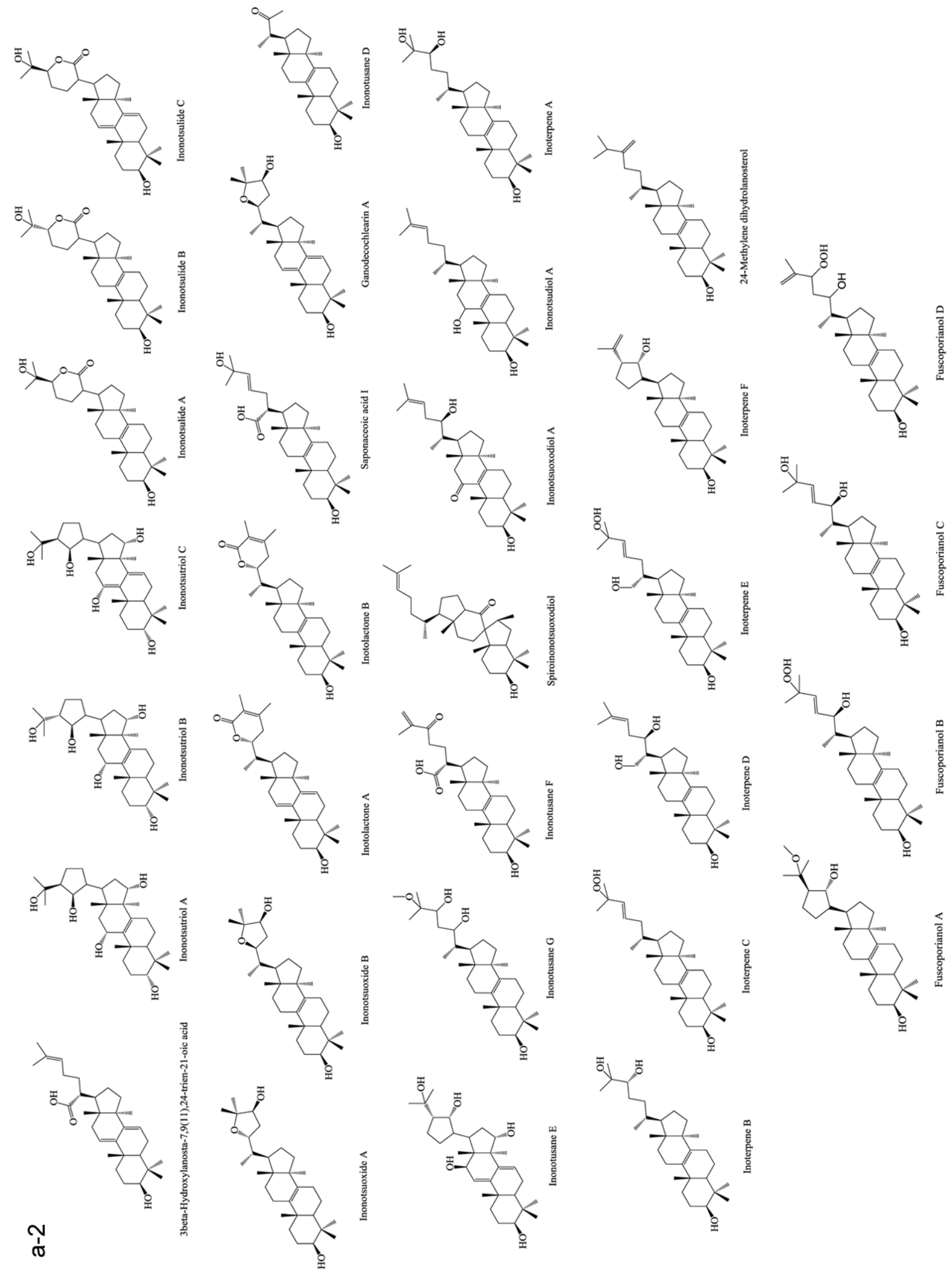




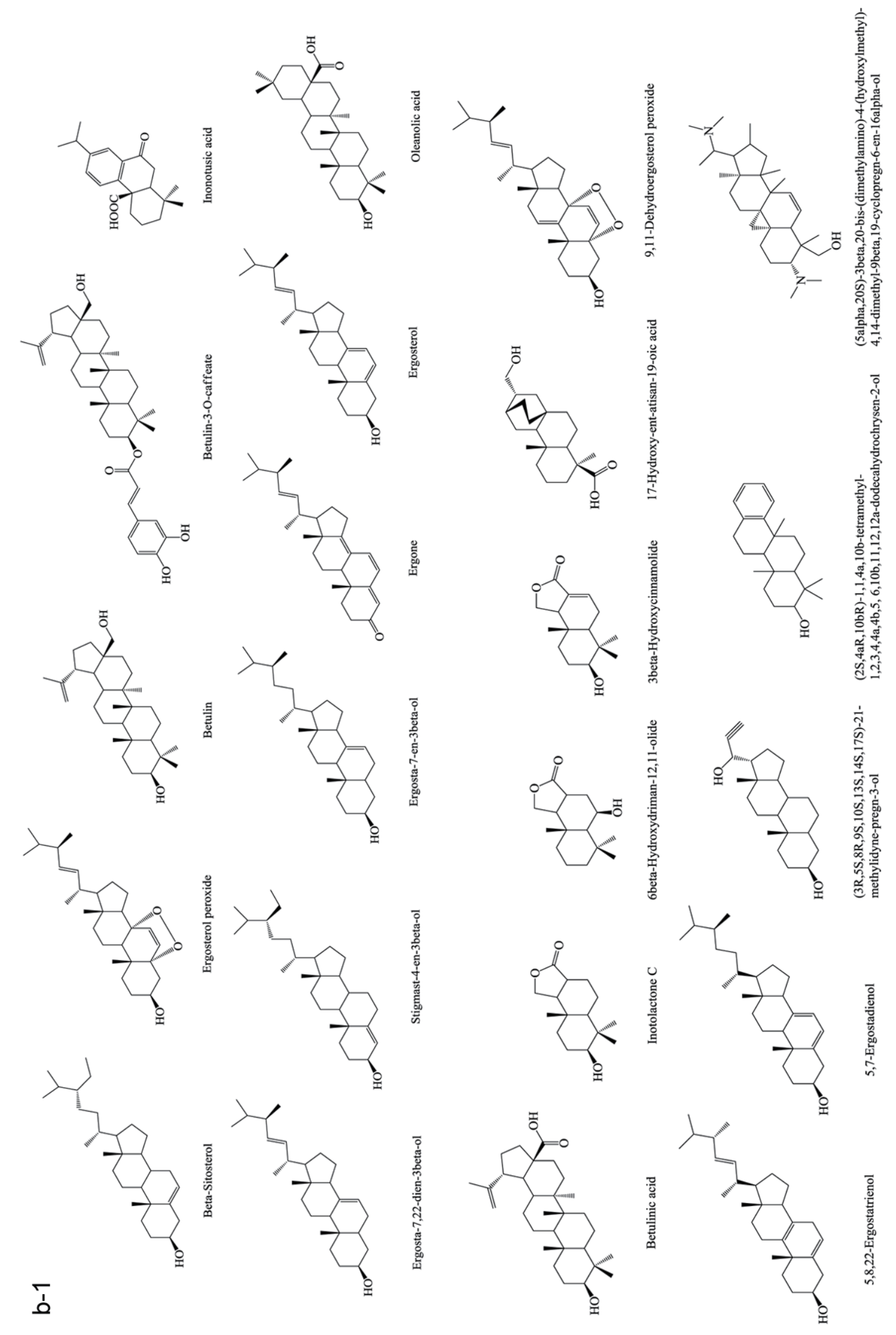



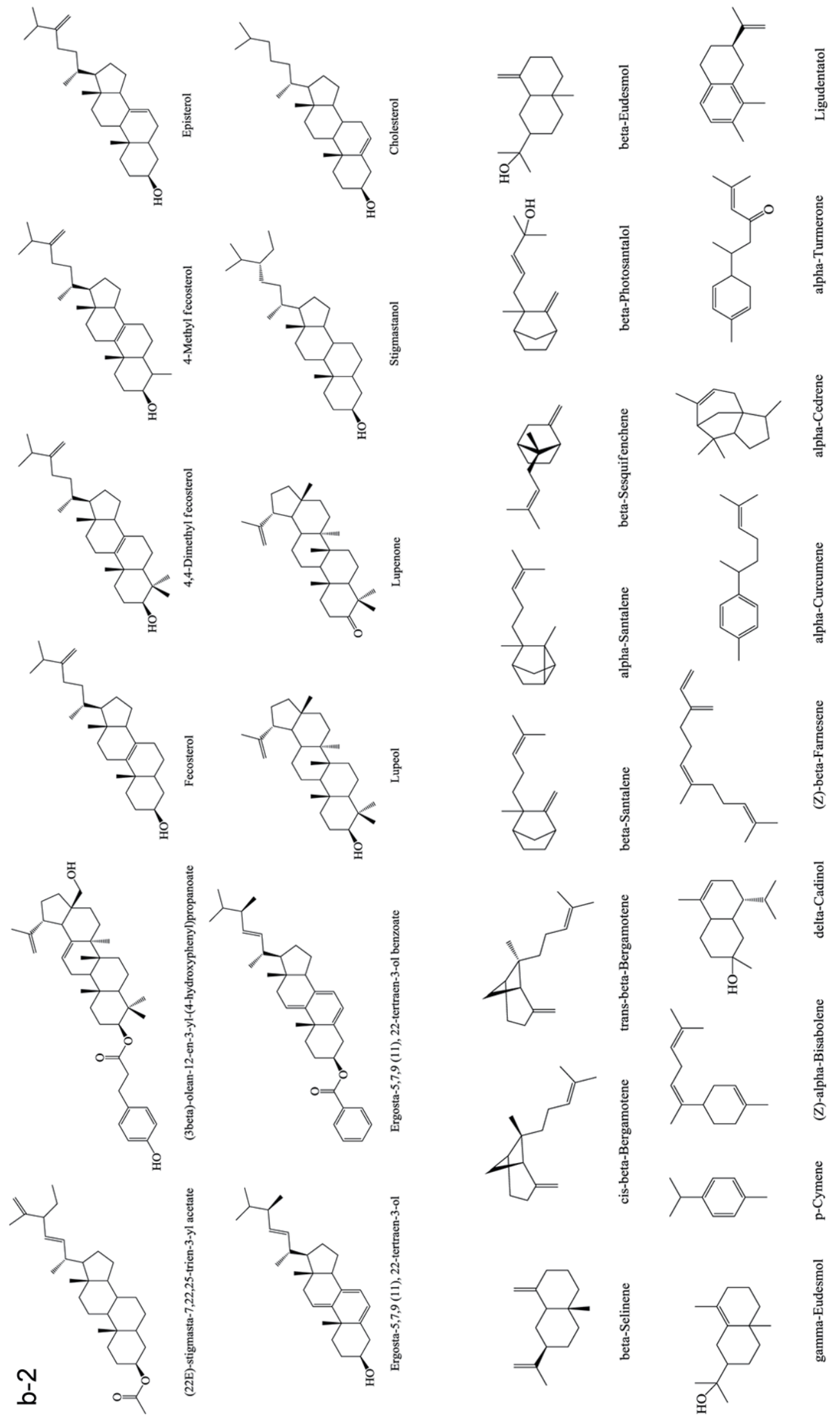

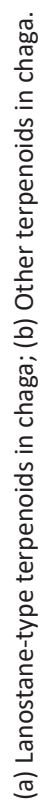
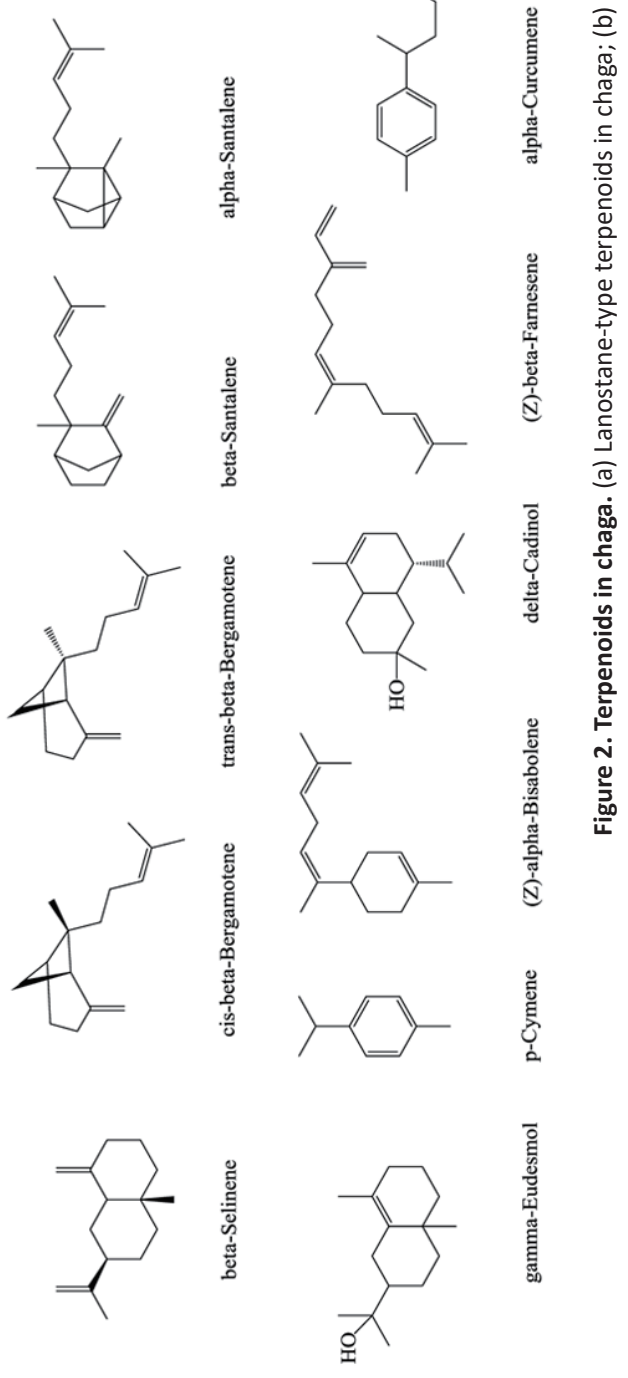


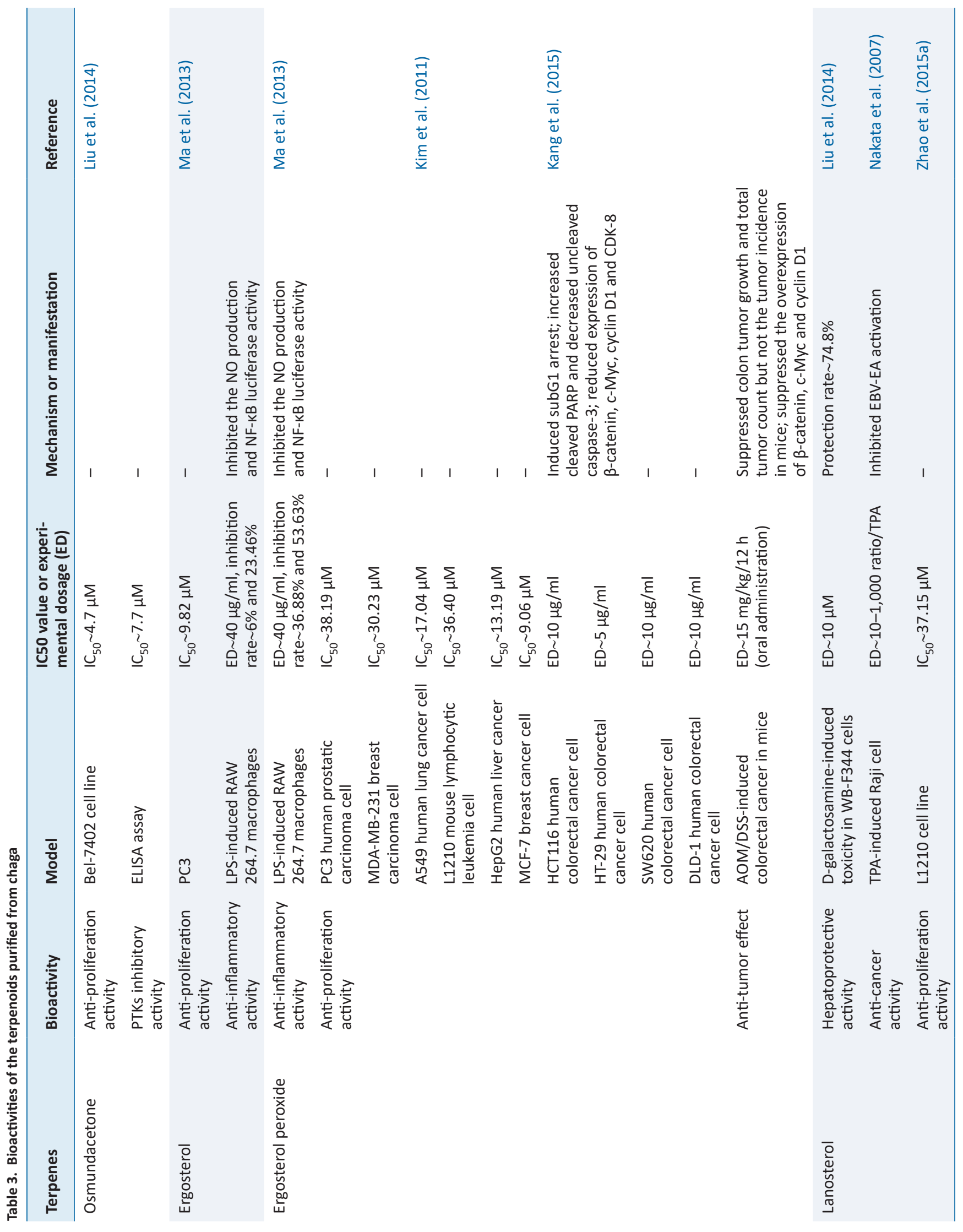




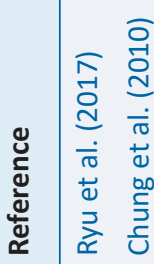

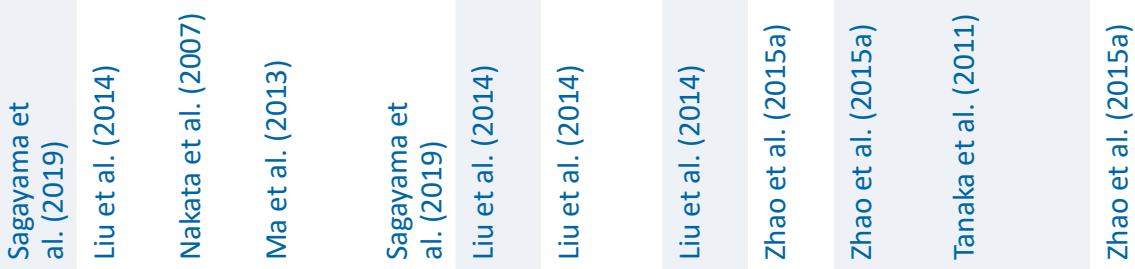

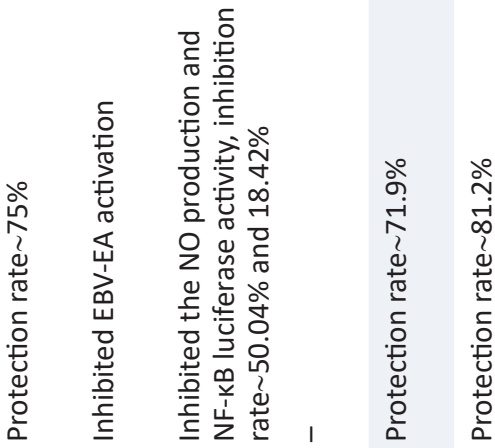

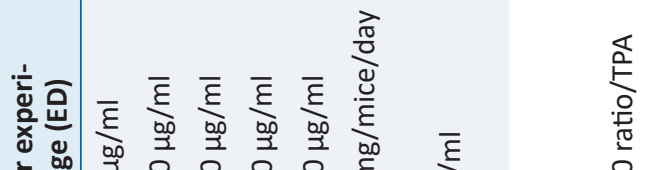

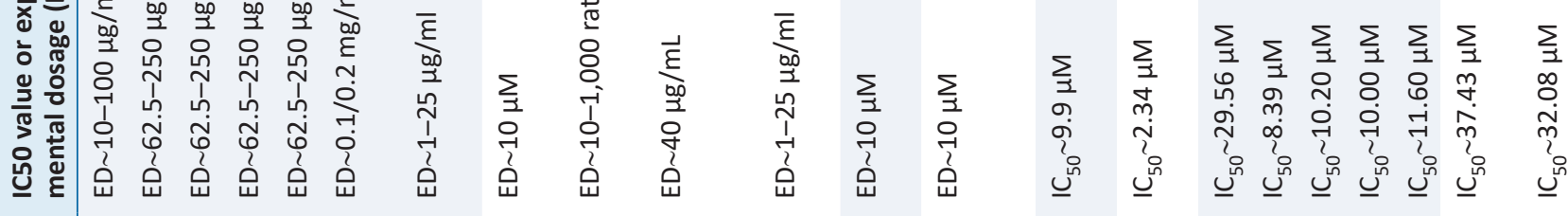
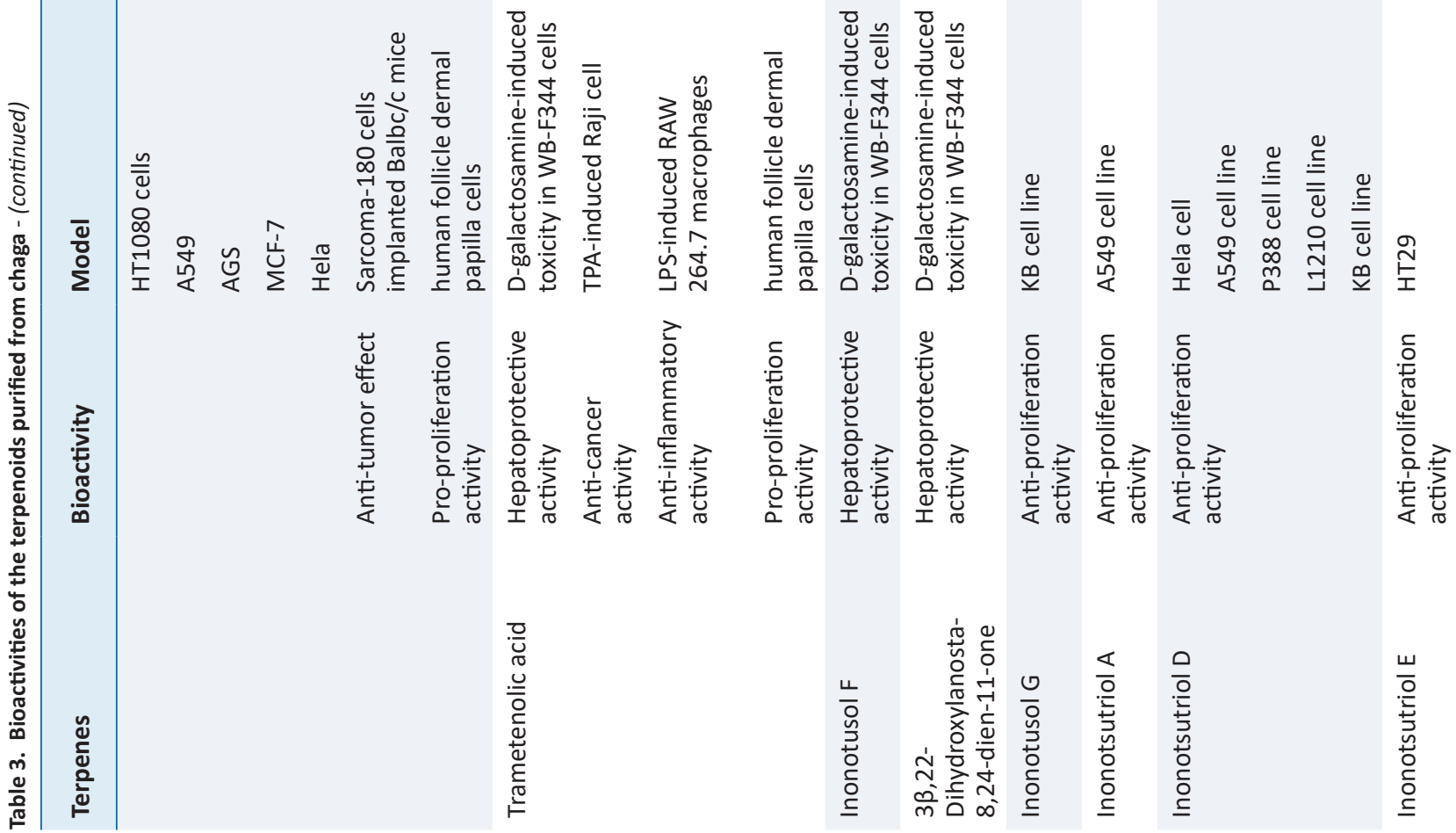


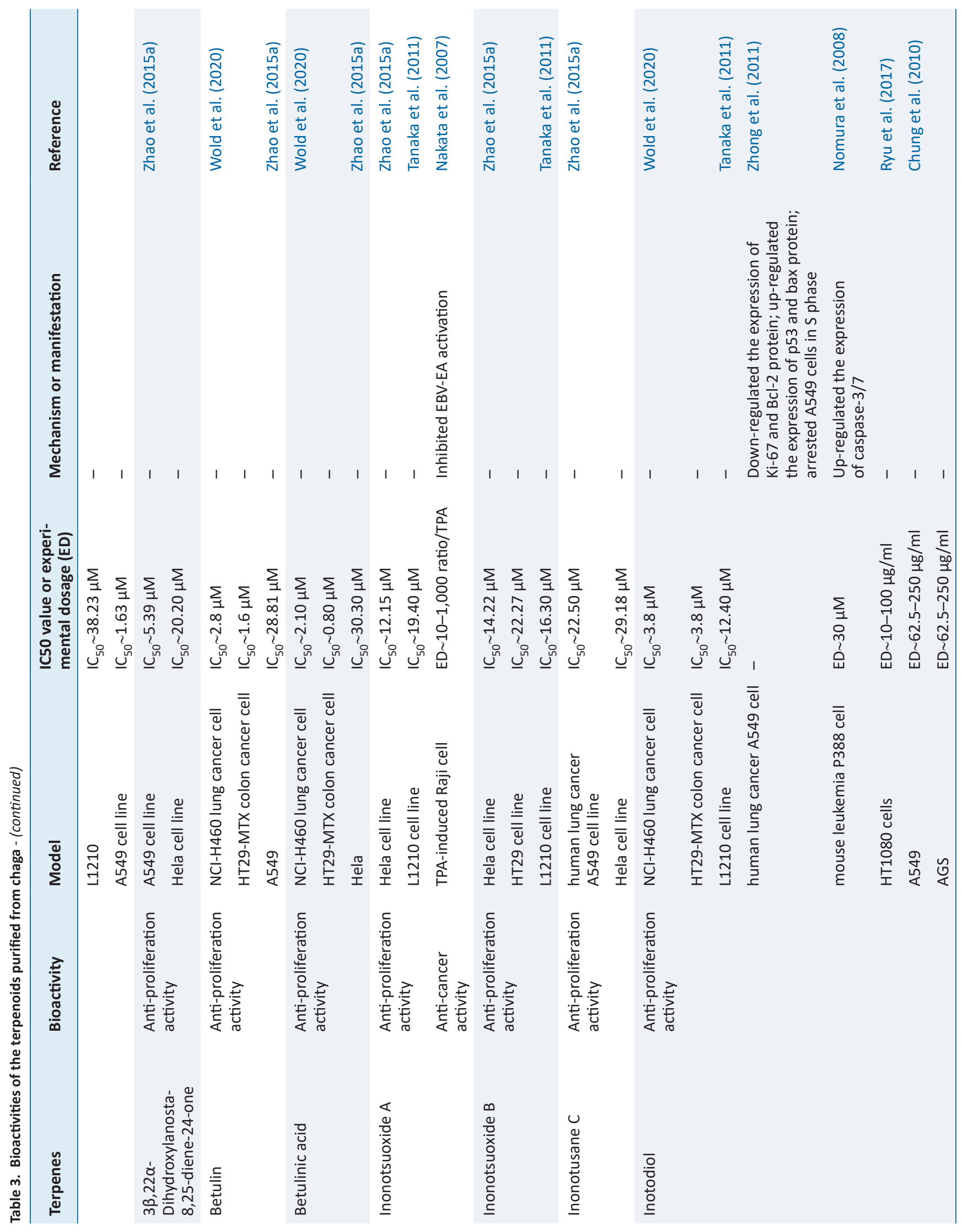




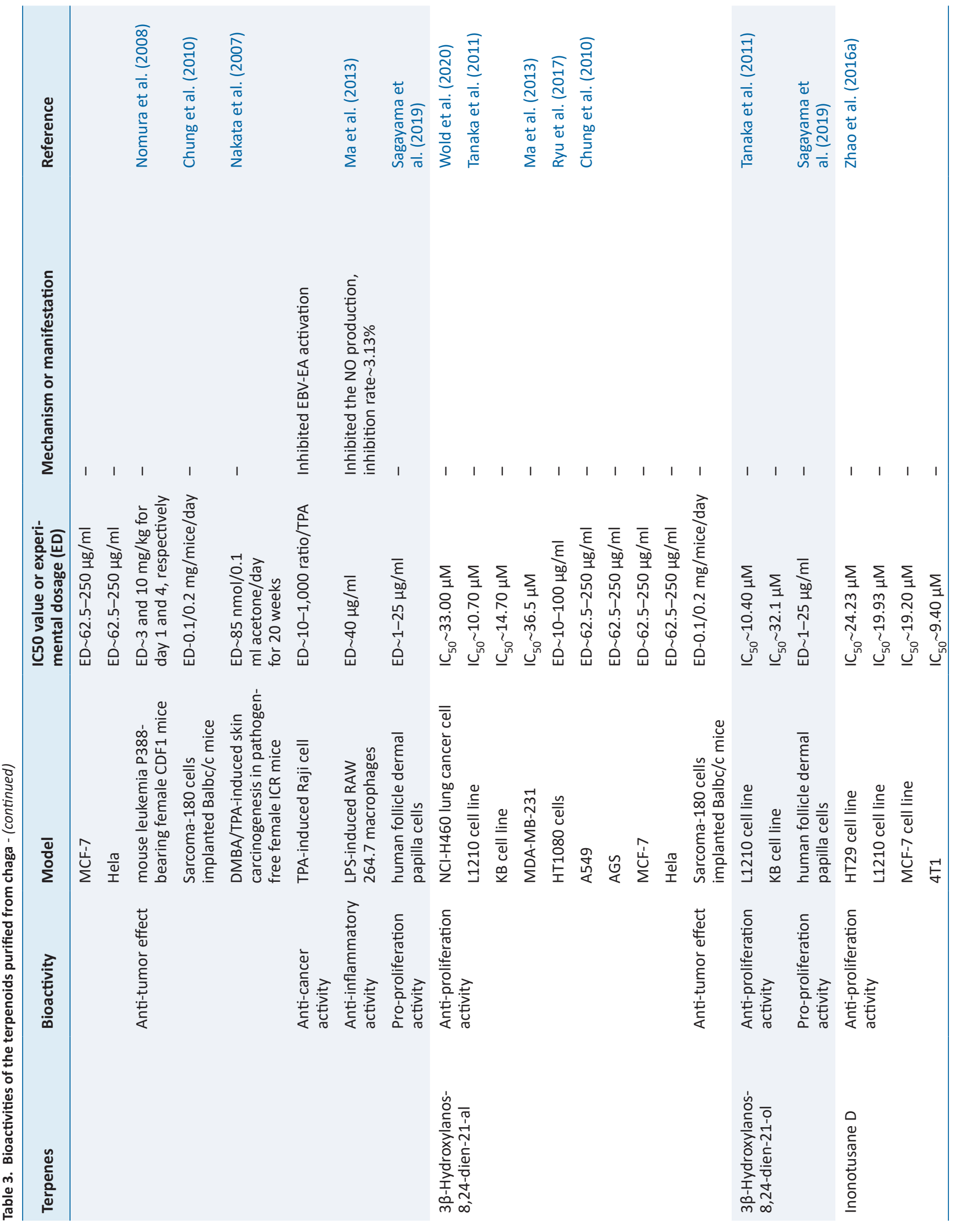




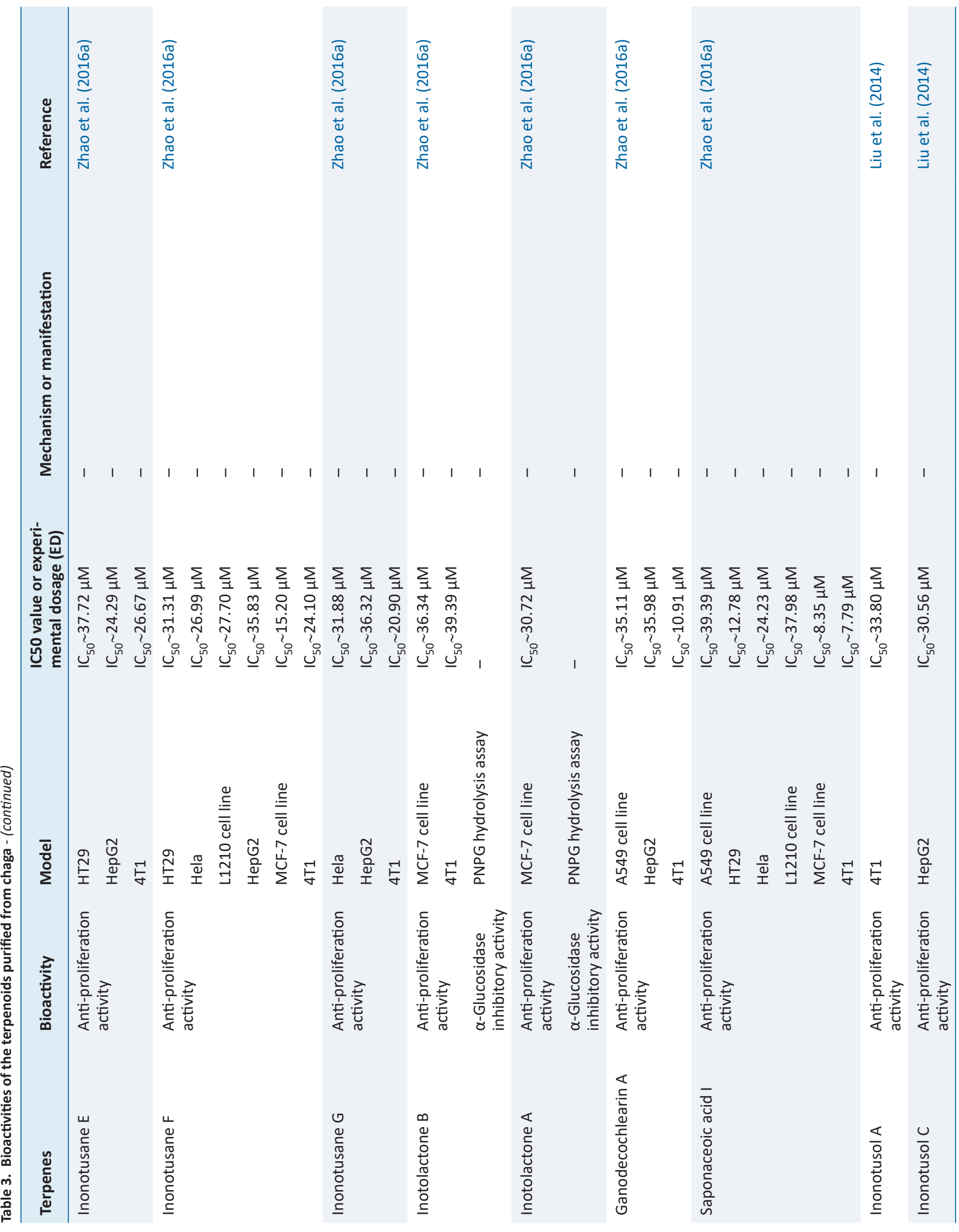




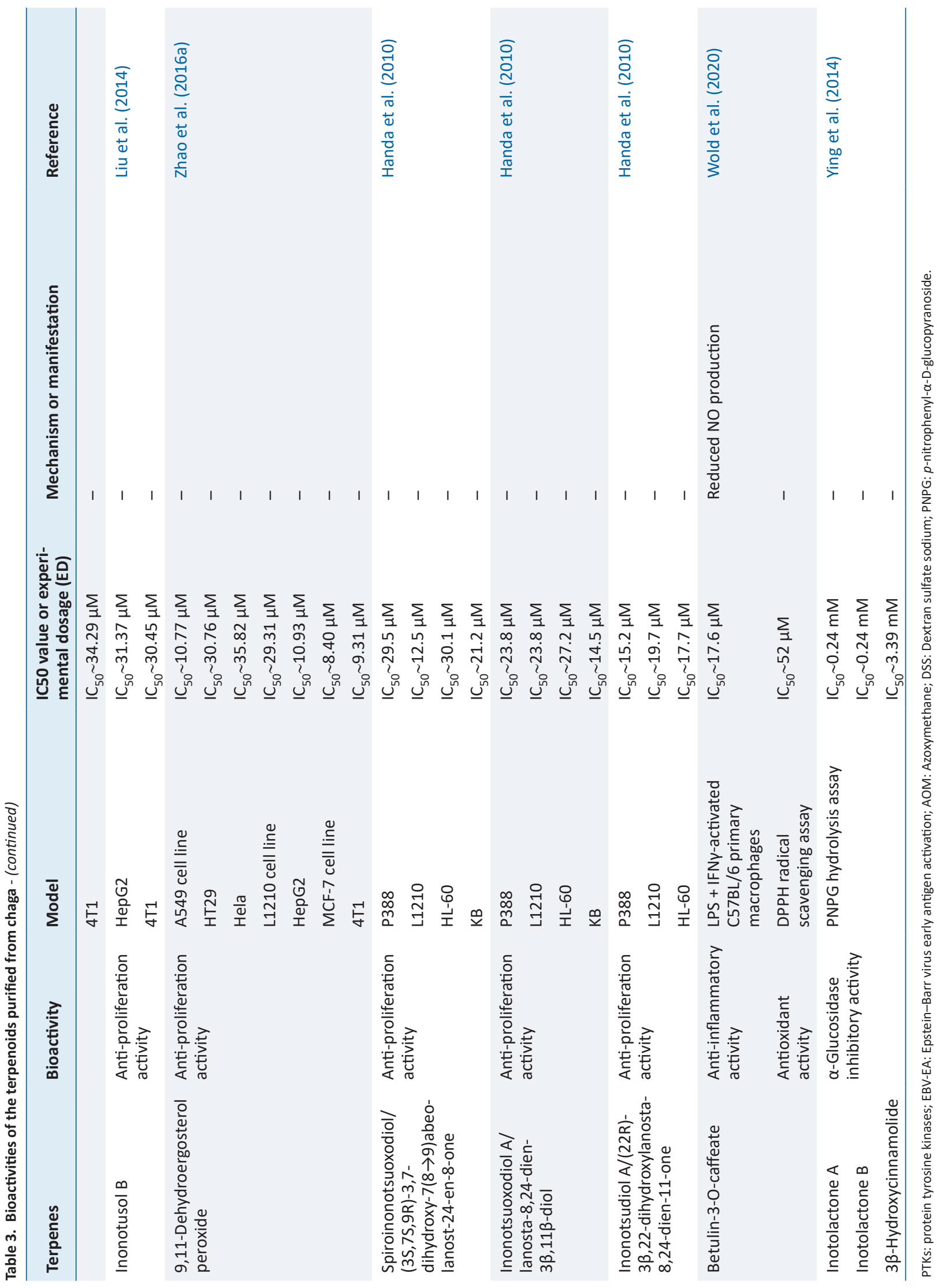


considered as contributors of various health benefits with relatively few toxic/side effects based on extensive cellular, animal, and molecular biology experiments, as well as intervention and epidemiological studies (Scalbert et al., 2005). The small-molecule phenolics could be classified according to the number of carbons on their skeleton cores, such as simple phenolics (C6), phenolic acids (C6-C1, C6-C2, C6-C3), coumarins (C6-C3), naphthoquinones (C6-C4), xanthones (C6-C1-C6), stilbenes and anthraquinones (C6-C2-C6), chalconoids and flavonoids (C6-C3-C6), and lignans (C6-C3) ${ }_{2}$ (Vermerris and Nicholson, 2008). As summarized in Table 4, there are a total of 64 small-molecule phenolics in chaga. Along with several small-molecules, common phenolics such as coumarins, phenolic acids, and flavonoids, a rare phenolic group, namely styrylpyrones (C6-C2-C5), was also reported in chaga. They are inonoblin A-C, inoscavin B-C, phelligridin $\mathrm{C}-\mathrm{H}$, methylinoscavin A-C, davallialactone, and methyl davallialactone (Figure 3). The styrylpyrones are mainly produced from Hymenochaetaceae family such as Phellinus and Inonotus genus macromycetes or primitive angiosperm families including Piperaceae, Lauraceae, Annonaceae, Ranuculaceae and Zingiberaceae (Lee and Yun, 2011). More data of the bioactivities and corresponding molecular mechanism of styrylpyrones are given in a review by Lee and Yun (2011). The bioactive studies of chaga-isolated phenolics are relatively few, as listed in Table 5. The purified 3,4-dihydroxybenzaldehyde, 4-(3,4-dihydroxyphenyl)-(E)-3-buten-2-one, and 3,4-dihydroxybenzalacetone exhibited considerable in vitro anti-proliferation activity on various cancer cell lines (Liu et al., 2014; Nakajima et al., 2009; Zhao et al., 2016a). The antioxidant activities of different chaga-isolated styrylpyrones are expressed as the ratios of $\mathrm{IC}_{50}$ values of these styrylpyrones $(\mu \mathrm{M})$ to $\mathrm{IC}_{50}$ values of Trolox $(\mu \mathrm{M})$ using DPPH and ABTS assays, which are 0.43 and 1.45 for inonoblin A, 0.58 and 1.42 for inonoblin B, 0.65 and 0.82 for inonoblin $\mathrm{C}, 0.33$ and 1.51 for phelligridin $\mathrm{D}, 0.40$ and 1.57 for phelligridin E, and 0.43 and 1.48 for phelligridin $G$, respectively (Lee et al., 2007). Besides, different fractions of lignin were recently isolated and identified from wild chaga in the form of lignin-carbohydrate complex and assessed using in vitro antioxidant, anti-proliferation, immunomodulatory, and anti-inflammatory activity studies (Niu et al., 2016; Wang et al., 2015).

Similar to other secondary metabolites, the specific diversity and quantity of phenolics in chaga are influenced by their nutritional and environmental conditions. Zheng et al. (2008b) compared the phenolic content of wild chaga and its submerged cultures, the predominant phenolics or their derivatives in wild chaga including phelligridin $\mathrm{A}$, phelligridin $\mathrm{D}$, inoscavin $\mathrm{A}$, inoscavin $\mathrm{B}$, and melanins could hardly be detected in the cultured product. Meanwhile, the main phenolics of cultured chaga such as naringenin, epicatechin gallate (ECG), and kaempferol barely existed in the wild group. This difference was assumed to be the cause of the less in vivo immune-stimulating effects by phenolic compounds of cultured chaga than wild chaga (Zheng et al., 2008b). In another cultivation study of chaga, davallialactone and inscavin B were only synthesized when using the culture medium consisting of lignocellulosic biomass, while the group cultured in medium containing no lignin did not show these two phenolics (Xu et al., 2014a). Besides, the lignocellulose-added medium gave a significantly higher production level of other flavonoids including ECG, epigallocatechin gallate (EGCG), phelligridin G, and a lower level of simple phenolic acids such as gallic acid and ferulic acid, which resulted in a significant enhancement of the total antioxidant ability of chaga extracts (Xu et al., 2014a; Zhu and Xu, 2013). Based on the functional nature of phenolics, the disadvantaged environmental factors may act as elicitors and skew certain pathways and affect their production. For example, instead of using lignocellu- losic medium during submerged cultures, the coculture of chaga with other white-rot fungi such as Phellinus punctatus or Phellinus morii leads to an increased accumulation of phenolic compounds including phelligridin $\mathrm{C}$, phelligridin $\mathrm{H}$, methyl inoscavin $\mathrm{A}$, inoscavin $\mathrm{C}$, inoscavin $\mathrm{B}$, davallialactone, methyl davallialactone, as well as melanins and various lanostane-type triterpenoids, even though production of mycelial biomass will be inhibited (Zheng et al., 2011c). Furthermore, imposing oxidative stress by moderately supplementing with $\mathrm{H}_{2} \mathrm{O}_{2}$ or $\mathrm{Na}_{2}\left[\mathrm{Fe}(\mathrm{CN})_{5} \mathrm{NO}\right.$ ] (sodium nitroprusside), or using other stimulatory agents such as $\gamma$-irradiation, Tween-20, Tween-80, jasmonic acid, L-tyrosine, linoleic acid, heavy metal ions $\left(\mathrm{Mg}^{2+}, \mathrm{Cu}^{2+}, \mathrm{Co}^{2+}, \mathrm{Zn}^{2+}\right.$, and $\left.\mathrm{Mn}^{2+}\right)$ and extracts or cell debris of Alternaria alternata, Aspergillus flavus and Mucor racemosus in mycelia medium of chaga can also significantly increase the production, accumulation and/or diversity of phenolics, and corresponding antioxidant ability of extracts thereof (Kim et al., 2009; Poyedinok et al., 2020; Xu et al., 2015a; Xu et al., 2015b; Xu et al., 2019b; Xu et al., 2016b; Yang and Zheng, 1994; Zhao et al., 2009; Zheng et al., 2007b; Zheng et al., 2009a; Zheng et al., 2009b). More insights into the regulatory machinery that controls biosynthesis of chaga phenolics, especially styrylpyrones, are discussed below. Different from mechanism of higher plants, the elicitors-induced increase of phenolic production in chaga is mediated by boosted NO (nitric oxide) synthesis via a signalling pathway independent of oxylipins or jasmonic acid (Zheng et al., 2009a). Later, the higher cellular NO-mediated homeostasis between Snitrosylation and denitrosylation of SNO (S-nitrosothiols) was found to play an important role in the biosynthesis of styrylpyrones in chaga (Zheng et al., 2011a). Suppressing GSNOR (S-nitrosoglutathione reductase)-mediated S-nitrosylation enhanced TrxR (thioredoxin reductase) activity and biosynthesis of phelligridins $\mathrm{C}$ and $\mathrm{H}$, inoscavin $\mathrm{C}$, and methyl inoscavin $\mathrm{B}$ while reducing that of phelligridin D, methyl inoscavin A, davallialactone and methyl davallialactone. Conversely, inhibiting TrxR-induced denitrosylation increased production of phelligridin $\mathrm{D}$, methyl inoscavin $\mathrm{A}$, davallialactone, and methyl davallialactone, but decreased that of phelligridins $\mathrm{C}$ and $\mathrm{H}$, methyl inoscavin $\mathrm{B}$ and inoscavin $\mathrm{C}$ (Zheng et al., 2011a). Besides, the elicitors-stimulated NO gerneration was followed with increased gene transcription and/or protein expression of phenylalanine ammonia lyase (PAL), 4-coumarate CoA ligase (4CL), inducible NO synthases-like protein (iNOSL), and styrylpyrone synthase (SPS), the key enzymes involved in styrylpyrone biosynthesis (Zhao et al., 2015b). Furthermore, the S-nitrosylation of these enzymes was also found with NO accumulation (Zhao et al., 2016b).

\subsection{Polysaccharides and their derivatives}

Polysaccharides are known for their role as structural and energyrelated elements in plants, animals, and microorganisms. They are formed through polymerization of at least 10 monosaccharides that are connected by glycosidic bonds in linear or branch sequence. The polysaccharides can be divided into homopolymers if they are composed of identical monosaccharides and heteropolymers if they contain more than one monosaccharide (Rodrigues et al., 2011). The structural complexity of polysaccharides involving the molecular weight, sequence and composition, anomeric configuration, type of glycosidic linkage, and presence of substituents can be used in demonstrating the discrepancies of their bioactive functions (Rodrigues et al., 2011; Wasser, 2002). In the studies of physicochemical properties of chaga polysaccharides, various fractions with different monosaccharide composition and molecular weight (MW) are achieved through various purification methods (Table 
6). For example, the purified chaga polysaccharide reported by Liu et al. (2019), is a proteoglycan with a MW of $40 \mathrm{kDa}$ and contains $57.17 \%$ carbohydrate and $32.53 \%$ protein. The carbohydrate part is comprised of D-galactose, D-glucose, D-xylose, and D-mannose in a 2.0:3.5:1.0:1.5 mole ratio. In the study by Xiang et al. (2012), the crude polysaccharide reported was composed of rhamnose, arabinose, xylose, mannose, glucose, galactose with a mole ratio of 2.64:5.09:3.03:24.8:10.3:54.1. Six fractions were purified from it with MW of $19-36 \mathrm{kDa}$ and consisted of $7.12-38.3 \%$ protein. Meanwhile, in the study of $\mathrm{Hu}$ et al. (2016), the purified polysaccharide contained $98.6 \%$ polysaccharide which was composed of mannose, rhamnose, glucose, galactose, xylose and arabinose in a mole ratio of 9.8:13.6: 29.1:20.5:21.6:5.4, and its molecular weight was $32.5 \mathrm{kDa}$. Besides, five homogeneous fractions were purified from chaga crude polysaccharides by Huang et al. (2012), the MWs of which were $150,93,230,44,100 \mathrm{kDa}$, respectively. Herein, the fraction with MW at $230 \mathrm{kDa}$ was a glycoprotein and the fractions with MW of 44 and $100 \mathrm{kDa}$ were acidic polysaccharides composed of 21.2 and $23.3 \%$ uronic acid. Kim et al. (2006) reported 5 purified fractions from chaga, among which one was identified as fucoglucomannan with a molecular weight of approximately 1,000 $\mathrm{kDa}$. This fraction consisted of $70.8 \%$ mannose, $1.6 \%$ glucose, $0.8 \%$ fucose, $0.1 \%$ glucosamine, and $26.8 \%$ protein. At the same time, some purified polysaccharide fractions of chaga also contained little or no protein (Chen et al., 2015; Fan et al., 2012; Hu et al., 2017a; Huang et al., 2012; Ma et al., 2012). In the study of Ma et al. (2012), 8.45\% protein, 30.01\% neutral sugar, and $14.47 \%$ uronic acid were present in one purified fraction of chaga polysaccharide $(122 \mathrm{kDa})$; around $48 \%$ of this purified polysaccharide were unknown compounds (neither protein nor polysaccharide). Its carbohydrate content was composed of $2.67 \%$ rhamnose, $3.20 \%$ arabinose, $6.57 \%$ xylose, $21.60 \%$ mannose, $48.00 \%$ glucose, and $17.90 \%$ galactose. More recently, Wold et al. (2018) isolated and fully analyzed three relatively pure polysaccharide fractions from chaga, neutral polysaccharides $(60-73 \mathrm{kDa})$, alkaline polysaccharides $(>450 \mathrm{kDa})$ and acidic polysaccharides $(10-31 \mathrm{kDa})$. The neutral polysaccharides consisted of a $(1 \rightarrow 3)$-linked $\beta$-Glc backbone with branches of $(1 \rightarrow 6)$-linked $\beta$-Glc, in addition to substantial amounts of $(1 \rightarrow 6)$-linked $\alpha$-Gal with 3-O-methylation at about every third Gal residue, and alkaline polysaccharides consisted mainly of $(1 \rightarrow 3)$ - and $(1 \rightarrow 6)$-linked $\beta$-Glc and $(1 \rightarrow 4)$-linked $\beta$ Xyl. The protein content of these fractions was less than $0.1 \%$ but the content of phenolics (trace-9.7\%) and unknown non-carbohydrate compounds was still remarkably high (11-58\%). Hence, it is worth noting that regardless of being "crude" or "purified", polysaccharides of chaga in these studies are, to a large extent, covalently linked to non-polysaccharide components. It is possible that these non-polysaccharide components could enhance certain bioactivities through their linkage with polysaccharides or simply function independently. Therefore, to clarify and differentiate the exact mode of action of various fractions of chaga "polysaccharides" in in vitro/in vivo bioactivity studies, a thorough purification and comprehensive analysis of their physicochemical properties also deserves further investigation.

For mushroom, a plethora of studies have shown that polysaccharides possess immense biological properties, especially immune-stimulating and anti-cancer/tumor activities (Rodrigues et al., 2011; Singdevsachan et al., 2016; Yu et al., 2018). Through intraperitoneal administration, mushroom polysaccharides were treated as antigens in the body of higher animals, although the analogy of cellular specificities between them and LPS is frequently made even if their structure and action mechanism are quite distinct (Hua et al., 2007; Kim et al., 2010; Kim et al., 2008a; Kim et al., 2005; Kim et al., 2006; Pan et al., 2015; Park et al., 2003;
Shao et al., 2004; Wang et al., 2018d; Won et al., 2011; Yang et al., 2015). Meanwhile, the diversity of the origin of these polysaccharides gives them a vast variability of regulatory mechanisms of various cell-cell interactions in higher organisms. For instance, polysaccharides of Platycodon grandiflorum only stimulate B cells and macrophages instead of T cells, while lentinan and schizophyllan stimulate T cells and macrophages but not B cells (Han et al., 2001). Earlier, It was reported that using chaga polysaccharides enhances the nitrite production and expression of IL-1 h, IL-6, TNF- $\alpha$, and iNOS in macrophages as well as the in vitro pro-proliferation activity on fractioned $\mathrm{B}$ cells but no effects on $\mathrm{T}$ cells (Kim et al., 2005). However, later on, dose-dependent activation between chaga polysaccharide and enhancement of Th1/Th2 cellrelated cytokine secretion (IFN- $\gamma$ and IL-4) in in vitro model of mouse splenocytes demonstrated that $\mathrm{T}$ cells were also affected (Won et al., 2011). Other studies indicating the in vitro and in vivo pro-proliferation ability of chaga polysaccharides on immune cells are given in Table 7 .

The polysaccharides of mushroom were deemed to function as anti-cancer/tumor agents which strive to inhibit or eliminate the growth of cancer cells by activating and reinforcing the immunological functions of the host instead of directly attacking cancer cells (Ooi and Liu, 2000). In fact, direct and indirect anti-tumor/ cancer ability was reported for both chaga polysaccharides and other mushroom polysaccharides. Kim et al. (2006) reported a purified fraction composed of $\alpha$-linked fucoglucomannan-protein complex $(\sim 1,000 \mathrm{kDa})$ from chaga that exerted pro-proliferation activity on Raw264.7 murine macrophages, albeit, no anti-proliferation activity on HEC-1B, B16F10, A549, KATO-III, SW156, and SK-OV3 cancer cell lines nor normal human cells HUVEC/ HEK293T at an even high concentration level of $200 \mu \mathrm{g} / \mathrm{ml}$. Meanwhile, intraperitoneal administration of this fraction significantly inhibited tumor incidence, prolonging the survival rate of B16F10implanted mice at a dose of $30 \mathrm{mg} / \mathrm{kg} /$ day (Kim et al., 2006). A similar result was reported by Chen et al. (2015), in in vitro assay showing that one purified chaga polysaccharide $(48.82 \mathrm{kDa})$ had no toxicity in Jurkat cells, but intake of this polysaccharide fraction not only inhibited the growth of transplantable Jurkat tumor in mice significantly, but also enhanced the splenocyte proliferation and lymphocyte proliferation induced by concanavalin $\mathrm{A}$ and LPS in a dose-dependent manner. However, the opposite results, showing significant toxicity of purified polysaccharide fractions (13.6-200 kDa), were observed in HepG2 cells at high concentrations of $80-240 \mu \mathrm{g} / \mathrm{ml}$ (Liu et al., 2018; Xue et al., 2018). Lee et al. (2014c) demonstrated the direct in vitro anti-migration and antiproliferation abilities of the crude polysaccharides by decreasing the expression levels and activity of MMP-2 (matrix metalloproteinase-2)/MMP-9, the phosphorylation levels of MAPKs (mitogen-activated protein kinases), PI3K (phosphoinositide 3-kinase)/ AKT (protein kinase B) and COX-2 (cyclooxygenase-2), as well as inhibiting the nuclear translocation of NF- $\mathrm{KB}$ (nuclear factor $\kappa \mathrm{B})$ in A549 human lung cancer cells. The same authors proposed a similar mechanism (MAPKS, COX-2 and NF- $\mathrm{kB}$ pathway) on direct in vitro anti-migration, anti-invasion, and anti-proliferation activity on B16-F10 mouse melanoma cells (Lee et al., 2014b). However, the same authors later refuted their own proposed antimigration ability (Lee et al., 2016). While in vitro trial of LLC1 cell, the purified chaga polysaccharide showed direct cytotoxicity for activating AMPK via phosphorylation of threonine 172 by LKB1, downregulating Bcl-2 and upregulating Bax, as well as enhancing cleavage of Caspase-3 and PARP, leading to the opening of mitochondrial permeability transition pore, and reducing MMP, eventually resulting in an inhibition of ATP production and cellular proliferation (Jiang et al., 2019). The inhibitory effect of LLC1 


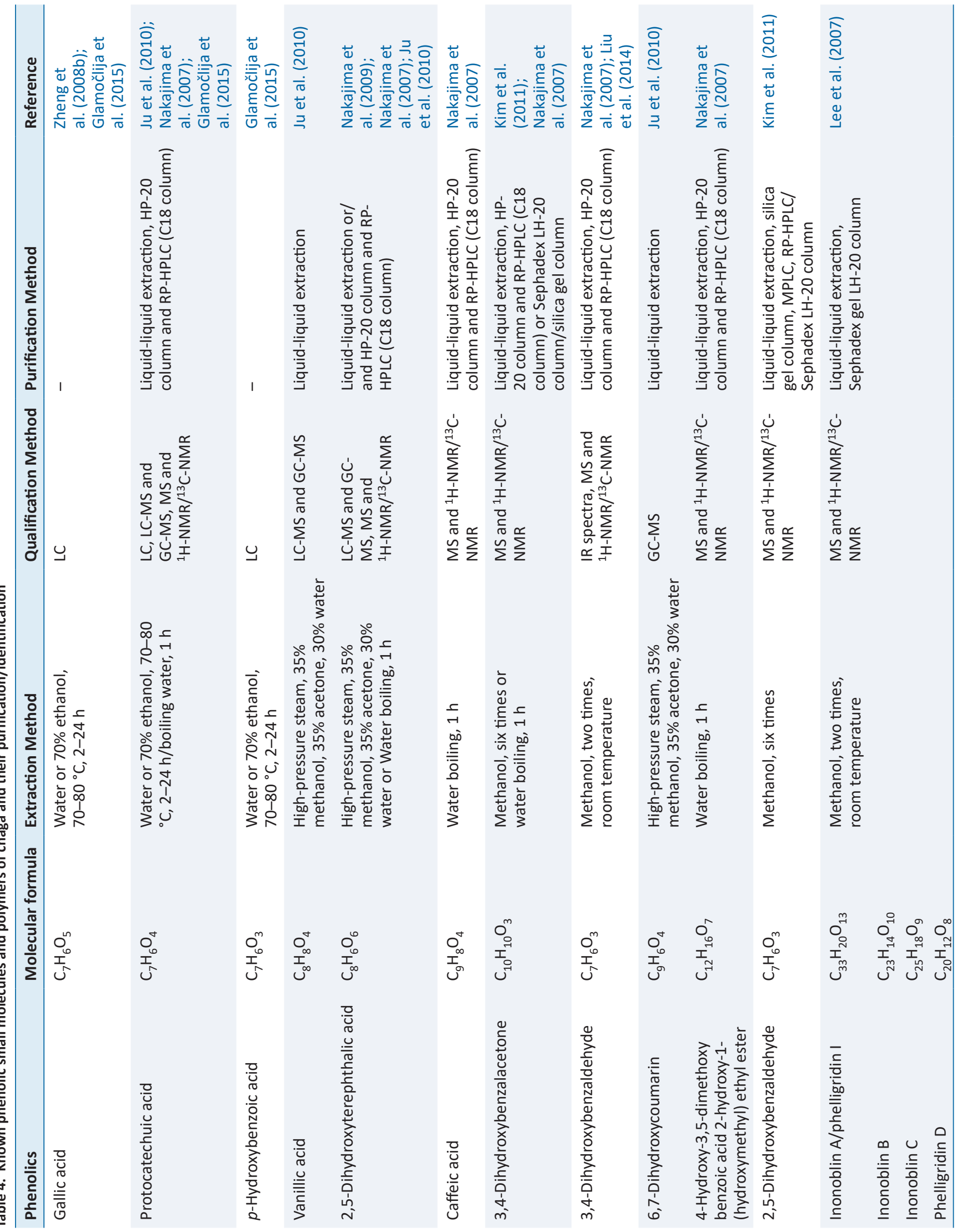




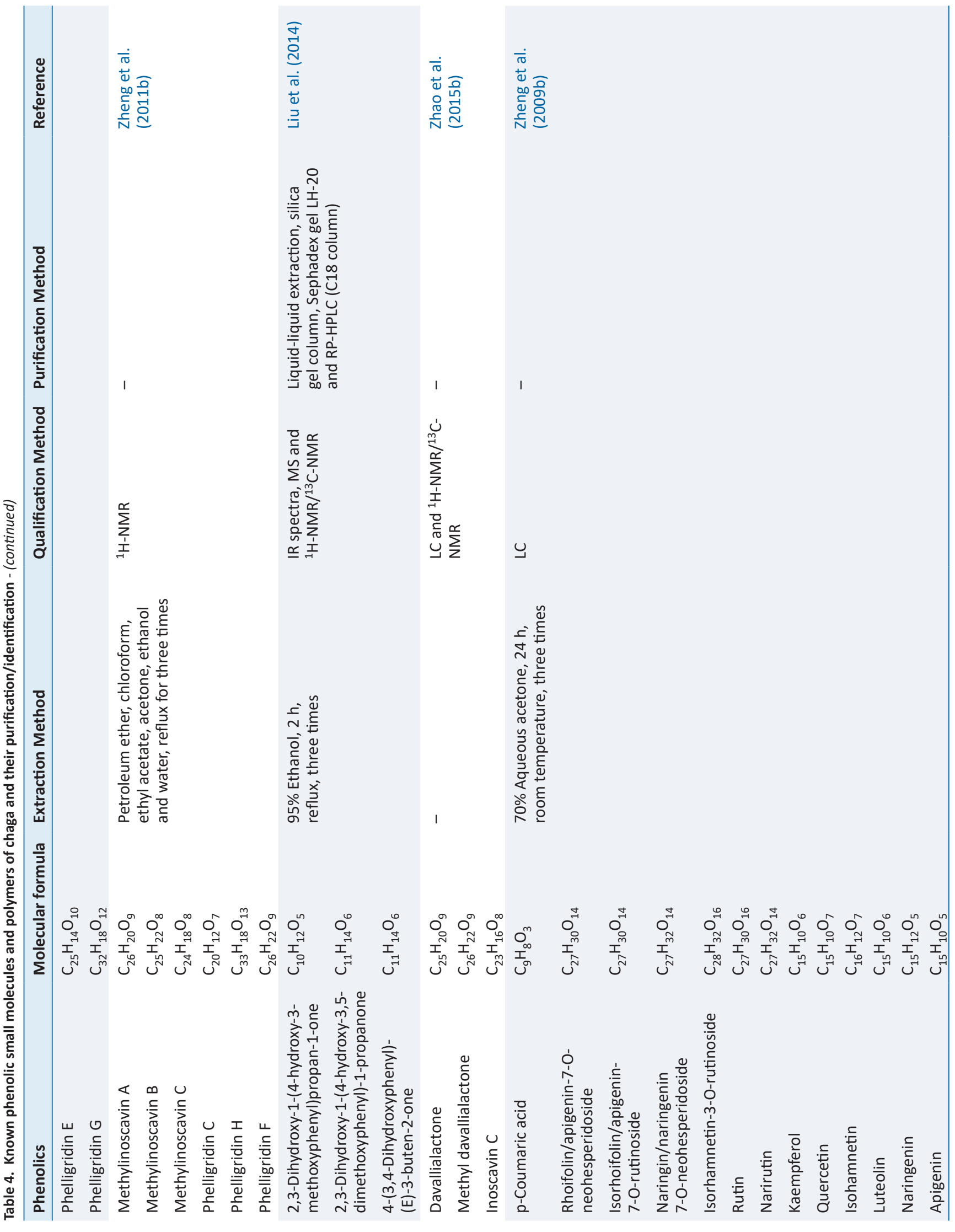




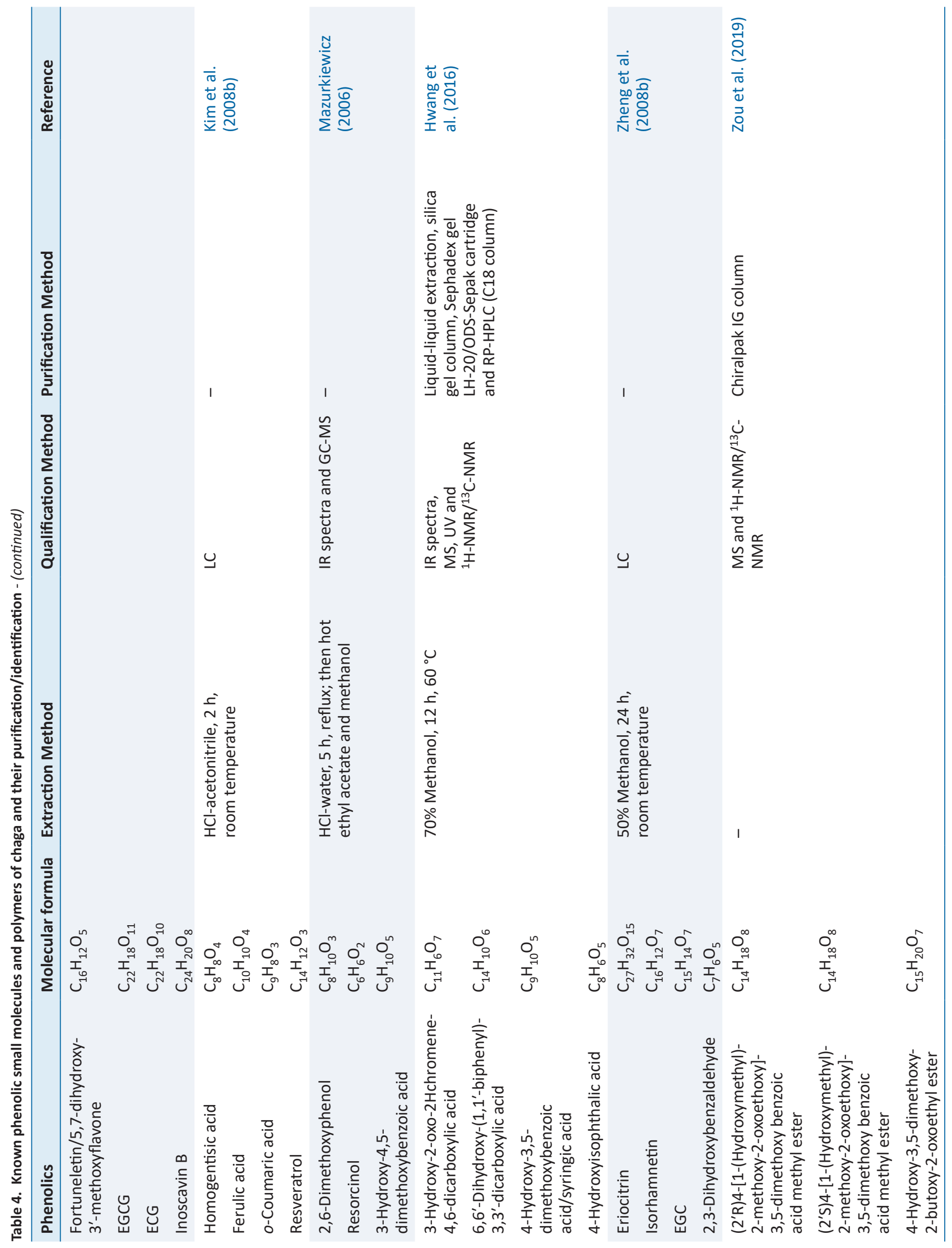


allograft tumor in mice was also verified through intraperitoneal injection of purified chaga polysaccharide at $50 \mathrm{mg} / \mathrm{kg} \mathrm{BW} /$ day (Jiang et al., 2019). The more interesting point is that these chaga polysaccharide fractions render in vivo anti-tumor/cancer effects through not only intraperitoneal injection but also via oral administration (Kim et al., 2006; Mizuno et al., 1999; Won et al., 2011). Specifically, the oral treatment of purified fraction of chaga polysaccharides at a dose of 50/100 mg/kg/day showed an excellent in vivo tumor-inhibitory effect in mice and in vitro immunoregulatory activities on spleen lymphocyte and macrophage without direct in vitro cytotoxicity on SGC-7901 human gastric cancer cells (Fan et al., 2012). A daily oral ingestion of chaga crude polysaccharides at a dose of $200 \mathrm{mg} / \mathrm{kg}$ body weight for 6 days could also effectively inhibit the growth of melanoma solid tumor (Won et al., 2011). Furthermore, Chen et al. (2010) found that crude polysaccharides can inhibit both the proliferation of in vitro tumor cells and tumor growth in orally-treated Balb/c-nu/nu nude mice. However, the results which include enhancement of NO, ROS, TNF- $\alpha$ and phagocytosis via regulating MAPKS (JNK, p38, ERK) and NF- $\mathrm{KB}$ signaling pathways in macrophages still imply that the anti-tumor effect of orally administrated chaga polysaccharides was also contributed by activating immune response systems. The exact mechanism of how the anti-tumor effect worked via oral administration is not yet clear. It was suggested that a major component of chaga polysaccharides, $\beta$-glucan, was taken up by intestinal macrophages, after which it was transported to lymph nodes, spleen and bone marrow, therefore upregulating and activating the intestinal immune system (Rhee et al., 2008; Rop et al., 2009; Won et al., 2011). Overall, the anti-cancer/tumor effects of chaga polysaccharides may be through oral or intraperitoneal treatments with both direct and indirect inhibitory effects.

Coinciding with those of chaga extracts, chaga crude polysaccharides exerted excellent in vivo antihyperglycemic and antihyperlipidemic effects in different diabetic models. Xu et al. (2010b) reported that oral administration of crude polysaccharide extract of cultured chaga in alloxan-induced type-1 diabetic mice, at 150 and $300 \mathrm{mg} / \mathrm{kg}$ body weight for 21 days, significantly decreased blood/ liver glucose level, liver malondialdehyde (MDA) and serum contents of free fatty acids (FFA), total cholesterol (TC), triacylglycerols (TAG), and low-density lipoprotein cholesterol (LDL-C). Meanwhile, it effectively increased high-density lipoprotein cholesterol (HDL-C), insulin levels, and hepatic glycogen contents, along with the enhancement of the catalase (CAT), superoxide dismutase (SOD), and glutathione peroxidase (GPx) activities in the liver of diabetic mice (Xu et al., 2010b). In the STZ-induced diabetic mice model, constant oral administration of chaga polysaccharides at $50 \mathrm{mg} / \mathrm{kg} \mathrm{BW} /$ day for 4 weeks down-regulated IL2R and MMP-9, and enhanced IL-2 level, and decreased the expression of phosphorylated NF- $\mathrm{KB}$ in the kidneys, thus, inhibiting inflammatory infiltrate and extracellular matrix deposit injuries in the mice kidneys (Wang et al., 2017b). Meanwhile, in STZ/highfat-diet-induced type-2 diabetic mice model, the high oral dose of polysaccharides at $900 \mathrm{mg} / \mathrm{kg} \mathrm{BW} /$ day for 4 weeks alleviated the STZ-lesioned organ tissues (liver, kidney, and pancreas), up-regulated protein expressions of PI3K, p-Akt, GLUT4 if mice adipose tissues (Wang et al., 2017c). In a subsequent paper (Wang et al., 2017a), the polysaccharides-Cr(III) complex orally administrated at 300,600 and $900 \mathrm{mg} / \mathrm{kg} \mathrm{BW} /$ day improved glucose tolerance capacity, promoted the metabolism of glucose and synthesis of glycogen, ameliorated severe pathological damages in kidneys including mesangial expansion, glomeruli partly sclerosis and glomerular hypertrophy in STZ/high-fat-diet-induced type-2 diabetic mice. Meanwhile, the improvement of antioxidant enzymes (CAT, $\mathrm{SOD}, \mathrm{GPx}$ ) and various blood/liver parameters (insulin, MDA, 

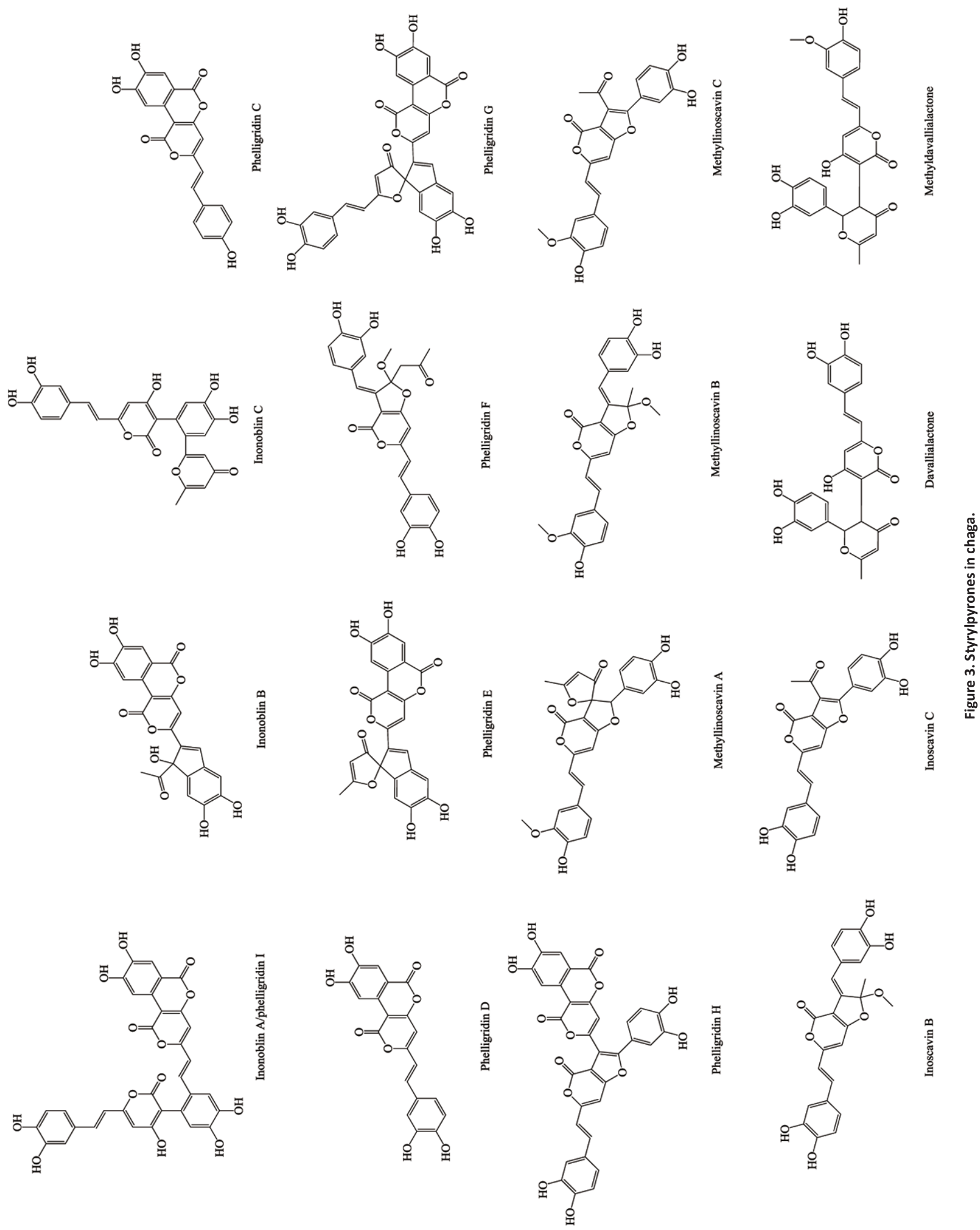


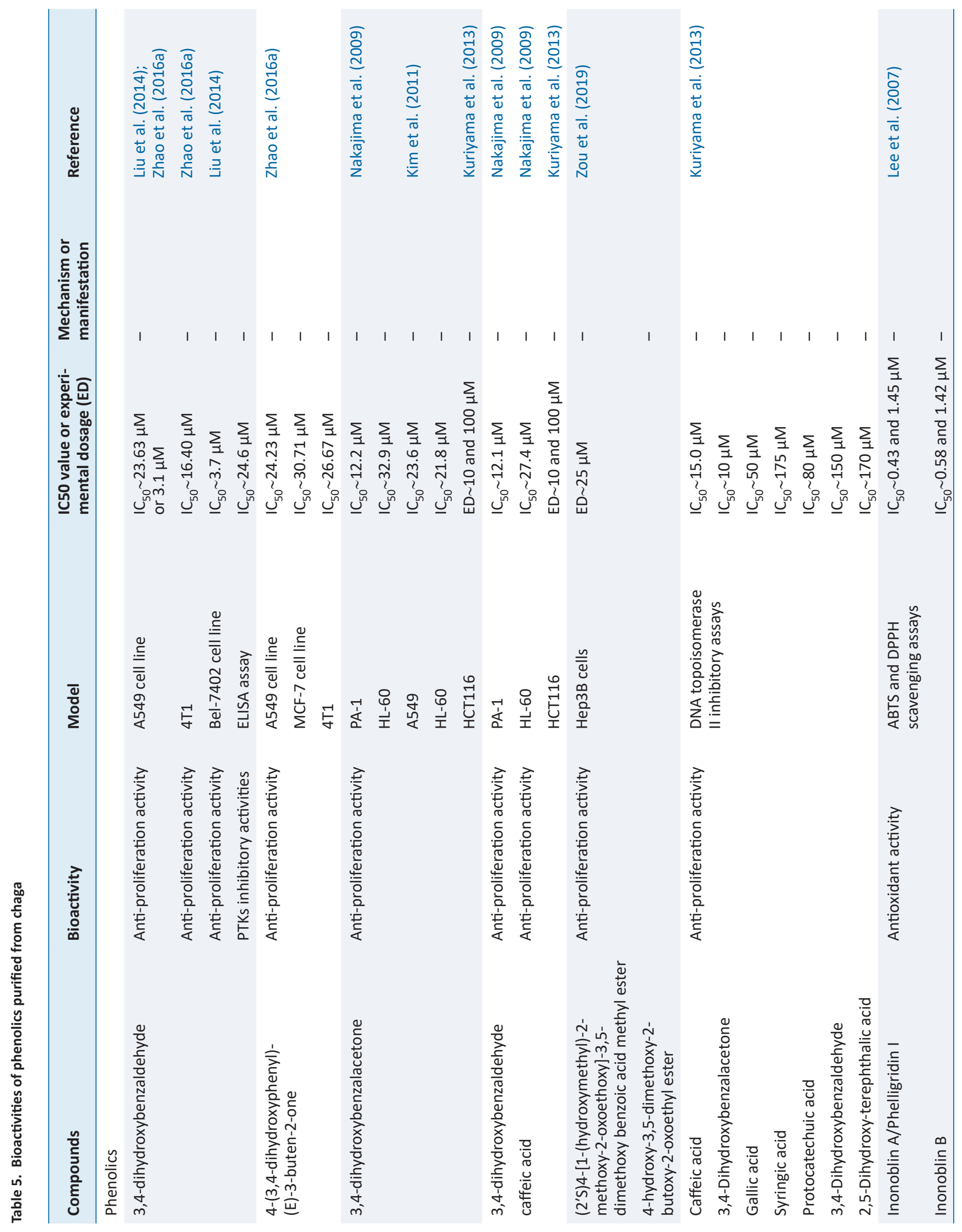




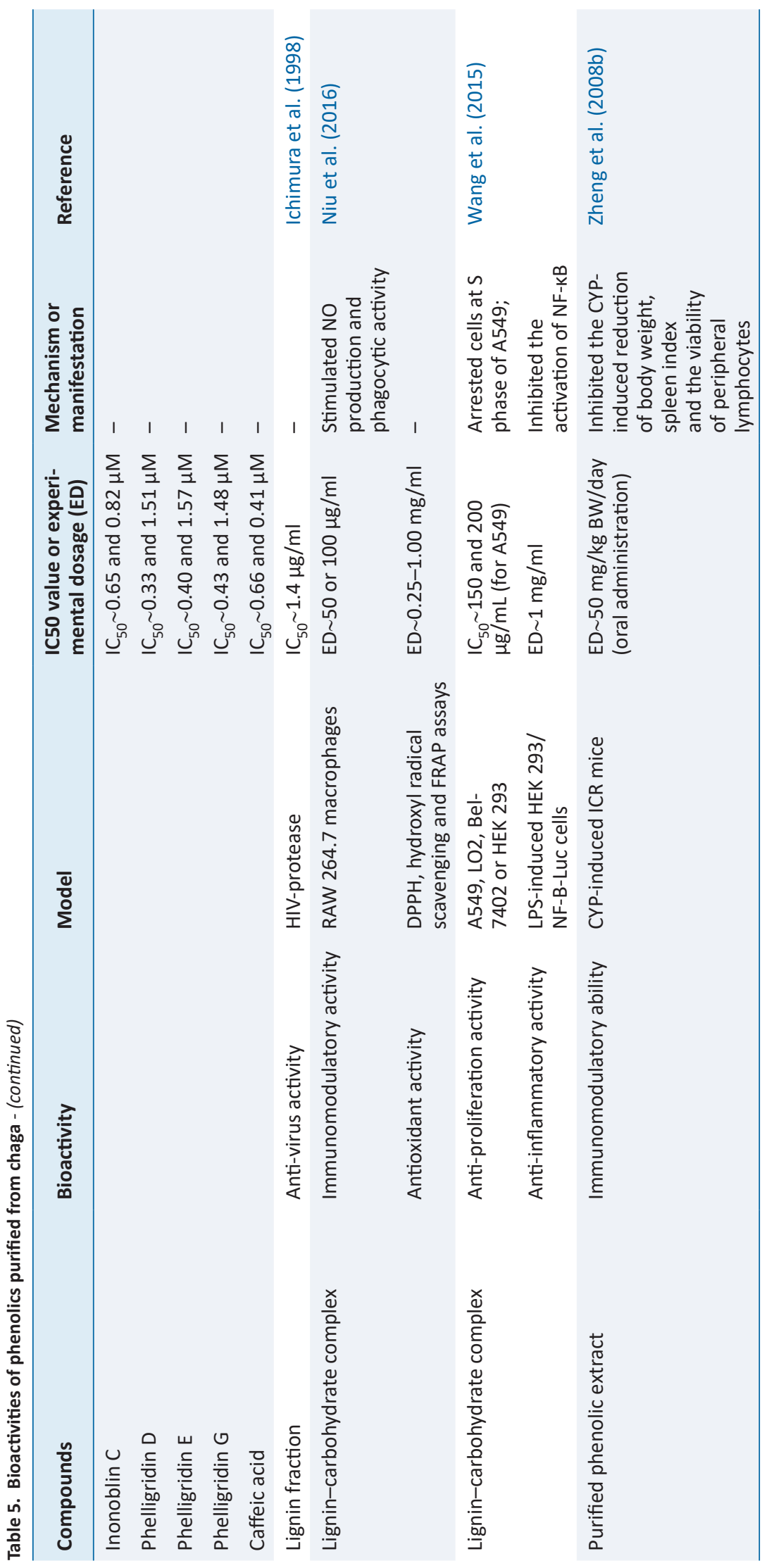


FFAs, TC, TG, LDL-C, and HDL-C) were mentioned in all models described above (Wang et al., 2017a; Wang et al., 2017b; Wang et al., 2017c).

Thus far, many studies have verified various significant in vitro antioxidant results of chaga polysaccharides including radical/ peroxide scavenging and metal reduction ability (Table 7). Classically, the "crude polysaccharides" are prepared through several primary steps such as water extraction/alcohol precipitation, deproteinization, and/or dialysis. However, for "purified polysaccharides", combinations of several chromatographic isolation techniques are necessary. The mixtures so produced are believed to be predominately composed of polysaccharides and therefore labeled as "crude/purified polysaccharides" in most of chaga studies. However, several studies have suggested that polysaccharides were not the only main constituents of chaga "crude/purified polysaccharides". The data of Chen et al. (2009) showed that $42.50 \%$ of chaga deproteinated "crude polysaccharides" was protein while only 18.50 and $6.10 \%$ of those were neutral sugar and uronic acid, respectively. More data about the protein content of chaga "crude polysaccharides" can be found in other articles citated here, ranging from 6.28 to $30.2 \%$ (Mu et al., 2012; Wang et al., 2018c; Xu et al., 2011a). As for purified polysaccharides, a high proportion of protein content was also found. Xiang et al. (2012) reported 6 purified fractions consisting of $7.12-38.3 \%$ protein, and the fraction with highest protein content $(38.3 \%)$ exerted the highest radical scavenging activity. Kim et al. (2006) obtained 5 purified fractions of chaga polysaccharides with a total protein content ranging from 22.1 to $59.3 \%$. While in another study, 5 fractions were purified through different columns (DEAE-Sepharose column and gel permeation column, Sepharose CL-6B), which contained relatively less protein (0-21.4\%) (Huang et al., 2012). In some cases, the deproteination process can even enhance protein content of chaga crude polysaccharides which demonstrates that the protein components are covalently bound to the polysaccharide matrix (Xiang et al., 2012; Xu et al., 2014a; Xu et al., 2014b). This result is consistent with the fact that polysaccharides, proteins and glycoproteins/ proteoglycans, are the shared main constituents of the fungi cell wall (Beauvais and Latgé, 2018; Ma et al., 2018; Peberdy, 1990). More compositional data of different "polysaccharides" fractions of chaga were later updated which helped to challenge its antioxidant results. $\mathrm{Mu}$ et al. (2012) once attributed moderate-strong radical scavenging ability to the polysaccharide components in chaga "crude polysaccharides", but later they found that lignincarbohydrate complex was also present in the purified fraction of this "crude polysaccharides", containing $64-80 \%$ lignin but only $16-28 \%$ neutral sugars and uronic acid (Wang et al., 2015). Besides, melanin is another group of aromatic copolymers rich in water extract of chaga. It possesses a similar polysaccharide hydrophilicity and range of molecular weight (ranging from less than 10 $\mathrm{kDa}$ to more than $120 \mathrm{kDa}$ ). Therefore it was rarely distinguished and identified during the analysis of chaga polysaccharides (Babitskaya et al., 2002; Wold et al., 2018). In the study of Wold et al. (2018), in spite of purifying through anion-exchange and size-exclusion (gel filtration) chromatography, three protein-free $(<0.1 \%)$ fractions of chaga polysaccharides were successfully produced but they still contained $4.2-9.7 \%$ phenolics due to the existence of covalently bound melanin pigment on polysaccharides. However, none of the quantification methods of protein (Bradford, BCA and Lowry assays) and sugar (sulfuric acid-phenol assay) used in these studies could entirely avoid the interference of abundant phenol groups in lignin or melanin (Dalilur Rahman and Richards, 1987; Owusu-Apenten, 2002; Redmile-Gordon et al., 2013). It should be noted that whether the health effects of natural "polysaccharides" is related to the existence or the synergistic effect of non-polysac- charide components especially the protein therein that has been proposed for decades remains controversial (Cruz et al., 2016; Cui and Chisti, 2003; Ng, 2003; Xu et al., 2011b; Zhang et al., 2011). However, there are insufficient studies on the exact structures and proportions of chaga melanin-, protein-, and lignin-polysaccharide complexes that allow full understanding of the authentic origin of the chemical mechanism underlying the antioxidant ability of chaga "polysaccharides". On the other hand, as mentioned before, the "purified chaga polysaccharides" indeed show significant in vivo antioxidant and anti-inflammatory effects, which further potentiate various tissue-protective effects, especially for pancreas/ liver/kidney protection (Diao et al., 2014; Hu et al., 2016; Wang et al., 2017a; Wang et al., 2017b; Xu et al., 2010b). Recently, Hu et al. (2016) found that ingestion of chaga polysaccharides alleviated DDC (diethyldithiocarbamate)-induced pancreatic acinar atrophy and weight loss by increasing pancreatic SOD, and decreasing LDH (lactate dehydrogenase), hydroxyproline, AMS (amylase), IFN- $\gamma$, IL-1 levels in serum of chronic pancreatitis mice. Later in the same model, the increase of pancreatic levels of GPx and TAOC (total antioxidant capacity) and the decrease of serum levels of TNF- $\alpha$, TGF- $\beta$ as well as lipase and trypsin, were also detected (Hu et al., 2017b). The improved gut microbiota composition through ingesting chaga polysaccharides were found to be positively correlated with relief of inflammation and oxidative stress (Hu et al., 2017b). Furthermore, the activation of the Nrf2/HO-1 signaling pathway by chaga polysaccharide also protected the mitochondrial damage and neuronal cells apoptosis in L-glutamic acid-damaged HT22 cell model and APP/PS1 transgenic mice model (Han et al., 2019). Similarly, the finding of Xu et al. (2019a) suggests that chaga polysaccharides protect mice against the $T$. gondii-induced liver injury, partially due to inhibition of the TLRs/NF signaling axis and the activation of the antioxidant response such as increasing the contents of serum/liver SOD and GSH, by inducing the Nrf2/HO-1 signaling.

In general, compared with the organic solvent extracts rich in phenolics or terpenoids, the polysaccharide-rich water extract/ decoction contains much higher amount of oxalic acid. However, the purification process of polysaccharide, including precipitation and dialysis, can effectively remove small-molecule compounds. However, there are limited investigations on oral safety of chaga polysaccharides. Chen et al. (2009) reported a single oral dose of chaga crude polysaccharide at $5,000 \mathrm{mg} / \mathrm{kg}$ body weight exerted no acute-toxicity damage on the liver, kidney, heart, thymus or spleen of male Kunming mice. Hu et al (2017a; 2017b) found that oral administration of purified fractions of chaga polysaccharide at a dose of $1,000 \mathrm{mg} / \mathrm{kg} \mathrm{BW}$ three times in one day showed no acute symptoms in pathogen-free male ICR mice including external morphological, behavioral, neurological, and autonomic changes. Another test conducted for 20 consecutive days of oral administration with a dose of $1,500 \mathrm{mg} / \mathrm{kg}$ body weight/day also showed no sub-acute-toxicity damage to the liver, pancreases, kidney, heart, thymus and spleen of male Kunming mice (Wang et al., 2017a). However, except for safe short-term doses, more toxicological trials of long-term administration are much desired.

\subsection{Other components}

As mentioned before, melanin is another antioxidant source in chaga. The natural melanin is polymerized by either aromatic amino acids or phenolics via C-C linkage, hence, could be divided into nitrogenous melanin (eumelanin, pheomelanin) and non-nitrogenous melanin (allomelanin, pyomelanin), respectively (Ahmad et al., 2016; Plonka and Grabacka, 2006). Therefore, the structure as 


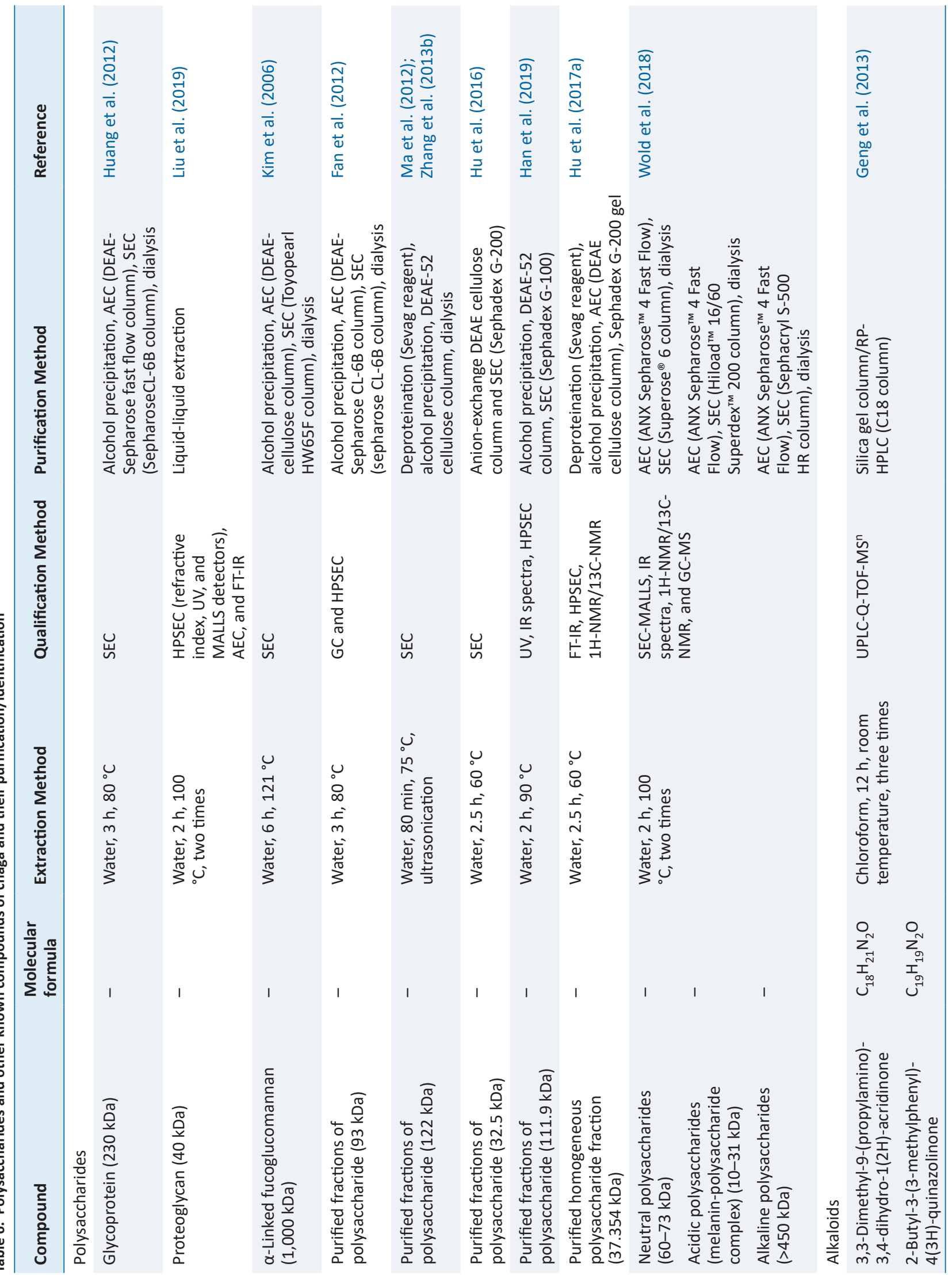




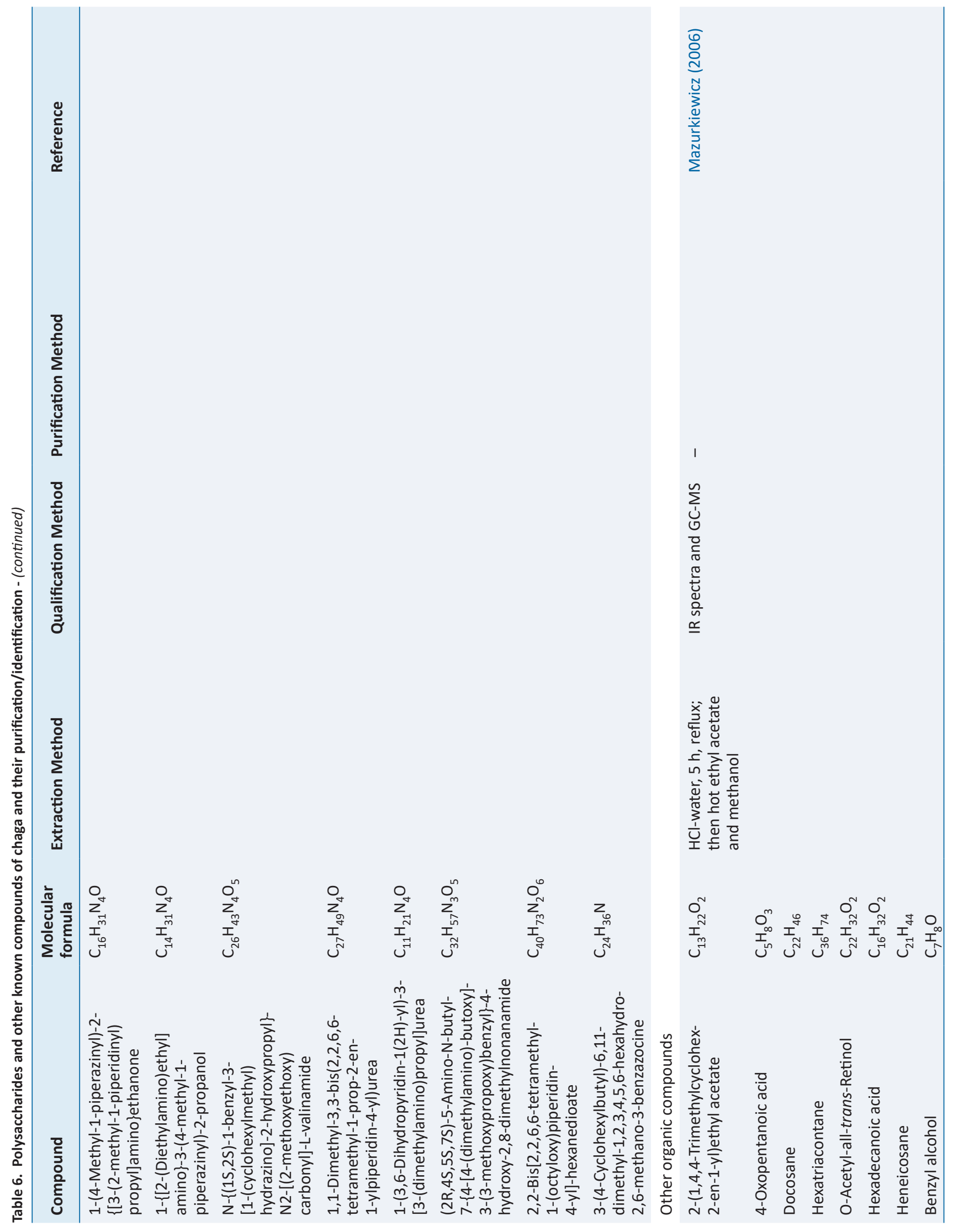




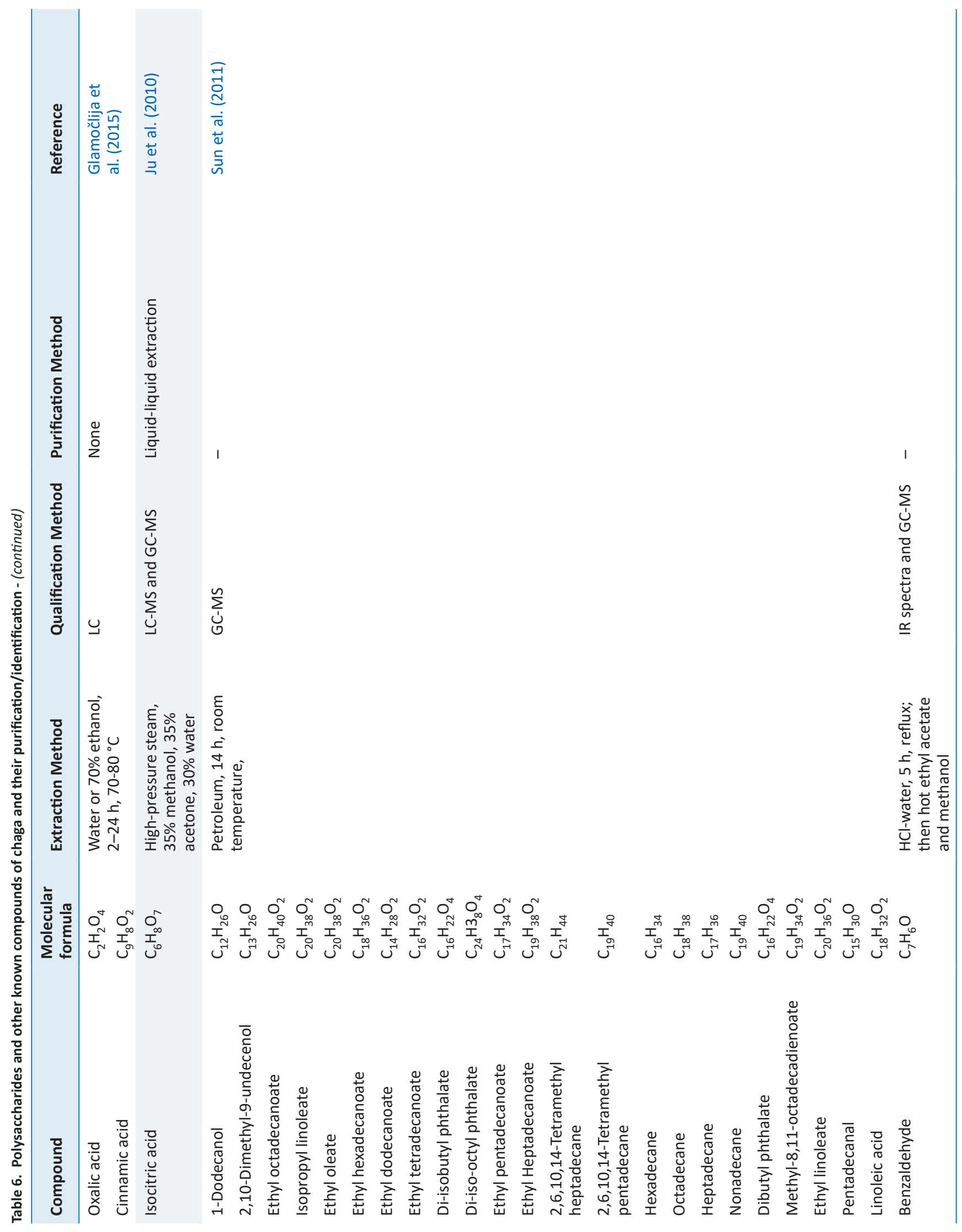




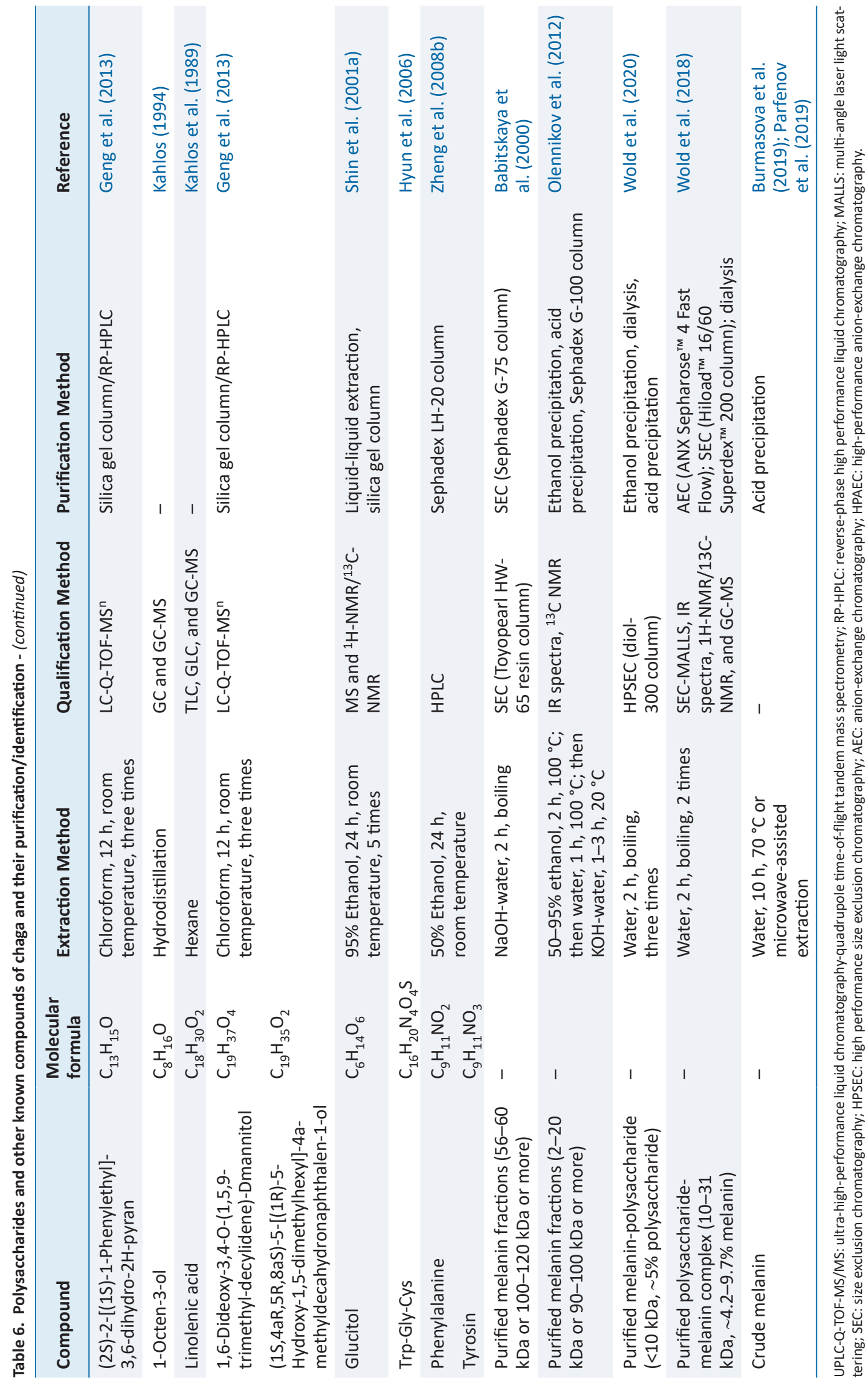




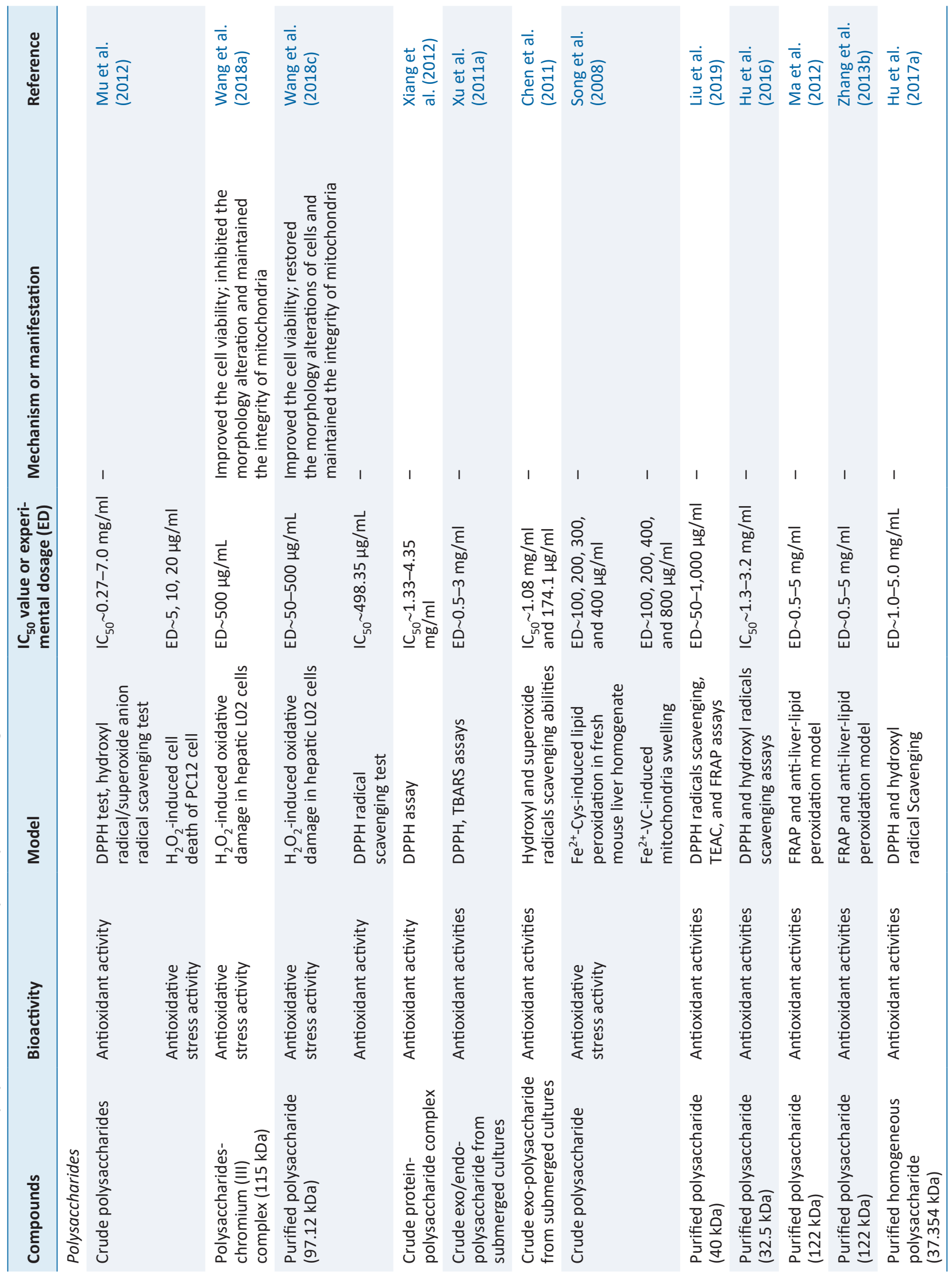




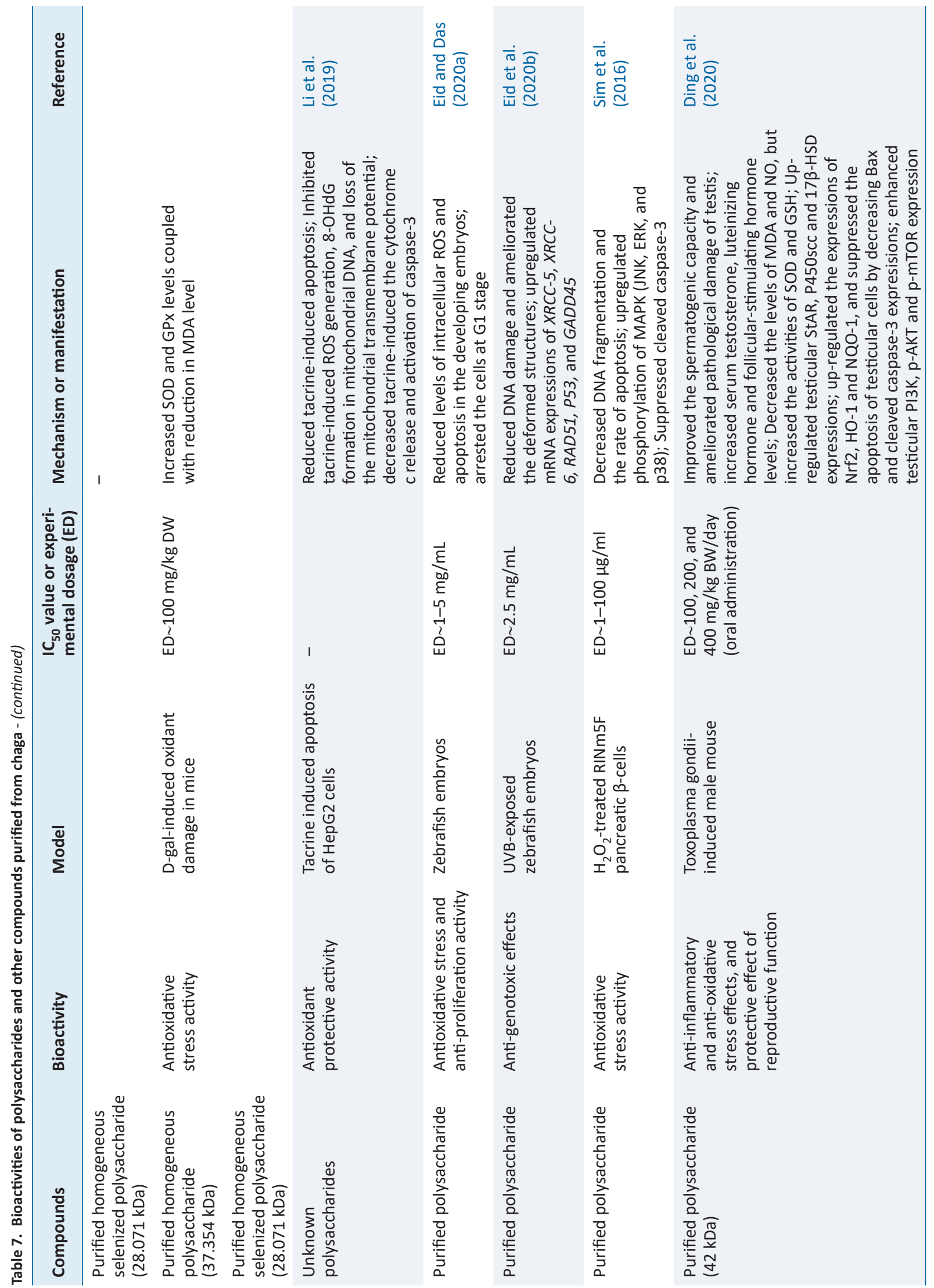




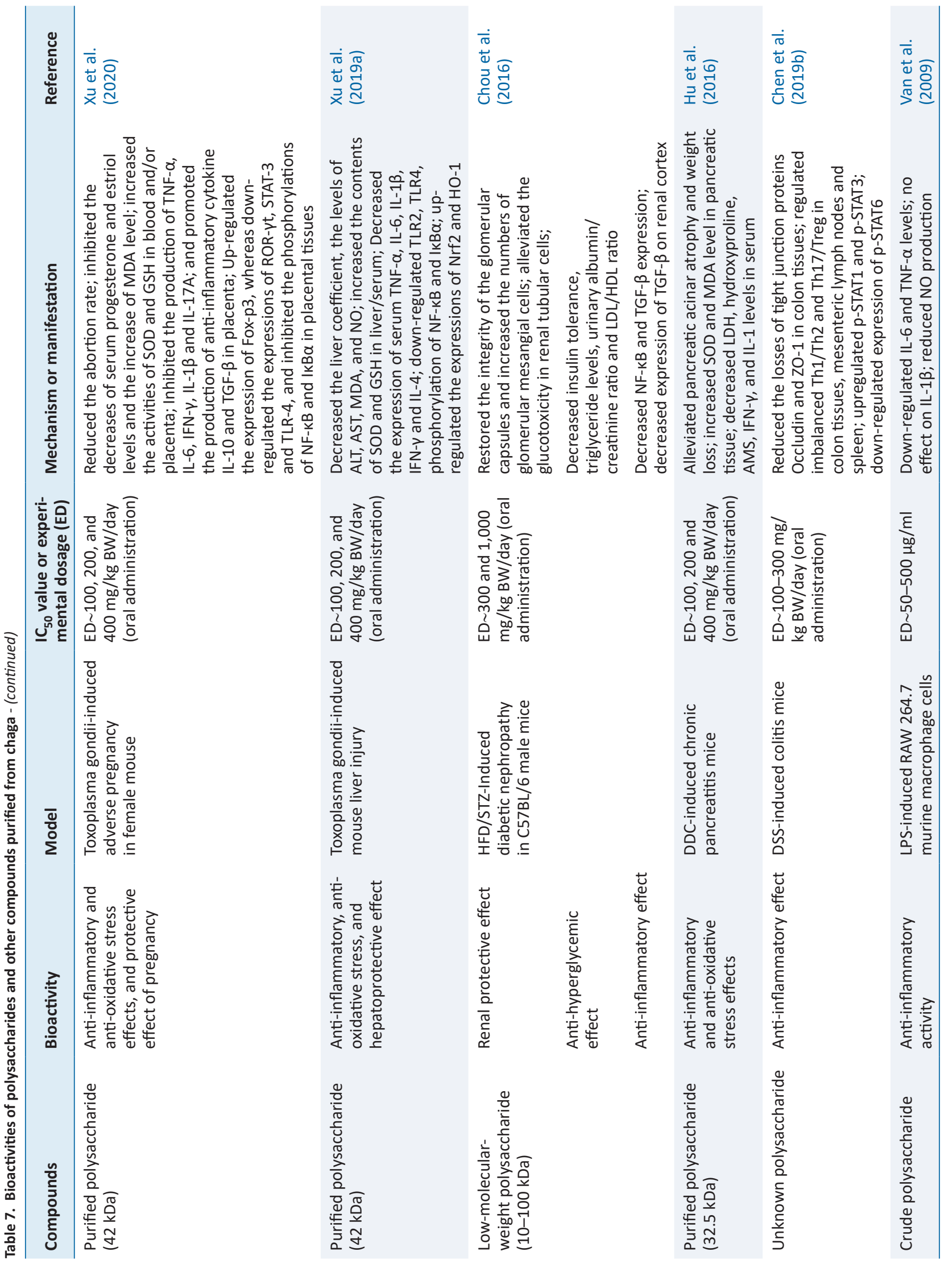




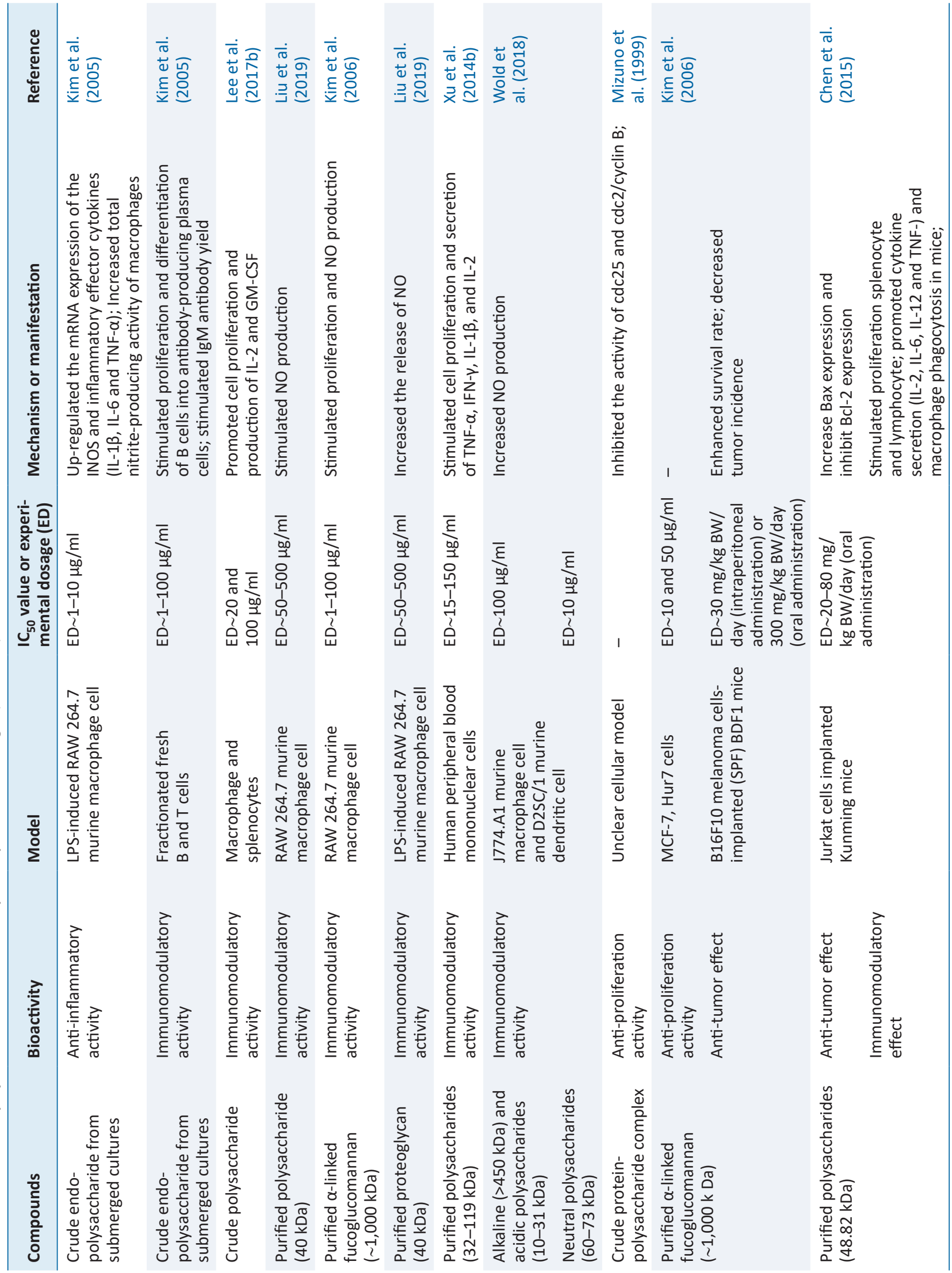




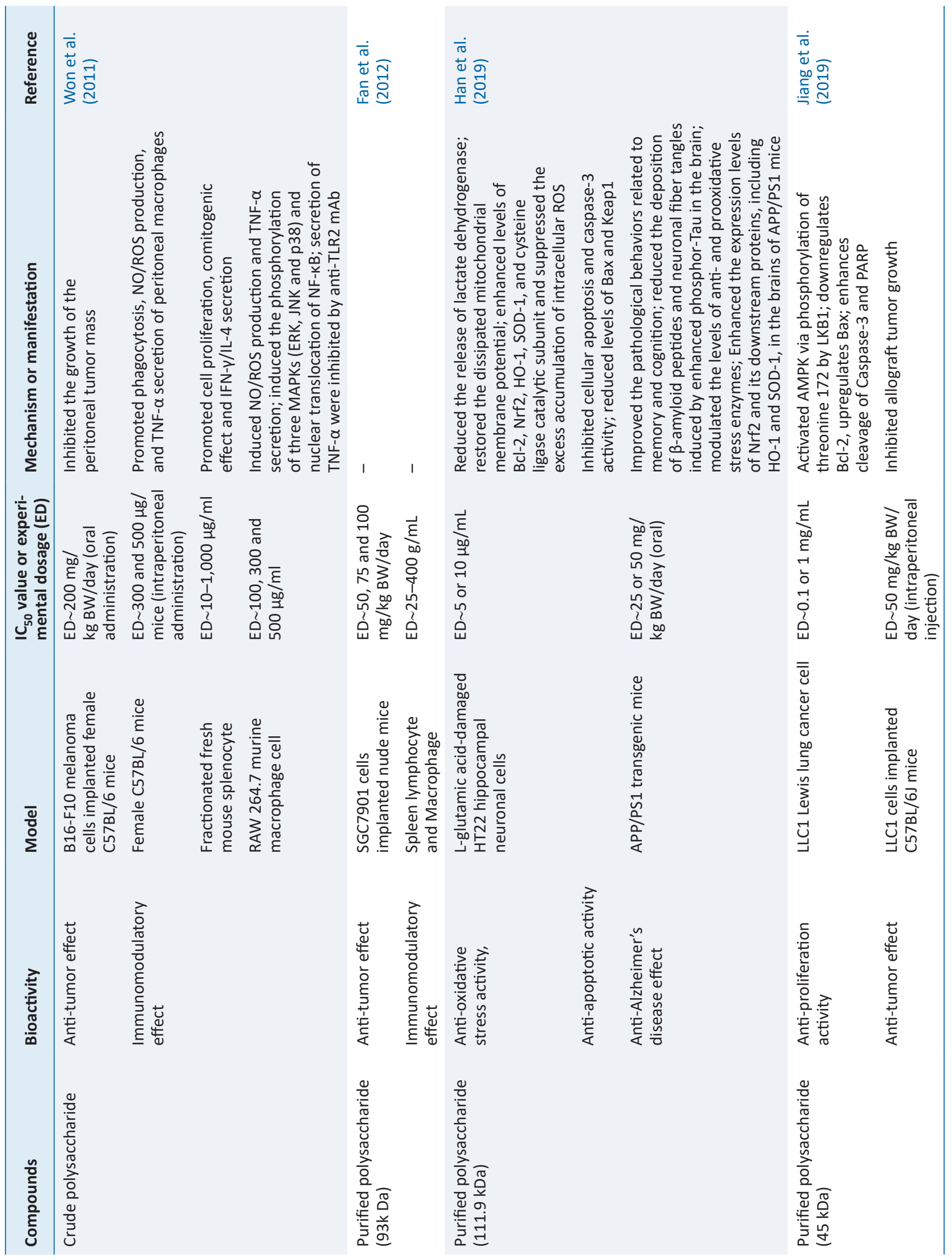




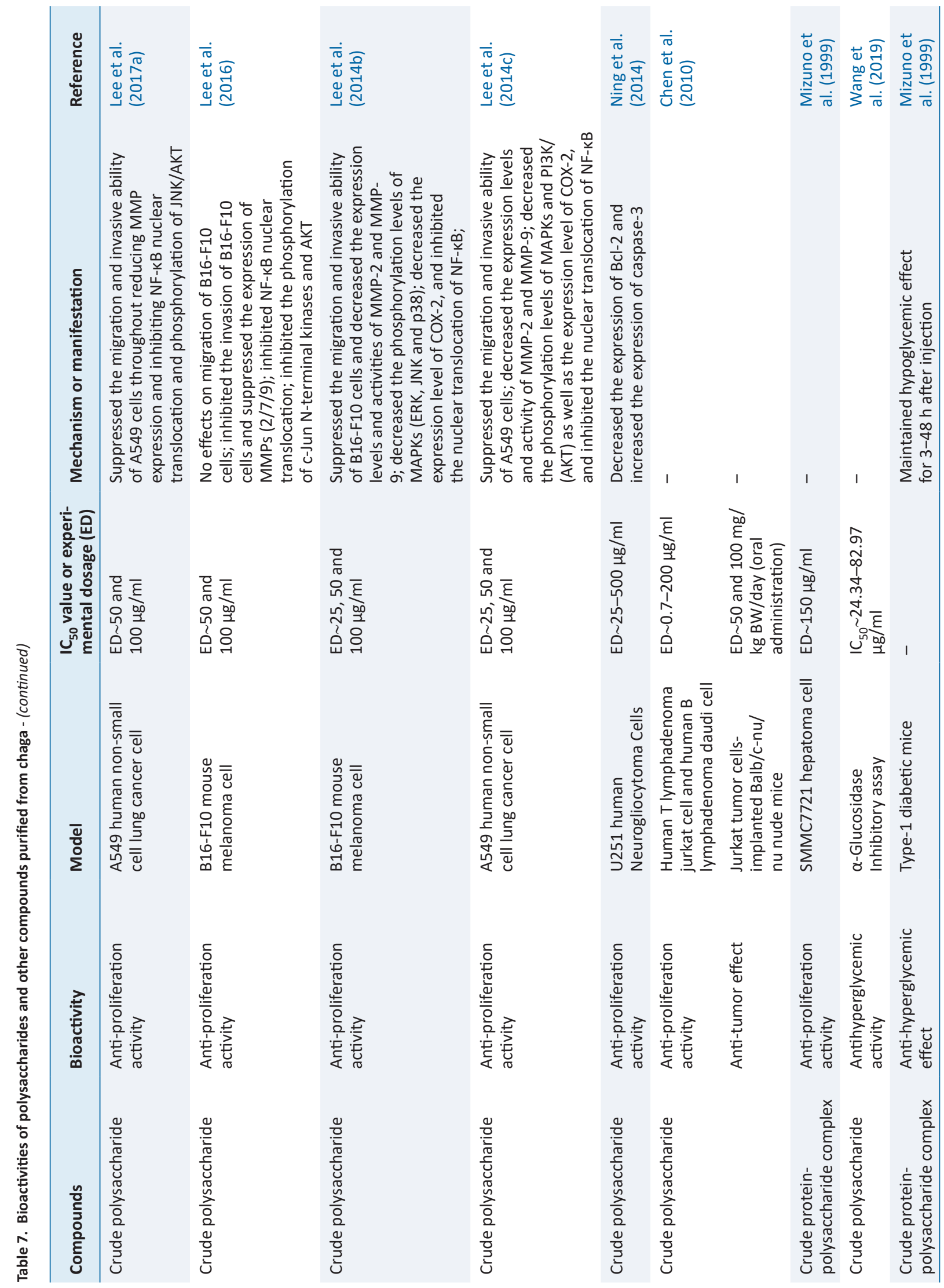




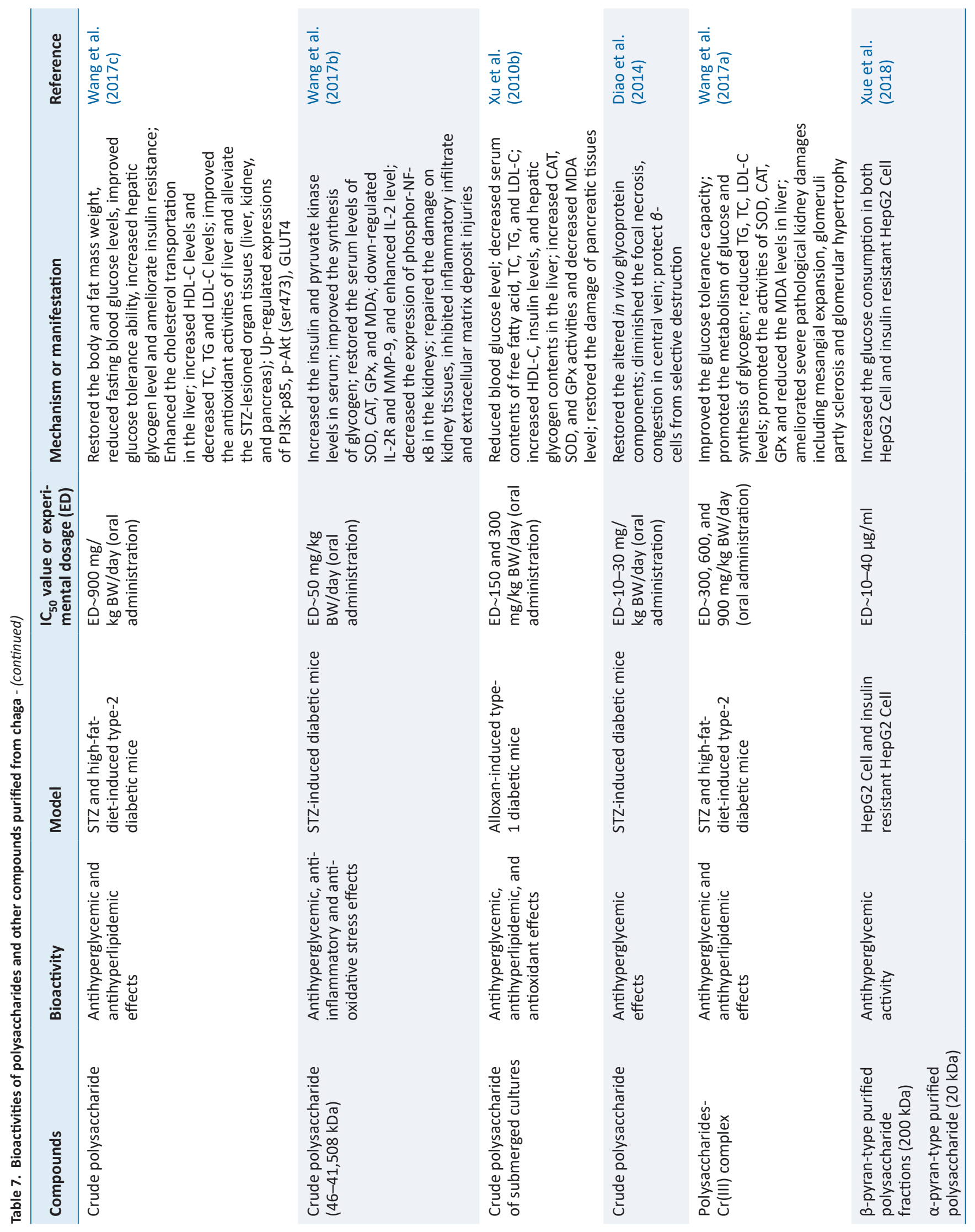




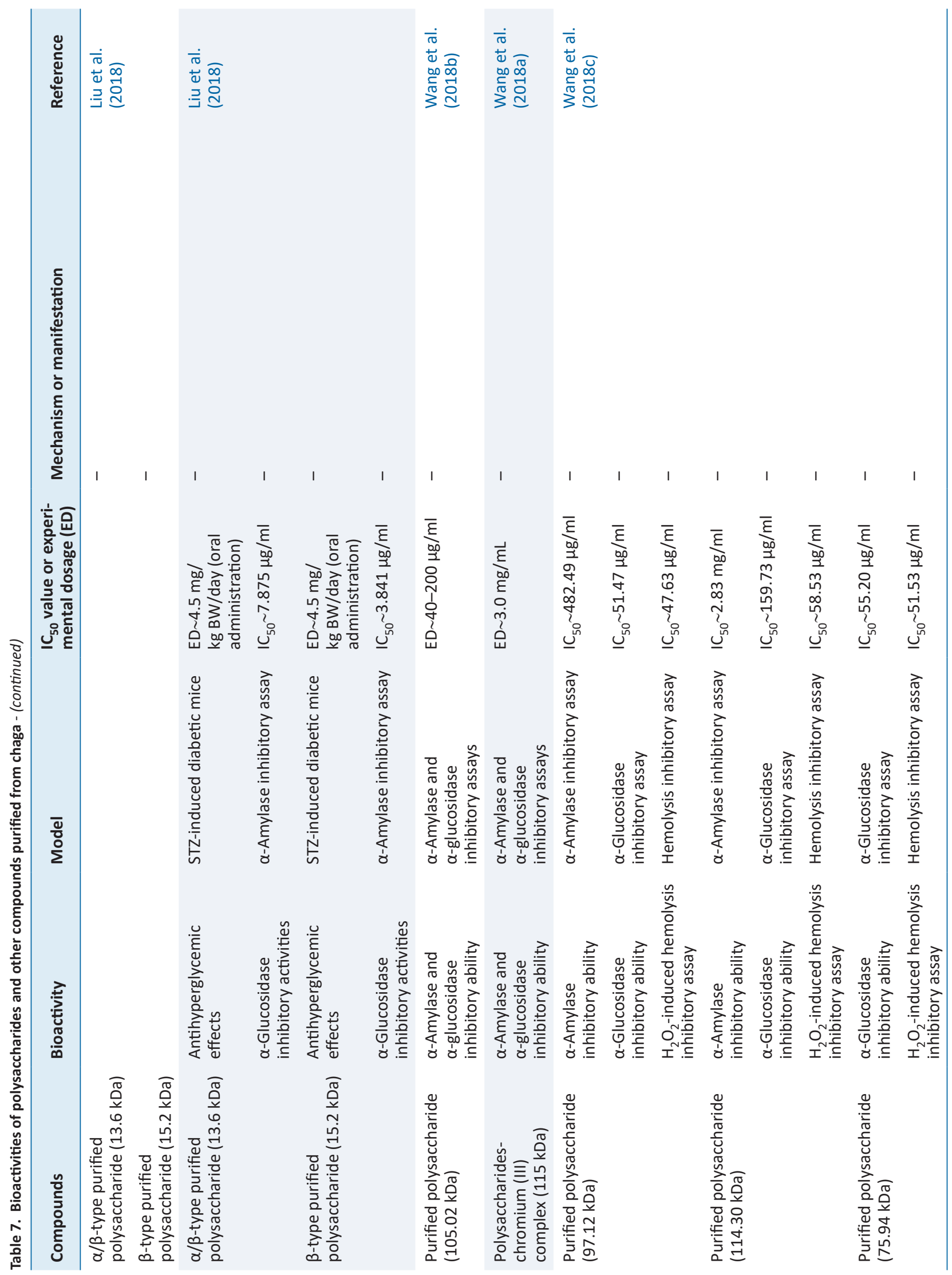




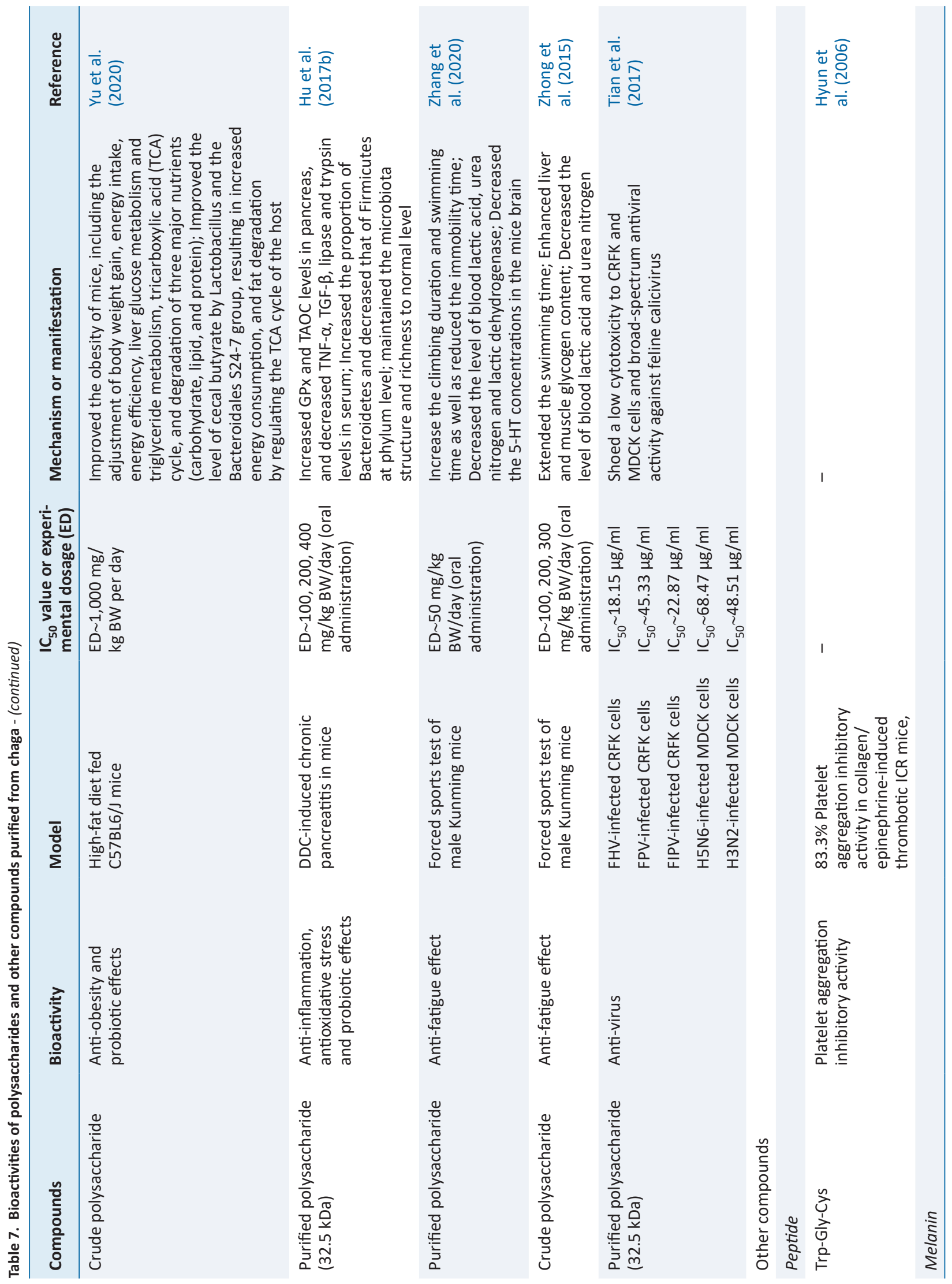




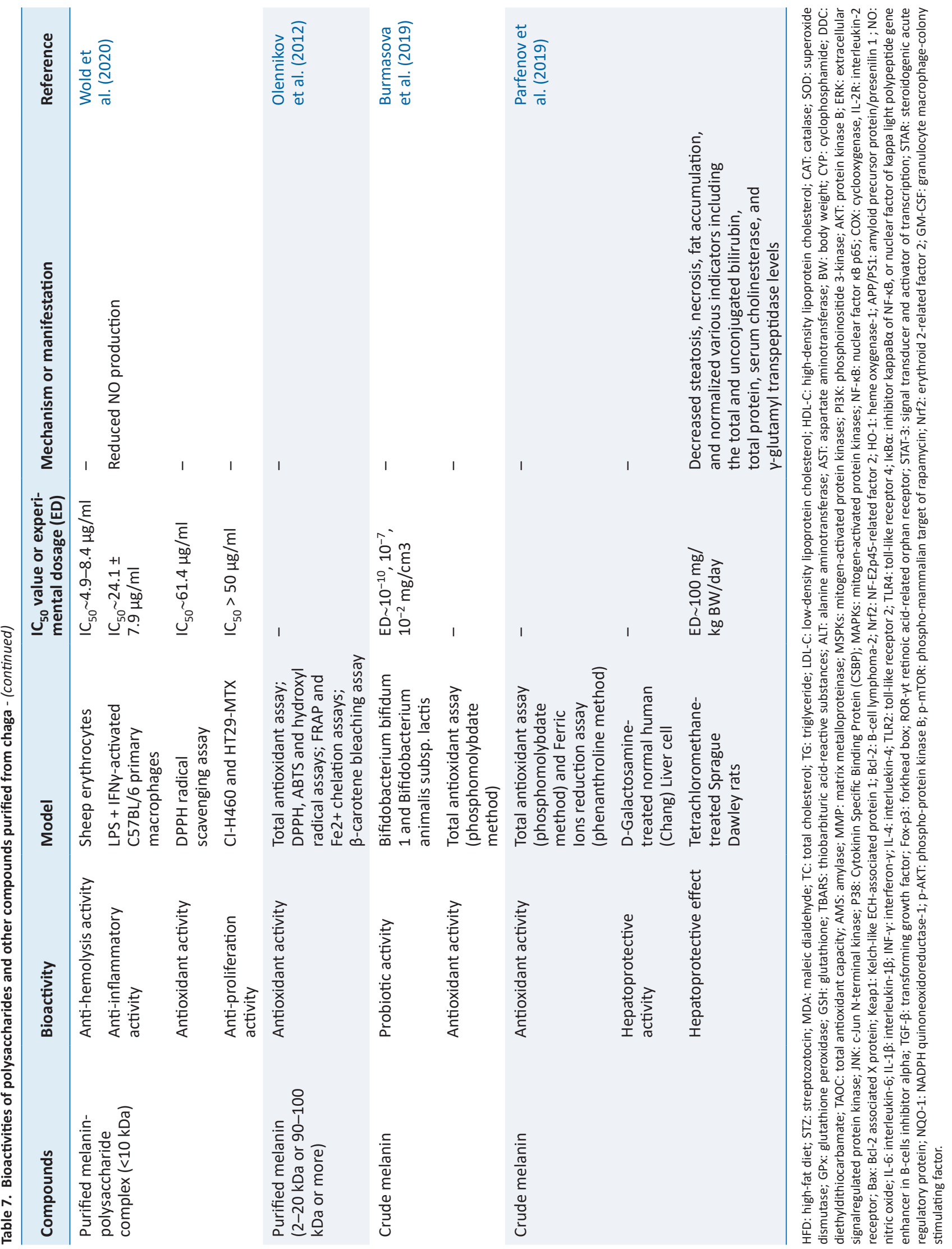


well as the physiochemical properties of non-nitrogenous melanin are somewhat similar to those of lignin (Babitskaya et al., 2000; Kukulyanskaya et al., 2002; Solano, 2014; Varga et al., 2016). Kukulyanskaya et al. (2002) suggested that the melanin in wild chaga was allomelanin while in cultured ones was eumelanin according to the difference in their mole ratio of $\mathrm{C} / \mathrm{N}$. In fungi, the allomelanin is believed to be mainly composed of 1,8-dihydroxynaphthalene (DHN)/tetrahydroxynaphthalene, while for eumelanin was L-3,4-dihyroxyphenylalanine (L-DOPA) (Eisenman and Casadevall, 2012; Plonka and Grabacka, 2006). One review mentioned around 17 amino acids hydrolyzed from eumelanin of cultured chaga, but reliability of this data needs to be confirmed (Balandaykin and Zmitrovich, 2015). The allomelanin of wild chaga is known to be heterogeneous and contains aromatic methoxy group, carboxyl group, pyrocatechol, along with the phenolic hydroxyl group (Olennikov et al., 2012; Wold et al., 2020). However, no original study has successfully clarified the exact units and linkages of chaga allomelanin. In fungi, melanin granules are localized in the cell wall, where they are likely cross-linked to polysaccharides, protein, or lignin. It contributes to the strengthening of the fungus cell wall and their defence mechanisms against harsh environmental conditions, such as ultraviolet radiation, extreme temperatures, free radicals, toxic heavy metal, and enzymatic degradation (Eisenman and Casadevall, 2012; Gómez and Nosanchuk, 2003; Varga et al., 2016). In addition, the fungus melanin could promote the penetration and invasion ability against the plant host by providing mechanical strength to the appressoria (Eisenman and Casadevall, 2012). So far, various MWs of different melanin fractions have been reported. Babitskaya et al. (2000) reported that the MWs of melanin from cultured and wild chaga mainly ranged from 50 to $60 \mathrm{kDa}$, and the MWs of a minor amount of the other melanin fractions went up to 100 or even several hundred daltons. Similarly, Olennikov et al. (2012) isolated dozens of fractions of purified chaga melanin, the MWs of which mainly ranged from 2 to $20 \mathrm{kDa}$, and the rest were more than $100 \mathrm{kDa}$. The melanin fraction in the study of Wold et al. (2018) had a MW range of 10-31 kDa because it was detected in a polysaccharide fraction of similar MW range. Meanwhile, this study suggested that melanin was not covalently bound to the polysaccharides (Wold et al., 2018). More recently, Wold et al. (2020) specifically measured the approximate polymer size of the melanin fraction to be less than $10 \mathrm{kDa}$. Furthermore, their study strengthened the hypothesis that melanin from wild chaga was allomelanin according to the analysis of the combustion and chemical degradation constituents, though still none of these degradation products were isolated and identified. Meanwhile, GC analysis of melanin hydrolysis of chaga showed that around 5\% polysaccharides existed in the melanin after repeated sedimentation purification, which demonstrated that the sugars were covalently bound to the melanin polymer (Wold et al., 2020). The melanin is also considered a main bioactive compound in the water extract of chaga. Besides the antioxidant nature of chaga melanin, its hepatoprotective, probiotic, anti-hemolysis, anti-inflammatory, and anti-proliferation activities have also been studied (Table 7). Table 6 presents more categories under "Other compounds", including various alkaloids, organic acids, organic acid esters, alkanes, alcohols, aldehydes, and amino acids. Chaga also contains an abundance of mineral microelements. Chen et al. (2009) quantified 12 microelements (in $\mu \mathrm{g} / \mathrm{g}$ ) in chaga including 22.41 boron, 726.00 calcium, 0.21 cobalt, 0.58 chromium, 5.55 copper, 213.33 iron, 1,127.80 magnesium, 117.84 manganese, 0.88 nickel, 0.18 selenium, 12.90 strontium, and 88.13 zinc, which indicated the possibility that chaga and its products might act as a candidates for mineral supplementation.

\section{Conclusion}

Chaga is recorded with numerous historical applications and anecdotal evidence of medicinal properties worldwide. The studies of bioactivities of chaga along with the latest technologies/methodologies and prevalence of "open access" policy of scientific journal may flourish even further. As summarized, the in vivo/in vitro bioactive properties of chaga include anti-proliferation, anti-tumor, immunomodulatory, anti-inflammation, antioxidant, antimutagenic, analgesic, anti-virus, antibacterial, antifungal, antibacterial, antihyperglycemic, anti-platelet-aggregation, anti-hypertension, anti-hyperuricemia, anti-obesity, probiotic, hepatoprotective, and enzyme inhibitory activities/effects. These bioactivity studies extend the understanding of pharmaceutical values of chaga and potentiate its future application in modern medicine if more rigorous biological/clinical studies could be conducted. In recent decades, the investigations of the chemical diversity of chaga have also achieved remarkable progress. The main secondary metabolites of fungi such as terpenoids, phenolics, polysaccharides, and melanin have been identified in various chaga extracts. They are considered as the main contributors to their wide spectrum of bioactivities. However, compared with small-molecule compounds, a further characterization of specific structures of bioactive polymers in chaga, such as polysaccharide, lignin, and melanin, is still needed. Besides, to a great extent, the use of chaga has been guided by the folk experience or obsolete data, and the reported cases showing potential adverse health effects have provoked serious safety concerns in administrating wild chaga and its products. On the other hand, the compositional variation among chaga samples (wild/ wild; wild/cultivated; cultivated/cultivated) are influencing judgement of both their safety and effectiveness. The standardized quality control based on fast detection technologies, and the dosage guideline under the promise of sufficient preclinical/clinical data of its acute and chronic toxicity are most urgently needed.

\section{Funding}

This work was supported by the NSERC (Natural Sciences and Engineering Research Council) and CSC (China Scholarship Council).

\section{Conflict of interest}

There is no conflict interest.

\section{References}

Ahmad, S., Lee, S.Y., Kong, H.G., Jo, E.J., Choi, H.K., Khan, R., and Lee, S.W. (2016). Genetic determinants for pyomelanin production and its protective effect against oxidative stress in Ralstonia solanacearum. PIOS one 11(8): e0160845.

Arata, S., Watanabe, J., Maeda, M., Yamamoto, M., Matsuhashi, H., Mochizuki, M., Kagami, N., Honda, K., and Inagaki, M. (2016). Continuous intake of the Chaga mushroom (Inonotus obliquus) aqueous extract suppresses cancer progression and maintains body temperature in mice. Heliyon 2(5): e00111.

Ayoub, N., Lass, D., and Schultze, W. (2009). Volatile constituents of the medicinal fungus chaga Inonotus obliquus (Pers.: Fr.) Pilát (Aphyllophoromycetideae). Int. J. Med. Mushrooms 11(1): 55-60.

Azab, A., Nassar, A., and Azab, A.N. (2016). Anti-inflammatory activity of natural products. Molecules 21(10): 1321-1339. 
Babitskaya, V., Shcherba, V., and Lkonnikova, N. (2000). Melanin complex of the fungus Inonotus obliquus. Appl. Biochem. Microbiol. 36(4): 377-381.

Babitskaya, V.G., Scherba, V.V., Ikonnikova, N.V., Bisko, N.A., and Mitropolskaya, N.Y. (2002). Melanin complex from medicinal mushroom Inonotus obliquus (Pers.: Fr.) Pilat (Chaga)(Aphyllophoromycetidae). Int. J. Med. Mushrooms 4: 139-145.

Baek, J., Roh, H.-S., Baek, K.-H., Lee, S., Lee, S., Song, S.-S., and Kim, K.H. (2018). Bioactivity-based analysis and chemical characterization of cytotoxic constituents from Chaga mushroom (Inonotus obliquus) that induce apoptosis in human lung adenocarcinoma cells. J. Ethnopharmacol. 224: 63-75.

Bai, Y.-H., Feng, Y.-Q., Mao, D.-B., and Xu, C.-P. (2012). Optimization for betulin production from mycelial culture of Inonotus obliquus by orthogonal design and evaluation of its antioxidant activity. J. Taiwan Inst. Chem. Eng. 43(5): 663-669.

Balandaykin, M.E., and Zmitrovich, I.V. (2015). Review on Chaga medicinal mushroom, Inonotus obliquus (Higher Basidiomycetes): Realm of medicinal applications and approaches on estimating its resource potential. Int. J. Med. Mushrooms 17(2): 95-104.

Battin, C., Hennig, A., Mayrhofer, P., Kunert, R., Zlabinger, G.J., Steinberger, P., and Paster, W. (2017). A human monocytic NF-KB fluorescent reporter cell line for detection of microbial contaminants in biological samples. PIOS one 12(5): e0178220.

BC-DPIC. (2016). Risk assessment of chaga mushroom tea. Retrieved from Vancouver, BC/Canada: http://www.bccdc.ca/resource-gallery/ Documents/Educational\%20Materials/EH/FPS/Food/Risk_Assessment of Chaga Mushroom Tea.pdf.

Beauvais, A., and Latgé, J.-P. (2018). Fungal cell wall. J. Fungi 4(3): 91-98.

Beug, M.W. (2019). Oxalates in Chaga-A Potential Health Threat. Retrieved from https://namyco.org/docs/Oxalates_in_Chaga_a_potential_health_threat_M_Beug.pdf.

Bishop, G.J., and Yokota, T. (2001). Plants steroid hormones, brassinosteroids: current highlights of molecular aspects on their synthesis/ metabolism, transport, perception and response. Plant Cell Physiol. 42(2): 114-120.

Biswas, T., and Dwivedi, U.N. (2019). Plant triterpenoid saponins: biosynthesis, in vitro production, and pharmacological relevance. Protoplasma. 256(6): 1463-1486.

Burmasova, M.A., Utebaeva, A.A., Sysoeva, E.V., and Sysoeva, M.A. (2019). Melanins of Inonotus Obliquus: bifidogenic and antioxidant properties. Biomolecules 9(6): 248-256.

Centers-for-Disease-Control-Prevention. (2020). National diabetes statistics report, 2020. Retrieved from Atlanta, GA/America: https://www. cdc.gov/diabetes/pdfs/data/statistics/national-diabetes-statisticsreport.pdf.

Cha, J.-Y., Jun, B.-S., Yoo, K.-S., Hahm, J.-R., and Cho, Y.-S. (2006). Fermented chaga mushroom (Inonotus obliquus) effects on hypolipidemia and hepatoprotection in Otsuka Long-Evans Tokushima fatty (OLETF) rats. Food Sci. Biotechnol. 15(1): 122-127.

Chatterjee, S., Biswas, G., Basu, S.K., and Acharya, K. (2011). Antineoplastic effect of mushrooms: a review. Aust. J. Crop Sci. 5(7): 904-907.

Chen, C. (2007). Aqueous extract of Inonotus obliquus (Fr.) Pilat (Hymenochaetaceae) significantly inhibits the growth of sarcoma 180 by inducing apoptosis. Am. J. Pharmacol. Toxicol. 2: 10-17.

Chen, H., Fu, L., Dong, P., Zhang, X., and Lu, X. (2009). Acute toxicity evaluation and compositional analysis of a polysaccharide from the medicinal mushroom Inonotus obliquus. Paper presented at the 2009 3rd International Conference on Bioinformatics and Biomedical Engineering.

Chen, H., Yan, M., Zhu, J., and Xu, X. (2011). Enhancement of exo-polysaccharide production and antioxidant activity in submerged cultures of Inonotus obliquus by lignocellulose decomposition. J. Ind. Microbiol. Biotechnol. 38(2): 291-298.

Chen, H.-J., Chen, Y.-S., Liu, S.-L., Liou, B.-K., and Chen, C.-S. (2020a). The Influence of Submerged Fermentation of Inonotus obliquus with Control Atmosphere Treatment on Enhancing Bioactive Ingredient Contents. Appl. Biochem. Biotechnol. 191: 412-425.

Chen, H.-J., Chen, Y.-S., Liu, S.-L., Liou, B.-K., and Chen, C.-S. (2020b). The Increase of Bioactive Ingredients by Solid State Fermentation of Inonotus obliquus with Spent Substrate. Waste Biomass Valor. 11:
6725-6739.

Chen, Y., Gu, X., Huang, S.-Q., Li, J., Wang, X., and Tang, J. (2010). Optimization of ultrasonic/microwave assisted extraction (UMAE) of polysaccharides from Inonotus obliquus and evaluation of its anti-tumor activities. Int. J. Biol. Macromol. 46(4): 429-435.

Chen, Y., Huang, Y., Cui, Z., and Liu, J. (2015). Purification, characterization and biological activity of a novel polysaccharide from Inonotus obliquus. Int. J. Biol. Macromol. 79: 587-594.

Chen, Y.F., Zheng, J.J., Qu, C., Xiao, Y., Li, F.F., Jin, Q.X., Li, H.H., Meng, F.P., Jin, G.H., and Jin, D. (2019b). Inonotus obliquus polysaccharide ameliorates dextran sulphate sodium induced colitis involving modulation of Th1/Th2 and Th17/Treg balance. Artif. Cells Nanomed. Biotechnol. 47(1): 757-766.

Chhikara, N., Devi, H.R., Jaglan, S., Sharma, P., Gupta, P., and Panghal, A. (2018). Bioactive compounds, food applications and health benefits of Parkia speciosa (stinky beans): a review. Agric. Food Secur. 7(1): 46-54.

Choi, S.Y., Hur, S.J., An, C.S., Jeon, Y.H., Jeoung, Y.J., Bak, J.P., and Lim, B.O. (2010). Anti-inflammatory effects of Inonotus obliquus in colitis induced by dextran sodium sulfate. Biomed Res. Int. 2010: 1-5.

Chou, Y.J., Kan, W.C., Chang, C.M., Peng, Y.J., Wang, H.Y., Yu, W.C., Cheng Y.H., Jhang, Y.R., Liu, H.W., and Chuu, J.J. (2016). Renal protective effects of low molecular weight of Inonotus obliquus polysaccharide (LIOP) on HFD/STZ-induced nephropathy in mice. Int. J. Mol. Sci. 17(9): 1535-1551.

Chung, M.J., Chung, C.-K., Jeong, Y., and Ham, S.-S. (2010). Anticancer activity of subfractions containing pure compounds of Chaga mushroom (Inonotus obliquus) extract in human cancer cells and in Balbc/c mice bearing Sarcoma-180 cells. Nutr. Res. Pract. 4(3): 177-182.

Cottesfeld, L.M.J. (1992). Short Communication: use of cinder conk (Inonotus obliquus) by the Gitksan of Northwestern British Columbia, Canada. J. Ethnobiol. 12(1): 153-156.

Coussens, L.M., and Werb, Z. (2002). Inflammation and cancer. Nature 420(6917): 860-867.

Cruz, A., Pimentel, L., Rodríguez-Alcalá, L.M., Fernandes, T., and Pintado, M. (2016). Health benefits of edible mushrooms focused on Coriolus versicolor: A review. J. Food Nutr. Res. 4(12): 773-781.

Cui, J., and Chisti, Y. (2003). Polysaccharopeptides of Coriolus versicolor: physiological activity, uses, and production. Biotechnol. Adv. 21(2): 109-122.

Cui, Y., Kim, D.-S., and Park, K.-C. (2005). Antioxidant effect of Inonotus obliquus. J. Ethnopharmacol. 96(1-2): 79-85.

Dalilur Rahman, M., and Richards, G.N. (1987). Interference by flavonoids in the phenol-sulfuric acid analysis of carbohydrates. Carbohydr. Res. 170(1): 112-115.

Daniel, M., and Mammen, D. (2016). Analytical Methods for Medicinal Plants and Economic Botany. Scientific Publishers, Jodhpur, India.

Debnath, T., Hasnat, M.A., Pervin, M., Lee, S.Y., Park, S.R., Kim, D.H., Kweon, H.J., Kim, J.M., and Lim, B.O. (2012). Chaga mushroom (Inonotus obliquus) grown on germinated brown rice suppresses inflammation associated with colitis in mice. Food Sci. Biotechnol. 21(5): 1235-1241.

Deng, G., Lin, H., Seidman, A., Fornier, M., D'Andrea, G., Wesa, K., Yeung, S., Cunningham-Rundles, S., Vickers, A.J., and Cassileth, B. (2009). A phase I/II trial of a polysaccharide extract from Grifola frondosa (Maitake mushroom) in breast cancer patients: immunological effects. J. Cancer Res. Clin. Oncol. 135(9): 1215-1221.

Diao, B.-Z., Jin, W.-R., and Yu, X.-J. (2014). Protective effect of polysaccharides from Inonotus obliquus on streptozotocin-induced diabetic symptoms and their potential mechanisms in rats. Evid. Based Complement. Alternat. Med. 2014: 1-5.

Ding, X., Ge, B., Wang, M., Zhou, H., Sang, R., Yu, Y., Xu, L., and Zhang, X. (2020). Inonotus obliquus polysaccharide ameliorates impaired reproductive function caused by Toxoplasma gondii infection in male mice via regulating Nrf2-PI3K/AKT pathway. Int. J. Biol. Macromol. 151: 449-458.

Dosychev, E., and Bystrova, V. (1973). Treatment o psoriasis using "Chaga" fungus preparations. Vestn. Dermatol. Venerol. 47(5): 79-83.

Douros, A., Bronder, E., Andersohn, F., Klimpel, A., Kreutz, R., Garbe, E., and Bolbrinker, J. (2016). Herb-induced liver injury in the Berlin casecontrol surveillance study. Int. J. Mol. Sci. 17(1): 114-124. 
Duru, K.C., Kovaleva, E.G., Danilova, I.G., and van der Bijl, P. (2019). The pharmacological potential and possible molecular mechanisms of action of Inonotus obliquus from preclinical studies. Phytother. Res. 33(8): 1966-1980.

Duru, M.E., and Çayan, G.T. (2015). Biologically active terpenoids from mushroom origin: a review. Rec. Nat. Prod. 9(4): 456-483.

Eid, J.I., and Das, B. (2020a). Molecular insights and cell cycle assessment upon exposure to chaga (Inonotus obliquus) mushroom polysaccharides in zebrafish (Danio rerio). Sci. Rep. 10(1): 1-9.

Eid, J.I., Mohanty, S., and Das, B. (2020b). Genoprotective effects of Chaga mushroom (Inonotus obliquus) polysaccharides in UVB-exposed embryonic zebrafish (Danio rerio) through coordinated expression of DNA repair genes. bioRxiv.

Eisenman, H.C., and Casadevall, A. (2012). Synthesis and assembly of fungal melanin. Appl. Microbiol. Biotechnol. 93(3): 931-940.

Fan, L., Ding, S., Ai, L., and Deng, K. (2012). Antitumor and immunomodulatory activity of water-soluble polysaccharide from Inonotus obliquus. Carbohydr. Polym. 90(2): 870-874.

Fedotov, A., and Rodsolainnen, I. (1981). Effect of befungin on the central nervous system in peptic ulcer. Klin. Med. 59(7): 22-25.

Fradj, N., Gonçalves dos Santos, K.C., de Montigny, N., Awwad, F., Boumghar, Y., Germain, H., and Desgagné-Penix, I. (2019). RNA-Seq de Novo Assembly and Differential Transcriptome Analysis of Chaga (Inonotus obliquus) Cultured with Different Betulin Sources and the Regulation of Genes Involved in Terpenoid Biosynthesis. Int. J. Mol. Sci. 20(18): 4334-4360.

Frost, M. (2016). Three popular medicinal mushroom supplements: a review of human clinical trials. All Faculty Publications. pp. 1609-1626.

Gao, Y. (1993). The evaluation of PSP capsules in clinical pharmacology. Paper presented at the PSP International Symposium.

Gao, Y., Chen, G., Dai, X., Ye, J., and Zhou, S. (2004a). A phase I/II study of ling zhi mushroom Ganoderma lucidum (W. Curt.: Fr.) Lloyd (Aphyllophoromycetideae) extract in patients with coronary heart disease. Int. J. Med. Mushrooms 6(4): 327-334.

Gao, Y., Lan, J., Dai, X., Ye, J., and Zhou, S. (2004b). A phase I/II study of Ling Zhi mushroom Ganoderma lucidum (W. Curt.: Fr.) Lloyd (Aphyllophoromycetideae) extract in patients with type II diabetes mellitus. Int. J. Med. Mushrooms 6(1): 33-40.

Geng, Y., Lu, Z.-M., Huang, W., Xu, H.-Y., Shi, J.-S., and Xu, Z.-H. (2013). Bioassay-guided isolation of DPP-4 inhibitory fractions from extracts of submerged cultured of Inonotus obliquus. Molecules 18(1): 11501161.

Géry, A., Dubreule, C., André, V., Rioult, J.P., Bouchart, V., Heutte, N., Eldin de Pecoulas, P., Krivomaz, T., and Garon, D. (2018a). Chaga (Inonotus obliquus), a future potential medicinal fungus in oncology? A chemical study and a comparison of the cytotoxicity against human lung adenocarcinoma cells (A549) and human bronchial epithelial cells (BEAS-2B). Integr. Cancer Ther. 17(3): 832-843.

Ghobad-Nejhad, M., and Kotiranta, H. (2008). The genus Inonotus sensu lato in Iran, with keys to Inocutis and Mensularia worldwide. Paper presented at the Annales Botanici Fennici.

Glamočlija, J., Ćirić, A., Nikolić, M., Fernandes, Â., Barros, L., Calhelha, R.C., Ferreira, I.C., Soković, M., and van Griensven, L.J. (2015). Chemical characterization and biological activity of Chaga (Inonotus obliquus), a medicinal "mushroom". J. Ethnopharmacol. 162: 323-332.

Gómez, B.L., and Nosanchuk, J.D. (2003). Melanin and fungi. Curr. Opin. Infect. Dis. 16(2): 91-96.

Gordon, M., Bihari, B., Goosby, E., Gorter, R., Greco, M., Guralnik, M., Mimura, T., Rudinicki, V., Wong, R., and Kaneko, Y. (1998). A placebocontrolled trial of the immune modulator, lentinan, in HIV-positive patients: a phase I/II trial. J. Med. 29(5-6): 305-330.

Grishko, V., Tolmacheva, I., and Pereslavtseva, A. (2015). Triterpenoids with a five-membered A-ring: distribution in nature, transformations, synthesis, and biological activity. Chem. Nat. Compd. 51(1): 1-21.

Haanen, C., and Vermes, I. (1995). Apoptosis and inflammation. Mediators Inflamm. 4(1): 5-15

Ham, S.S., Kim, S.H., Moon, S.Y., Chung, M.J., Cui, C.B., Han, E.K., Chung, C.K., and Choe, M. (2009). Antimutagenic effects of subfractions of Chaga mushroom (Inonotus obliquus) extract. Mutat. Res. Genet. Toxicol. Environ. Mutagen 672(1): 55-59.

Ham, S.-S., Oh, S., Kim, Y.-K., Shin, K., Chang, H.-Y., and Chung, G.-H. (2003).
Antioxidant and genotoxic inhibition activity of ethanol extract from the Inonotus obliquus. J. Korean Soc. Food Sci. Nutr. 32: 1071-1075.

Hamid, K., Alqahtani, A., Kim, M.S., Cho, J.L., Cui, P.H., Li, C.G., Groundwater, P.W., and Li, G.Q. (2015). Tetracyclic triterpenoids in herbal medicines and their activities in diabetes and its complications. Curr. Top. Med. Chem. 15(23): 2406-2430.

Han, S.B., Park, S.H., Lee, K.H., Lee, C.W., Lee, S.H., Kim, H.C., Kim, Y.S., Lee, H.S., and Kim, H.M. (2001). Polysaccharide isolated from the radix of Platycodon grandiflorum selectively activates B cells and macrophages but not T cells. Int. Immunopharmacol. 1(11): 1969-1978.

Han, Y., Nan, S., Fan, J., Chen, Q., and Zhang, Y. (2019). Inonotus obliquus polysaccharides protect against Alzheimer's disease by regulating Nrf2 signaling and exerting antioxidative and antiapoptotic effects. Int. J. Biol. Macromol. 131: 769-778.

Handa, N., Yamada, T., and Tanaka, R. (2010). An unusual lanostane-type triterpenoid, spiroinonotsuoxodiol, and other triterpenoids from Inonotus obliquus. Phytochemistry 71(14-15): 1774-1779.

Hapuarachchi, J.R., Chalmers, A.H., Winefield, A.H., and Blake-Mortimer, J.S. (2003). Changes in clinically relevant metabolites with psychological stress parameters. Behav. Med. 29(2): 52-59.

He, J., Feng, X.-Z., Lu, Y., and Zhao, B. (2001). Three new triterpenoids from Fuscoporia obliqua. J. Asian Nat. Prod. Res. 3(1): 55-61.

Hou, R., Wang, H.-Y., and Chen, Z.-A. (2018). A study on apoptosis of fermented fnonotus obliquus on hepatocellular carcinoma HepG2 cells. J. Postgrad. Med. 31(1): 25-28.

Houlden, R.L. (2018). 2018 Clinical Practice Guidelines, Introduction. Can. J. Diabetes 42: 1-6.

Hu, H., Zhang, Z., Lei, Z., Yang, Y., and Sugiura, N. (2009). Comparative study of antioxidant activity and antiproliferative effect of hot water and ethanol extracts from the mushroom Inonotus obliquus. J. Biosci. Bioeng. 107(1): 42-48.

Hu, Y., Sheng, Y., Yu, M., Li, K., Ren, G., Xu, X., and Qu, J. (2016). Antioxidant activity of Inonotus obliquus polysaccharide and its amelioration for chronic pancreatitis in mice. Int. J. Biol. Macromol. 87: 348-356.

Hu, Y., Shi, S., Lu, L., Teng, C., Yu, S., Wang, X., Yu, M., Liang, J., and Qu, J. (2017a). Effects of selenizing modification on characteristics and antioxidant activities of Inonotus obliquus polysaccharide. Macromol. Res. 25(3): 222-230.

Hu, Y., Teng, C., Yu, S., Wang, X., Liang, J., Bai, X., Dong, L., Song, T., Yu, M., and Qu, J. (2017b). Inonotus obliquus polysaccharide regulates gut microbiota of chronic pancreatitis in mice. AMB Express 7(1): 39

Hua, K.F., Hsu, H.Y., Chao, L.K., Chen, S.T., Yang, W.B., Hsu, J., and Wong, C.H. (2007). Ganoderma lucidum polysaccharides enhance CD14 endocytosis of LPS and promote TLR4 signal transduction of cytokine expression. J. Cell. Physiol. 212(2): 537-550.

Huang, S.-Q., Ding, S., and Fan, L. (2012). Antioxidant activities of five polysaccharides from Inonotus obliquus. Int. J. Biol. Macromol. 50(5) 1183-1187.

Hwang, B.S., Lee, I.-K., and Yun, B.-S. (2016). Phenolic compounds from the fungus Inonotus obliquus and their antioxidant properties. J. Antibiot. 69(2): 108-110.

Hyun, K.W., Jeong, S.C., Lee, D.H., Park, J.S., and Lee, J.S. (2006). Isolation and characterization of a novel platelet aggregation inhibitory peptide from the medicinal mushroom, Inonotus obliquus. Peptides 27(6): 1173-1178.

Ichimura, T., Watanabe, O., and Maruyama, S.J.B. (1998). Inhibition of HIV-1 protease by water-soluble lignin-like substance from an edible mushroom, Fuscoporia obliqua. Biosci. Biotechnol. Biochem. 62(3): 575-577.

Jarosz, A., Skórska, M., Rzymowska, J., Kochmanska-Rdest, J., and Malarczyk, E. (1990). Effect of the extracts from fungus Inonotus obliquus on catalase level in HeLa and nocardia cells. Acta Biochim. Pol. 37(1): 149-151.

Javed, S., Mitchell, K., Sidsworth, D., Sellers, S.L., Reutens-Hernandez, J., Massicotte, H.B., Egger, K.N., Lee, C.H., and Payne, G.W. (2019). Inonotus obliquus attenuates histamine-induced microvascular inflammation. PLoS one 14(8): e0220776.

Jiang, S., Shi, F., Lin, H., Ying, Y., Luo, L., Huang, D., and Luo, Z. (2019). Inonotus obliquus polysaccharides induces apoptosis of lung cancer cells and alters energy metabolism via the LKB1/AMPK axis. Int. J. Biol. Macromol. 151: 1277-1286. 
Jing, J., and Teschke, R. (2018). Traditional Chinese medicine and herb-induced liver injury: comparison with drug-induced liver injury. J. Clin. Transl. Hepatol. 6(1): 57-68.

Joo, J.I., Kim, D.H., and Yun, J.W. (2010). Extract of Chaga mushroom (Inonotus obliquus) stimulates 3t3-I1 adipocyte differentiation. Phytother. Res. 24(11): 1592-1599.

Ju, H.K., Chung, H.W., Hong, S.-S., Park, J.H., Lee, J., and Kwon, S.W. (2010). Effect of steam treatment on soluble phenolic content and antioxidant activity of the Chaga mushroom (Inonotus obliquus). Food Chem. 119(2): 619-625.

Kahlos, K. (1994). Inonotus obliquus (Chaga Fungus): in vitro culture and the production of inotodiol, sterols, and other secondary metabolites. Biotechnology in Agriculture and Forestry. Springer, Berlin, Heidelberg/Germany, pp. 179-198.

Kahlos, K., and Hiltunen, R. (1986). 33, 22-dihydroxylanosta-7, 9 (11): 24-triene: a new, minor compound from Inonotus obliquus. Planta Med. 52(06): 495-496.

Kahlos, K., and Hiltunen, R. (1987). Gas chromatographic mass spectrometric study of some sterols and lupines from Inonotus obliquus. Acta Pharm. Fenn. 96(2): 85-80.

Kahlos, K., Hintsanen, E., Seppänen-Laakso, T., and Hiltunen, R. (1989). Lipid compounds of three species of cultivated Inonotus. Planta Med. 55(07): 621-622.

Kahlos, K., Toikka, R., and Hiltunen, R. (1992). Effect of some glucosamine derivatives on the production of fungal volatiles of Inonotus obliquus in vitro. Planta Med. 58(S1): 610-610.

Kang, J.H., Jang, J.E., Mishra, S.K., Lee, H.J., Nho, C.W., Shin, D., Jin, M., Kim, M.K., Choi, C., and Oh, S.H. (2015). Ergosterol peroxide from Chaga mushroom (Inonotus obliquus) exhibits anti-cancer activity by down-regulation of the $\beta$-catenin pathway in colorectal cancer. J. Ethnopharmacol. 173: 303-312.

Kari, P.R. (1987). Tanaina Plantlore: An Ethnobotany of the Dena'ina Indians of Southcentral Alaska. National Park Service, Alaska Region, Canada.

Kidd, P.M. (2000). The use of mushroom glucans and proteoglycans in cancer treatment. Altern. Med. Rev. 5(1): 4-27.

Kikuchi, Y., Seta, K., Ogawa, Y., Takayama, T., Nagata, M., Taguchi, T., and Yahata, K. (2014). Chaga mushroom-induced oxalate nephropathy. Clin. Nephrol. 81(6): 440-444.

Kim, H.G., Yoon, D.H., Kim, C.H., Shrestha, B., Chang, W.C., Lim, S.Y., Lee, W.H., Han, S.G., Lee, J.O., Lim, M.H., Kim, G.Y., Choi, S., Song, W.O., Sung, J.M., Hwang, K.C., and Kim, T.W. (2007). Ethanol extract of Inonotus obliquus inhibits lipopolysaccharide-induced inflammation in RAW 264.7 macrophage cells. J. Med. Food 10(1): 80-89.

Kim, H.S., Kim, J.Y., Kang, J.S., Kim, H.M., Kim, Y.O., Hong, I.P., Lee, M.K., Hong, J.T., Kim, Y., and Han, S.-B. (2010). Cordlan polysaccharide isolated from mushroom Cordyceps militaris induces dendritic cell maturation through toll-like receptor 4 signalings. Food Chem. Toxicol. 48(7): 1926-1933.

Kim, J.H., Sung, N.Y., Kwon, S.K., Srinivasan, P., Song, B.S., Choi, J.I., Yoon, Y., Kim, J.K., Byun, M.W., Kim, M.R., and Lee, J.W. (2009). y-Irradiation improves the color and antioxidant properties of Chaga mushroom (Inonotus obliquus) extract. J. Med. Food. 12(6): 1343-1347.

Kim, J.-Y., Byeon, S.-E., Lee, Y.-G., Lee, J.-Y., Park, J., Hong, E.-K., and Cho, J.-Y. (2008a). Immunostimulatory activities of polysaccharides from liquid culture of pine-mushroom Tricholoma matsutake. J. Microbiol. Biotechnol. 18(1): 95-103.

Kim, M.Y., Seguin, P., Ahn, J.K., Kim, J.J., Chun, S.C., Kim, E.H., Seo, S.H., Kang, E.Y., Kim, S.L., Park, Y.J., Ro, H.M., and Chung, I.M. (2008b). Phenolic compound concentration and antioxidant activities of edible and medicinal mushrooms from Korea. J. Agric. Food Chem. 56(16): 7265-7270.

Kim, Y.J., Park, J., Min, B.S., and Shim, S.H. (2011). Chemical constituents from the sclerotia of Inonotus obliquus. J. Korean Soc. Appl. Biol. Chem. 54(2): 287-294.

Kim, Y.O., Han, S.B., Lee, H.W., Ahn, H.J., Yoon, Y.D., Jung, J.K., Kim, H.M., and Shin, C.S. (2005). Immuno-stimulating effect of the endo-polysaccharide produced by submerged culture of Inonotus obliquus. Life Sci. 77(19): 2438-2456.

Kim, Y.O., Park, H.W., Kim, J.H., Lee, J.Y., Moon, S.H., and Shin, C.S. (2006). Anti-cancer effect and structural characterization of endo-polysac- charide from cultivated mycelia of Inonotus obliquus. Life Sci. 79(1): 72-80.

Kimura, I., Yoshikawa, M., Kobayashi, S., Sugihara, Y., Suzuki, M., Oominami, H., Murakami, T., Matsuda, H., and Doiphode, V.V. (2001). New triterpenes, myrrhanol $A$ and myrrhanone $A$, from guggul-gum resins, and their potent anti-inflammatory effect on adjuvant-induced air-pouch granuloma of mice. Bioorganic Med. Chem. Lett. 11(8): 985-989.

Kiraly, O., Gong, G., Olipitz, W., Muthupalani, S., and Engelward, B.P. (2015). Inflammation-induced cell proliferation potentiates DNA damage-induced mutations in vivo. PLOS Genet. 11(2): e1004901.

Kirk, P., Cannon, P., Minter, D., and Stalpers, J. (Ed.). (2008). Dictionary of the Fungi. 10th ed. CAB International, Wallingford, UK.

Koyama, T. (2017). 18. Bioactive foods and herbs in prevention and treatment of cardiovascular disease. In: Watson, R.R., and Zibadi, S. (Ed.). Handbook of nutrition in heart health (Vol. 14). Wageningen Academic Publishers, Wageningen, the Nertherland, pp. 373-398.

Koyama, T., Gu, Y., and Taka, A. (2008). Fungal medicine, Fuscoporia obliqua, as a traditional herbal medicine: its bioactivities, in vivo testing and medicinal effects. Asian Biomed. 2(6): 459-469.

Koyama, T., Taka, A., and Togashi, H. (2006). Cardiovascular effects produced by a traditional fungal medicine, Fuscoporia obliqua extract, and microvessels in the left ventricular wall of stroke-prone spontaneously hypertensive rat (SHRSP). Clin. Hemorheol. Microcirc. 35(4): 491-498.

Kukulyanskaya, T., Kurchenko, N., Kurchenko, V., and Babitskaya, V. (2002). Physicochemical properties of melanins produced by the sterile form of Inonotus obliquus ("Chagi") in natural and cultivated fungus. Appl. Biochem. Microbiol. 38(1): 58-61.

Kuriyama, I., Nakajima, Y., Nishida, H., Konishi, T., Takeuchi, T., Sugawara, F., Yoshida, H., and Mizushina, Y. (2013). Inhibitory effects of low molecular weight polyphenolics from Inonotus obliquus on human DNA topoisomerase activity and cancer cell proliferation. Mol. Med. Rep. 8(2): 535-542.

Lee, H.S., Kim, E.J., and Kim, S.H. (2015a). Ethanol extract of Innotus obliquus (Chaga mushroom) induces G1 cell cycle arrest in HT-29 human colon cancer cells. Nutr. Res. Pract. 9(2): 111-116.

Lee, I.-K., Kim, Y.-S., Jang, Y.-W., Jung, J.-Y., and Yun, B.-S. (2007). New antioxidant polyphenols from the medicinal mushroom Inonotus obliquus. Bioorganic Med. Chem. Lett. 17(24): 6678-6681.

Lee, I.-K., and Yun, B.-S. (2011). Styrylpyrone-class compounds from medicinal fungi Phellinus and Inonotus spp., and their medicinal importance. J. Antibiot. 64(5): 349-359.

Lee, J.H., and Hyun, C.K. (2014a). Insulin-sensitizing and beneficial lipidmetabolic effects of the water-soluble melanin complex extracted from Inonotus obliquus. Phytother. Res. 28(9): 1320-1328.

Lee, J.S., Lee, K.R., Lee, S., Lee, H.J., Yang, H.-S., Yeo, J., Park, J.M., Choi, B.H., and Hong, E.K. (2017a). Polysaccharides isolated from liquid culture broth of Inonotus obliquus inhibit the invasion of human non-small cell lung carcinoma cells. Biotechnol. Bioprocess Eng. 22(1): 45-51.

Lee, K.R., Lee, J.S., Kim, Y.R., Song, I.G., and Hong, E.K. (2014b). Polysaccharide from Inonotus obliquus inhibits migration and invasion in B16-F10 cells by suppressing MMP-2 and MMP-9 via downregulation of NF-kB signaling pathway. Oncol. Rep. 31(5): 2447-2453.

Lee, K.R., Lee, J.S., Lee, S., Son, Y.K., Kim, G.R., Sim, Y.C., Song, J.E., Ha, S.-J., and Hong, E.K. (2016). Polysaccharide isolated from the liquid culture broth of Inonotus obliquus suppresses invasion of B16-F10 melanoma cells via AKT/NF-KB signaling pathway. Mol. Med. Rep. 14(5): 4429-4435.

Lee, K.R., Lee, J.S., Song, J.E., Ha, S.J., and Hong, E.K. (2014c). Inonotus obliquus-derived polysaccharide inhibits the migration and invasion of human non-small cell lung carcinoma cells via suppression of MMP-2 and MMP-9. Int. J. Oncol. 45(6): 2533-2540.

Lee, K.-H., Kim, H., Oh, S.-H., Hwang, J.-H., and Yu, K.-W. (2017b). Immunomodulating Activity of Crude Polysaccharide from Inonotus obliquus Sclerotia by Fractionation including $\mathrm{MeOH}$ Reflux. Korean J. Food Nutr. 30(1): 96-104.

Lee, M.-W., Hur, H., Chang, K.-C., Lee, T.-S., Ka, K.-H., and Jankovsky, L. (2008). Introduction to distribution and ecology of sterile conks of Inonotus obliquus. Mycobiology 36(4): 199-202. 
Lee, S.H., Hwang, H.S., and Yun, J.W. (2009). Antitumor activity of water extract of a mushroom, Inonotus obliquus, against HT-29 human coIon cancer cells. Phytother. Res. 23(12): 1784-1789.

Lee, S., Lee, H.Y., Park, Y., Ko, E.J., Ban, T.H., Chung, B.H., Lee, H.S., and Yang, C.W. (2020). Development of End Stage Renal Disease after Long-Term Ingestion of Chaga Mushroom: Case Report and Review of Literatures. J. Korean Med. Sci. 35(19): e122.

Lee, W.-J., Kim, H.-W., Lee, H.-Y., and Son, C.-G. (2015b). Systematic review on herb-induced liver injury in Korea. Food Chem. Toxicol. 84: 47-54.

Lemieszek, M.K., Langner, E., Kaczor, J., Kandefer-Szerszen, M., Sanecka, B., Mazurkiewicz, W., and Rzeski, W. (2011). Anticancer effects of fraction isolated from fruiting bodies of Chaga medicinal mushroom, Inonotus obliquus (Pers.: Fr.) Pilát (Aphyllophoromycetideae): in vitro studies. Int. J. Med. Mushrooms 13(2): 131-143.

Lewandowski, S., Rodgers, A.L., Laube, N., von Unruh, G., Zimmermann, D., and Hesse, A. (2005). Oxalate and its handling in a low stone risk vs a stone-prone population group. World J. Urol. 23(5): 330-333.

Lewandowski, S., Rodgers, A., and Schloss, I. (2001). The influence of a high-oxalate/low-calcium diet on calcium oxalate renal stone risk factors in non-stone-forming black and white South African subjects. BJU Int. 87(4): 307-311.

Li, Z., Mei, J., Jiang, L., Geng, C., Li, Q., Yao, X., and Cao, J. (2019). Chaga Medicinal Mushroom, Inonotus obliquus (Agaricomycetes) Polysaccharides Suppress Tacrine-induced Apoptosis by ROS-scavenging and Mitochondrial Pathway in HepG2 Cells. Int. J. Med. Mushrooms 21(6): 583-593.

Liang, L., Zhang, Z., and Wang, H. (2009). Antioxidant activities of extracts and subfractions from Inonotus Obliquus. Int. J. Food Sci. Nutr. 60(sup2): 175-184.

Limón-Pacheco, J., and Gonsebatt, M.E. (2009). The role of antioxidants and antioxidant-related enzymes in protective responses to environmentally induced oxidative stress. Mutat. Res. Genet. Toxicol. Environ. Mutagen 674(1-2): 137-147.

Lin, N.-H., Yang, H.-W., Su, Y.-J., and Chang, C.-W. (2019). Herb induced liver injury after using herbal medicine: A systemic review and casecontrol study. Medicine 98(13): e14992.

Liu, C., Zhao, C., Pan, H.H., Kang, J., Yu, X.T., Wang, H.Q., Li, B.M., Xie, Y.Z., and Chen, R.Y. (2014). Chemical constituents from Inonotus obliquus and their biological activities. J. Nat. Prod. 77(1): 35-41.

Liu, P., Xue, J., Tong, S., Dong, W., and Wu, P. (2018). Structure Characterization and Hypoglycaemic Activities of Two Polysaccharides from Inonotus obliquus. Molecules 23(8): 1948

Liu, Z., Yu, D., Li, L., Liu, X., Zhang, H., Sun, W., Lin, C.C., Chen, J., Chen, Z., Wang, W., and Jia, W. (2019). Three-phase partitioning for the extraction and purification of polysaccharides from the immunomodulatory medicinal mushroom Inonotus obliquus. Molecules 24(3): 403.

Lu, X., Chen, H., Dong, P., Fu, L., and Zhang, X. (2010). Phytochemical characteristics and hypoglycaemic activity of fraction from mushroom Inonotus obliquus. J. Sci. Food Agric. 90(2): 276-280.

Lumlertgul, N., Siribamrungwong, M., Jaber, B.L., and Susantitaphong, P. (2018). Secondary oxalate nephropathy: a systematic review. Kidney Int. Rep. 3(6): 1363-1372.

Ma, G., Yang, W., Zhao, L., Pei, F., Fang, D., and Hu, Q. (2018). A critical review on the health promoting effects of mushrooms nutraceuticals. Food Sci. Hum. Wellness 7(2): 125-133.

Ma, L., Chen, H., Dong, P., and Lu, X. (2013). Anti-inflammatory and anticancer activities of extracts and compounds from the mushroom Inonotus obliquus. Food Chem. 139(1-4): 503-508.

Ma, L., Chen, H., Zhang, Y., Zhang, N., and Fu, L. (2012). Chemical modification and antioxidant activities of polysaccharide from mushroom Inonotus obliquus. Carbohydr. Polym. 89(2): 371-378.

Maenaka, T., Oshima, M., Itokawa, Y., Masubuchi, T., Takagi, Y., Choi, J.S., Ishida, T., and Gu, Y. (2008). Effects of Fuscoporia obliqua on postprandial glucose excursion and endothelial dysfunction in type 2 diabetic patients. J. Tradit. Chin. Med. 28(1): 49-57.

Mandal, S.M., Chakraborty, D., and Dey, S. (2010). Phenolic acids act as signaling molecules in plant-microbe symbioses. Plant Signal. Behav. 5(4): 359-368.

Mazurkiewicz, W. (2006). Analysis of aqueous extract of Inonotus obliquus. Acta Pol. Pharm. Drug Res. 63(8): 497-501.

Mbaveng, A.T., Hamm, R., and Kuete, V. (2014). Harmful and protective effects of terpenoids from African medicinal plants. Toxicological survey of African medicinal plants. Elsevier, Amsterdam, the Netherlands, pp. 557-576.

Merdivan, S., and Lindequist, U. (2017). Ergosterol peroxide: a mushroomderived compound with promising biological activities- a review. Int. J. Med. Mushrooms 19(2): 93-105

Mishra, S.K., Kang, J.-H., Kim, D.-K., Oh, S.H., and Kim, M.K. (2012). Orally administered aqueous extract of Inonotus obliquus ameliorates acute inflammation in dextran sulfate sodium (DSS)-induced colitis in mice. J. Ethnopharmacol. 143(2): 524-532.

Mishra, S.K., Kang, J-H., Song, K-H., Park, M.S., Kim, D-K., Park, Y-J., Choi, C., Kim, H.M., Kim, M.K., and Oh, S.H. (2013). Inonotus obliquus suppresses proliferation of colorectal cancer cells and tumor growth in mice models by downregulation of $\beta$-catenin/NF-KB-signaling pathways. Eur. J. Inflamm. 11(3): 615-629.

Miura, T. (2007). Antidiabetic activity of Fuscoporia oblique and Samallanthus sonchifolius in genetically type 2 diabetic mice. J. Tradit. Med. 24(2): 47-50.

Mizuno, T., Zhuang, C., Abe, K., Okamoto, H., Kiho, T., Ukai, S., Leclerc S., and Meijer, L. (1999). Antitumor and hypoglycemic activities of polysaccharides from the sclerotia and mycelia of Inonotus obliquus (Pers.: Fr.) Pil.(Aphyllophoromycetideae). Int. J. Med. Mushrooms 1(4): 301-316.

Moghaddam, M.G., Ahmad, F.B.H., and Samzadeh-Kermani, A. (2012). Biological activity of betulinic acid: a review. Pharmacol. Pharm. 3: 119-123.

Mu, H., Zhang, A., Zhang, W., Cui, G., Wang, S., and Duan, J. (2012). Antioxidative properties of crude polysaccharides from Inonotus obliquus. Int. J. Mol. Sci. 13(7): 9194-9206.

Muszyńska, B., Grzywacz-Kisielewska, A., Kała, K., and Gdula-Argasińska, J. (2018). Anti-inflammatory properties of edible mushrooms: A review. Food Chem. 243: 373-381.

Nagajyothi, P., Sreekanth, T., Lee, J.-I., and Lee, K.D. (2014). Mycosynthesis: antibacterial, antioxidant and antiproliferative activities of silver nanoparticles synthesized from Inonotus obliquus (Chaga mushroom) extract. J. Photochem. Photobiol. B 130: 299-304.

Najafzadeh, M., Reynolds, P.D., Baumgartner, A., Jerwood, D., and Ander son, D. (2007). Chaga mushroom extract inhibits oxidative DNA damage in lymphocytes of patients with inflammatory bowel disease. Biofactors 31(3-4): 191-200.

Nakajima, Y., Nishida, H., Matsugo, S., and Konishi, T. (2009). Cancer cell cytotoxicity of extracts and small phenolic compounds from Chaga [Inonotus obliquus (Persoon) Pilat]. J. Med. Food 12(3): 501-507.

Nakajima, Y., Sato, Y., and Konishi, T. (2007). Antioxidant small phenolic ingredients in Inonotus obliquus (persoon) Pilat (Chaga). Chem. Pharm. Bull. 55(8): 1222-1226.

Nakamura, S., Iwami, J., Matsuda, H., Mizuno, S., and Yoshikawa, M. (2009). Absolute stereostructures of inoterpenes A-F from sclerotia of Inonotus obliquus. Tetrahedron 65(12): 2443-2450.

Nakata, T., Yamada, T., Taji, S., Ohishi, H., Wada, S.-I., Tokuda, H., Sakuma, K., and Tanaka, R. (2007). Structure determination of inonotsuoxides $A$ and $B$ and in vivo anti-tumor promoting activity of inotodio from the sclerotia of Inonotus obliquus. Bioorg. Med. Chem. 15(1): 257-264.

$\mathrm{Ng}$, T. (2003). Bioactive Fungal Polysaccharides and Polysaccharopeptides. In: Arora, D.K. (Ed.). Handbook of Fungal Biotechnology. CRC Press, New York, America, p. 331.

Nguyen, H.T., Ho, D.V., Nguyen, P.D.Q., Vo, H.Q., Do, T.T., and Raal, A. (2018), Cytotoxic Evaluation of Compounds Isolated from the Aerial Parts of Hedyotis pilulifera and Methanol Extract of Inonotus obliquus. Nat. Prod. Commun. 13(8): 939-941.

NIH, N.C.I. (2020). Cancer Statistics. Retrieved from https://www.cancer. gov/about-cancer/understanding/statistics.

Nikitina, S., Habibrakhmanova, V., and Sysoeva, M. (2016). Chemical composition and biological activity of triterpenes and steroids of chaga mushroom. Biochem. (Mosc.), Suppl., Ser. B Biomed. chem. 10(1): 63-69.

Ning, X., Luo, Q., Li, C., Ding, Z., Pang, J., and Zhao, C. (2014). Inhibitory effects of a polysaccharide extract from the Chaga medicinal mushroom, Inonotus obliquus (higher Basidiomycetes), on the proliferation of human neurogliocytoma cells. Int. J. Med. Mushrooms 16(1) 
29-36.

Niu, H., Song, D., Mu, H., Zhang, W., Sun, F., and Duan, J. (2016). Investigation of three lignin complexes with antioxidant and immunological capacities from Inonotus obliquus. Int. J. Biol. Macromol. 86: 587593.

Nomura, M., Takahashi, T., Uesugi, A., Tanaka, R., and Kobayashi, S. (2008). Inotodiol, a lanostane triterpenoid, from Inonotus obliquus inhibits cell proliferation through caspase-3-dependent apoptosis. Anticancer Res. 28(5A): 2691-2696

Ohno, S., Sumiyoshi, Y., Hashine, K., Shirato, A., Kyo, S., and Inoue, M. (2011). Phase I clinical study of the dietary supplement, Agaricus blazei Murill, in cancer patients in remission. Evid. Based Complement. Alternat. Med. 2011: 192381.

Olennikov, D., Tankhaeva, L., Rokhin, A., and Agafonova, S. (2012). Physicochemical properties and antioxidant activity of melanin fractions from Inonotus obliquus sclerotia. Chem. Nat. Compd. 48(3): 396-403.

Ooi, V.E.C., and Liu, F. (2000). Immunomodulation and anti-cancer activity of polysaccharide-protein complexes. Curr. Med. Chem. 7(7): 715-729.

Owusu-Apenten, R. (2002). Food protein analysis: quantitative effects on processing (Vol. 118). CRC press, New York, America.

Pahwa, R., Goyal, A., Bansal, P., and Jialal, I. (2019). Chronic inflammation. Retrieved from https://www.ncbi.nlm.nih.gov/books/NBK493173/.

Pan, H., Han, Y., Huang, J., Yu, X., Jiao, C., Yang, X., Dhaliwal, P., Xie, Y., and Yang, B.B. (2015). Purification and identification of a polysaccharide from medicinal mushroom Amauroderma rude with immunomodulatory activity and inhibitory effect on tumor growth. Oncotarget 6(19): 17777-17791.

Parfenov, A., Vyshtakalyuk, A., Sysoeva, M., Sysoeva, E., Latipova, A., Gumarova, L., and Zobov, V. (2019). Hepatoprotective Effect of Inonotus obliquus Melanins: In Vitro and In Vivo Studies. Bionanoscience 9(2): 528-538.

Park, E., Jeon, K.-I., and Byun, B.-H. (2005a). Ethanol extract of Inonotus obliquus shows antigenotoxic effect on hydrogen peroxide induced DNA damage in human lymphocytes. Cancer Prev. Res. 10(1): 54-59.

Park, S-K., Kim, G.-Y., Lim, J.-Y., Kwak, J.-Y., Bae, Y.-S., Lee, J.-D., Oh, Y.-H., Ahn, S.-C., and Park, Y.-M. (2003). Acidic polysaccharides isolated from Phellinus linteus induce phenotypic and functional maturation of murine dendritic cells. Biochem. Biophys. Res. Commun. 312(2): 449-458.

Park, Y.K., Lee, H.B., Jeon, E.-J., Jung, H.S., and Kang, M.-H. (2004). Chaga mushroom extract inhibits oxidative DNA damage in human lymphocytes as assessed by comet assay. Biofactors 21(1-4): 109-112.

Park, Y.-M., Won, J.-H., Kim, Y.-H., Choi, J.-W., Park, H.-J., and Lee, K.-T. (2005b). In vivo and in vitro anti-inflammatory and anti-nociceptive effects of the methanol extract of Inonotus obliquus. J. Ethnopharmacol. 101(1-3): 120-128.

Patel, S. (2015). Chaga (Inonotus Obliquus) mushroom: Nutraceutical assesement based on latest findings. Emerging Bioresources with Nutraceutical and Pharmaceutical Prospects. Springer, Berlin, Heidelberg/Germany, pp. 115-126.

Peberdy, J. (1990). Fungal cell walls-a review. Biochemistry of cell walls and membranes in fungi. Springer, Berlin, Heidelberg/Germany, pp. $5-30$.

Perveen, S. (2018). Terpenes and Terpenoids. IntechOpen, London, UK.

Plonka, P.M., and Grabacka, M. (2006). Melanin synthesis in microorganisms--biotechnological and medical aspects. Acta Biochim. Pol. 53(3): 429-443.

Poyedinok, N., Mykhaylova, O., Sergiichuk, N., Tugay, T., Tugay, A., Lopatko, S., and Matvieieva, N. (2020). Effect of Colloidal Metal Nanoparticles on Biomass, Polysaccharides, Flavonoids, and Melanin Accumulation in Medicinal Mushroom Inonotus obliquus (Ach.:Pers.) Pilát. Appl. Biochem. Biotechnol. 191(3): 1315-1325.

Poyedinok, N., Mykhaylova, O., Tugay, T., Tugay, A., Negriyko, A., and Dudka, I. (2015). Effect of light wavelengths and coherence on growth, enzymes activity, and melanin accumulation of liquid-cultured Inonotus obliquus (Ach.: Pers.) Pilát. Biotechnol. Appl. Biochem. 176(2): 333-343.

Rascon-Valenzuela, L., Velazquez-Contreras, C., Garibay-Escobar, A., and Robles-Zepeda, R.J.N.S.P. (2017). Triterpenoids: synthesis, use in cancer treatment and other biological activities. In: Berhardt, L.V. (Ed.).
Advances in Medicine and Biology. Nova Science, New York, America. Redmile-Gordon, M., Armenise, E., White, R.P., Hirsch, P., and Goulding, K. (2013). A comparison of two colorimetric assays, based upon Lowry and Bradford techniques, to estimate total protein in soil extracts. Soil Biol. Biochem. 67: 166-173.

Reid, D. (1976). Inonotus obliquus (pers. Ex Fr.) pilat in Britain. Trans. Brit. Mycol. Soc. 67(2): 329-332.

Ren, G.-J., and Dai, Y.-C. (2018). Inonotus castanopsidis sp. nov.(Hymenochaetaceae, Basidiomycota) from southwestern China. Phytotaxa 338(1): 117-124.

Reuter, S., Gupta, S.C., Chaturvedi, M.M., and Aggarwal, B.B. (2010). Oxidative stress, inflammation, and cancer: how are they linked? Free Radic. Biol. Med. 49(11): 1603-1616.

Rhee, S.J., Cho, S.Y., Kim, K.M., Cha, D.-S., and Park, H.-J. (2008). A comparative study of analytical methods for alkali-soluble $\beta$-glucan in medicinal mushroom, Chaga (Inonotus obliquus). LWT - Food Sci. Technol. 41(3): 545-549.

Rodrigues, M., Nimrichter, L., Cordero, R., and Casadevall, A. (2011). Fungal polysaccharides: biological activity beyond the usual structural properties. Front. Microbiol. 2: 171.

Rogers, R.D. (2012). The true tinder conk: First Nation's use. Fungi 5: 5657.

Rop, O., Mlcek, J., and Jurikova, T. (2009). Beta-glucans in higher fungi and their health effects. Nutr. Rev. 67(11): 624-631.

Ryu, K., Nakamura, S., Nakashima, S., Aihara, M., Fukaya, M., Iwami, J., Asao, Y., Yoshikawa, M., and Matsuda, H. (2017). Triterpenes with Anti-invasive Activity from Sclerotia of Inonotus obliquus. Nat. Prod. Commun. 12(2): 225-228.

Ryvarden, L. (2005). The genus Inonotus a synopsis (Vol. 21). Fungiflora A/S.

Rzymowska, J. (1998). The effect of aqueous extracts from Inonotus obliquus on the mitotic index and enzyme activities. Boll. Chim. Farm. 137(1): 13-15.

Saar, M. (1991). Fungi in Khanty folk medicine. J. Ethnopharmacol. 31(2): 175-179.

Sagayama, K., Tanaka, N., Fukumoto, T., and Kashiwada, Y. (2019). Lanostane-type triterpenes from the sclerotium of Inonotus obliquus (Chaga mushrooms) as proproliferative agents on human follicle dermal papilla cells. J. Nat. Med. 73(3): 597-601.

Sakuma, K. (2004). US Patent No. US20040105869A1.

Scalbert, A., Manach, C., Morand, C., Rémésy, C., and Jiménez, L. (2005). Dietary polyphenols and the prevention of diseases. Crit. Rev. Food Sci. Nutr. 45(4): 287-306.

Scerbak, C., Vayndorf, E.M., Hernandez, A., McGill, C., and Taylor, B.E. (2016). Mechanosensory neuron aging: differential trajectories with lifespan-extending alaskan berry and fungal treatments in Caenorhabditis elegans. Front. Aging Neurosci. 8: 173.

Shao, B.-M., Xu, W., Dai, H., Tu, P., Li, Z., and Gao, X.-M. (2004). A study on the immune receptors for polysaccharides from the roots of Astragalus membranaceus, a Chinese medicinal herb. Biochem. Biophys. Res. Commun. 320(4): 1103-1111.

Sharma, E., Anand, G., and Kapoor, R. (2017). Terpenoids in plant and arbuscular mycorrhiza-reinforced defence against herbivorous insects. Ann. Bot. 119(5): 791-801.

Shashkina, M.Y., Shashkin, P., and Sergeev, A. (2006). Chemical and medicobiological properties of chaga. Pharm. Chem. J. 40(10): 560-568.

Shibnev, V., Garaev, T., Finogenova, M., Kalnina, L., and Nosik, D. (2015). Antiviral activity of aqueous extracts of the birch fungus Inonotus obliquus on the human immunodeficiency virus. Vopr. Virusol. 60(2): 35-38.

Shibnev, V., Mishin, D., Garaev, T., Finogenova, N., Botikov, A., and Deryabin, P. (2011). Antiviral activity of Inonotus obliquus fungus extract towards infection caused by hepatitis $C$ virus in cell cultures. Bull. Exp. Biol. Med. 151(5): 612.

Shikov, A.N., Pozharitskaya, O.N., Makarov, V.G., Wagner, H., Verpoorte, R., and Heinrich, M. (2014). Medicinal Plants of the Russian Pharmacopoeia; their history and applications. J. Ethnopharmacol. 154: 520.

Shin, Y., Tamai, Y., and Terazawa, M. (2000). Chemical Constituents of Inonotus obliquus I.: A new triterpene, 3ß-hydroxy-8, 24-dien-lanosta-21, 23-lactone from sclerotium. Eurasian J. Forest Res. 1: 43-50.

Shin, Y., Tamai, Y., and Terazawa, M. (2001a). Chemical Constituents of In- 
onotus obliquus IV.: Triterpene and Steroids from Cultured Mycelia. Eurasian J. Forest Res. 2: 27-30.

Shin, Y., Tamai, Y., and Terazawa, M. (2001b). Chemical constituents of Inonotus obliquus II: a new triterpene, 21, 24-cyclopentalanosta-3 $\beta$, 21, 25-triol-8-ene from sclerotium. J. Wood Sci. 47(4): 313-316.

Shin, Y., Yutaka, T., and Minoru, T. (2002). Triterpenoids, steroids, and a new sesquiterpen from Inonotus obliquus (Pers.: Fr.) Pilat. Int. J. Med. Mushrooms 4(2): 5ebd323c1a4ddbed.

$\mathrm{Si}, \mathrm{C}$. (2018). Composition of Triterpenoids in Inonotus obliquus and Their Anti-Proliferative Activity on Cancer Cell Lines. (Master), Seoul National University, Seoul, South Korea. Retrieved from http://s-space. snu.ac.kr/bitstream/10371/142173/3/000000149362.pdf.

Sim, Y.C., Lee, J.S., Lee, S., Son, Y.K., Park, J.E., Song, J.E., Ha, S.J., and Hong, E.K. (2016). Effects of polysaccharides isolated from Inonotus obliquus against hydrogen peroxide-induced oxidative damage in RINm5F pancreatic $\beta$-cells. Mol. Med. Rep. 14(5): 4263-4270.

Singdevsachan, S.K., Auroshree, P., Mishra, J., Baliyarsingh, B., Tayung, K., and Thatoi, H. (2016). Mushroom polysaccharides as potential prebiotics with their antitumor and immunomodulating properties: A review. Bioact. Carbohydr. Diet. Fibre 7(1): 1-14.

Solano, F. (2014). Melanins: skin pigments and much more-types, structural models, biological functions, and formation routes. New J. Sci. 2014: 498276

Song, H.-S., Lee, Y.-J., Kim, S.-K., Moon, W.-K., Kim, D.-W., Kim, Y.S., and Moon, K.-Y. (2004). Downregulatory effect of AGI-1120 ( $\alpha$-Glucosidase Inhibitor) and chaga mushroom (Inonotus obliquus) on cellular NF- $\mathrm{K}$ B activation and their antioxidant activity. Saengyak Hakhoe Chi 35(1): 92-97.

Song, K.-C., Choi, B.-L., Shin, J.-W., Son, J.-Y., Yoo, H.-S., Cho, J.-H., Lee, Y.-W., Son, C.-G., and Cho, C.-K. (2007). Effects of Inonotus obliquus extracts on immunomodulating activity. J. Korean Med. 28(4): 27-41.

Song, Y., Hui, J., Kou, W., Xin, R., Jia, F., Wang, N., Hu, F., Zhang, H., and Liu, $\mathrm{H}$. (2008). Identification of Inonotus obliquus and analysis of antioxidation and antitumor activities of polysaccharides. Curr. Microbiol. 57(5): 454-462.

Stanczyk, F.Z. (2009). Production, clearance, and measurement of steroid hormones, pp. 1-19. Peter von Dadelszen-ed, Glob. libr. women's med., London.

Sun, J.-E., Ao, Z.-H., Lu, Z.-M., Xu, H.-Y., Zhang, X.-M., Dou, W.-F., and Xu, Z.$H$. (2008). Antihyperglycemic and antilipidperoxidative effects of dry matter of culture broth of Inonotus obliquus in submerged culture on normal and alloxan-diabetes mice. J. Ethnopharmacol. 118(1): 7-13.

Sun, Y., Yin, T., Chen, X.-H., Zhang, G., Curtis, R.B., Lu, Z.-H., and Jiang, J.$H$. (2011). In vitro antitumor activity and structure characterization of ethanol extracts from wild and cultivated Chaga medicinal mushroom, Inonotus obliquus (Pers.: Fr.) Pilát (Aphyllophoromycetideae). Int. J. Med. Mushrooms 13(2): 121-130.

Szychowski, K.A., Rybczyńska-Tkaczyk, K., Tobiasz, J., Yelnytska-Stawasz, V., Pomianek, T., and Gmiński, J. (2018). Biological and anticancer properties of Inonotus obliquus extracts. Process Biochem. 73: 180-187.

Taguchi, T., Furue, H., Kimura, T., Kondo, T., Hattori, T., Itoh, I., and Ogawa, N. (1985). Results of phase III study of lentinan. Gan To Kagaku Ryoho 12(2): 366-378.

Taji, S., Yamada, T., and Tanaka, R. (2008a). Three new lanostane triterpenoids, inonotsutriols A, B, and C, from Inonotus obliquus. Helv. Chim. Acta 91(8): 1513-1524.

Taji, S., Yamada, T., In, Y., Wada, S.i., Usami, Y., Sakuma, K., and Tanaka, R. (2007). Three new lanostane triterpenoids from Inonotus obliquus. Helv. Chim. Acta 90(11): 2047-2057.

Taji, S., Yamada, T., Wada, S.-I., Tokuda, H., Sakuma, K., and Tanaka, R. (2008b). Lanostane-type triterpenoids from the sclerotia of Inonotus obliquus possessing anti-tumor promoting activity. Eur. J. Med. Chem. 43(11): 2373-2379.

Takikawa, H. (2006). Drug-induced liver injury by dietary supplements in Japan. Japan Med. Assoc. J. 49(9/10): 327-329.

Tanaka, R., Toyoshima, M., and Yamada, T. (2011). New lanostane-type triterpenoids, inonotsutriols $\mathrm{D}$, and $\mathrm{E}$, from Inonotus obliquus. Phytochem. Lett. 4(3): 328-332.

Theis, N., and Lerdau, M. (2003). The evolution of function in plant secondary metabolites. Int. J. Plant Sci. 164(S3): S93-S102.

Tian, J., Hu, X., Liu, D., Wu, H., and Qu, L. (2017). Identification of Inono- tus obliquus polysaccharide with broad-spectrum antiviral activity against multi-feline viruses. Int. J. Biol. Macromol. 95: 160-167.

Tiziana, M., Stefano, G., Alessio, F., Rosa, S., Donatella, G., and Annalisa, D. (2020). Mushrooms Integrative Treatment with Inonotus obliquus and Ganoderma lucidum in a Triple Negative Breast Cancer Patient: A Case Report. World J. Breast Cancer Res. 3(1): 1017.

Tong, W. (2013). Biotransformation of terpenoids and steroids. Nat. Prod. Springer, Berlin, Heidelberg/Germany, pp. 2733-2759.

Tsai, C.-C., Li, Y.-S., and Lin, P.-P. (2017). Inonotus obliquus extract induces apoptosis in the human colorectal carcinoma's HCT-116 cell line. Biomed. Pharmacother. 96: 1119-1126.

Tsuboi, H., Hamer, M., Tanaka, G., Takagi, K., Kinae, N., and Steptoe, A (2008). Responses of ultra-weak chemiluminescence and secretory IgA in saliva to the induction of angry and depressive moods. Brain Behav. Immun. 22(2): 209-214.

Van, Q., Nayak, B., Reimer, M., Jones, P., Fulcher, R., and Rempel, C. (2009) Anti-inflammatory effect of Inonotus obliquus, Polygala senega $\mathrm{L}$. and Viburnum trilobum in a cell screening assay. J. Ethnopharmacol. 125(3): 487-493.

Varga, M., Berkesi, O., Darula, Z., May, N.V., and Palágyi, A. (2016). Structural characterization of allomelanin from black oat. Phytochemistry 130: 313-320.

Vermerris, W., and Nicholson, R. (2008). Families of phenolic compounds and means of classification. Phenolic Compound Biochemistry. Springer, Berlin, Heidelberg/Germany, pp. 1-34.

Wang, C., Chen, Z, Pan, Y., Gao, X, and Chen, H. (2017a). Anti-diabetic effects of Inonotus obliquus polysaccharides-chromium (III) complex in type 2 diabetic mice and its sub-acute toxicity evaluation in normal mice. Food Chem. Toxicol. 108: 498-509.

Wang, C., Gao, X., Santhanam, R.K., Chen, Z., Chen, Y., Xu, L., Wang, C., Ferri, N., and Chen, H. (2018a). Effects of polysaccharides from Inonotus obliquus and its chromium (III) complex on advanced glycation end-products formation, $\alpha$-amylase, $\alpha$-glucosidase activity and $\mathrm{H} 2 \mathrm{O} 2$-induced oxidative damage in hepatic LO2 cells. Food Chem. Toxicol. 116: 335-345.

Wang, C., Li, W., Chen, Z., Gao, X., Yuan, G., Pan, Y., and Chen, H. (2018b) Effects of simulated gastrointestinal digestion in vitro on the chemical properties, antioxidant activity, $\alpha$-amylase and $\alpha$-glucosidase inhibitory activity of polysaccharides from Inonotus obliquus. Food Res. Int. 103: 280-288.

Wang, C., Santhanam, R.K., Gao, X., Chen, Z., Chen, Y., Wang, C., Xu, L., and Chen, H. (2018c). Preparation, characterization of polysaccharides fractions from Inonotus obliquus and their effects on $\alpha$-amylase, $\alpha$-glucosidase activity and $\mathrm{H} 2 \mathrm{O} 2$-induced oxidative damage in he patic LO2 cells. J. Funct. Foods 48: 179-189.

Wang, J., Hu, W., Li, L., Huang, X., Liu, Y., Wang, D., and Teng, L. (2017b). Antidiabetic activities of polysaccharides separated from Inonotus obliquus via the modulation of oxidative stress in mice with streptozotocin-induced diabetes. PLoS One 12(6): e0180476.

Wang, J., Wang, C., Li, S., Li, W., Yuan, G., Pan, Y., and Chen, H. (2017c). Anti-diabetic effects of Inonotus obliquus polysaccharides in streptozotocin-induced type 2 diabetic mice and potential mechanism via PI3K-Akt signal pathway. Biomed. Pharmacother. 95: 1669-1677.

Wang, L.-X., Lu, Z.-M., Geng, Y., Zhang, X.-M., Xu, G.-H., Shi, J.-S., and Xu, Z.-H. (2014). Stimulated production of steroids in Inonotus obliquus by host factors from birch. J. Biosci. Bioeng. 118(6): 728-731.

Wang, M., Zhao, Z., Zhou, X., Hu, J., Xue, J., Liu, X., Zhang, J., Liu, P., and Tong, S. (2019). Simultaneous use of stimulatory agents to enhance the production and hypoglycaemic activity of polysaccharides from Inonotus obliquus by submerged fermentation. Molecules 24(23): 4400

Wang, Q., Mu, H., Zhang, L., Dong, D., Zhang, W., and Duan, J. (2015) Characterization of two water-soluble lignin metabolites with antiproliferative activities from Inonotus obliquus. Int. J. Biol. Macromol. 74: 507-514.

Wang, Y., Tian, Y., Shao, J., Shu, X., Jia, J., Ren, X., and Guan, Y. (2018d). Macrophage immunomodulatory activity of the polysaccharide isolated from Collybia radicata mushroom. Int. J. Biol. Macromol. 108: 300-306.

Wasser, S. (2002). Medicinal mushrooms as a source of antitumor and immunomodulating polysaccharides. Appl. Microbiol. Biotechnol. 
60(3): 258-274

Wei, Z.-H., Chen, N., Li, Y.-J., Fan, Q.-L., Yu, T.-F., Wang, K.-X., Dong, B.-T., Fan, E.-Y., Yuan, P.-L., Hu, G.-W., Qiao, F., Ge, L., Deng, Y.-Y., Lv, Y.-N., $\mathrm{Hu}, \mathrm{B} .-\mathrm{F}$. , and Liu, L. (2018). Glucose fed-batch integrated dissolved oxygen control strategy enhanced polysaccharide, total triterpenoids and inotodiol production in fermentation of a newly isolated Inonotus obliquus strain. Process Biochem. 66: 1-6.

WHO. (2017). Global report on diabetes. Retrieved from https://apps. who.int/iris/bitstream/handle/10665/204871/9789241565257 eng.pdf?sequence $=1$.

WHO. (2018). Cancer. Retrieved from https://www.who.int/news-room/ fact-sheets/detail/cancer.

Wold, C.W., Gerwick, W.H., Wangensteen, H., and Inngjerdingen, K.T. (2020). Bioactive triterpenoids and water-soluble melanin from Inonotus obliquus (Chaga) with immunomodulatory activity. J. Funct. Foods 71: 104025

Wold, C.W., Kjeldsen, C., Corthay, A., Rise, F., Christensen, B.E., Duus, J. $\varnothing$., and Inngjerdingen, K.T. (2018). Structural characterization of bioactive heteropolysaccharides from the medicinal fungus Inonotus obliquus (Chaga). Carbohydr. Polym. 185: 27-40.

Won, D.P., Lee, J.S., Kwon, D.S., Lee, K.E., Shin, W.C., and Hong, E.K. (2011). Immunostimulating activity by polysaccharides isolated from fruiting body of Inonotus obliquus. Mol. Cells 31(2): 165-173.

Wu, S.-H., Lin, Y.-T., Chern, C.-L., and Ke, S.-Y. (2018). Inonotus taiwanensis sp. nov.(Basidiomycota) from Taiwan. Mycoscience 59(5): 325-330.

Xiang, T., Shibuya, M., Katsube, Y., Tsutsumi, T., Otsuka, M., Zhang, H. Masuda, K., and Ebizuka, Y. (2006). A New Triterpene Synthase from Arabidopsis t-haliana Produces a Tricyclic Triterpene with Two Hydroxyl Groups. Org. Lett. 8(13): 2835-2838.

Xiang, Y., Xu, X., and Li, J. (2012). Chemical properties and antioxidant activity of exopolysaccharides fractions from mycelial culture of Inonotus obliquus in a ground corn stover medium. Food Chem. 134(4): 1899-1905.

Xiao, S., Tian, Z., Wang, Y., Si, L., Zhang, L., and Zhou, D. (2018). Recent progress in the antiviral activity and mechanism study of pentacyclic triterpenoids and their derivatives. Med. Res. Rev. 38(3): 951-976.

Xu, C., Wang, B., Pu, Y., Tao, J., and Zhang, T. (2018). Techniques for the analysis of pentacyclic triterpenoids in medicinal plants. J. Sep. Sci. 41(1): 6-19.

Xu, H.-Y., Sun, J.-E., Lu, Z.-M., Zhang, X.-M., Dou, W.-F., and Xu, Z.-H. (2010a). Beneficial effects of the ethanol extract from the dry matter of a culture broth of Inonotus obliquus in submerged culture on the antioxidant defence system and regeneration of pancreatic $\beta$-cells in experimental diabetes in mice. Nat. Prod. Res. 24(6): 542-553.

Xu, L., Sang, R., Yu, Y., Li, J., Ge, B., and Zhang, X. (2019a). The polysaccharide from Inonotus obliquus protects mice from Toxoplasma gondiiinduced liver injury. Int. J. Biol. Macromol. 125: 1-8.

Xu, L., Yu, Y., Sang, R., Ge, B., Wang, M., Zhou, H., and Zhang, X. (2020). Inonotus obliquus polysaccharide protects against adverse pregnancy caused by Toxoplasma gondii infection through regulating Th17/ Treg balance via TLR4/NF-KB pathway. Int. J. Biol. Macromol. 146: 832-840.

Xu, T., Beelman, R.B., and Lambert, J.D. (2012). The cancer preventive effects of edible mushrooms. Anti-Cancer Agents Med. Chem. 12(10): 1255-1263.

$\mathrm{Xu}, \mathrm{X}$. , Li, J., and Hu, Y. (2014b). Polysaccharides from Inonotus obliquus sclerotia and cultured mycelia stimulate cytokine production of human peripheral blood mononuclear cells in vitro and their chemical characterization. Int. Immunopharmacol. 21(2): 269-278.

Xu, X., Pang, C., Yang, C., Zheng, Y., Xu, H., Lu, Z., and Xu, Z.-H. (2010b). Antihyperglycemic and antilipidperoxidative effects of polysaccharides extracted from medicinal mushroom Chaga, Inonotus obliquus (Pers.: Fr.) Pilat (Aphyllophoromycetideae) on alloxan-diabetes mice. Int. J. Med. Mushrooms 12(3): 235-244.

Xu, X., Quan, L., and Shen, M. (2015a). Effect of chemicals on production, composition and antioxidant activity of polysaccharides of Inonotus obliquus. Int. J. Biol. Macromol. 77: 143-150.

Xu, X., Shen, M., and Quan, L. (2015b). Stimulatory agents simultaneously improving the production and antioxidant activity of polyphenols from Inonotus obliquus by submerged fermentation. Appl. Biochem. Biotechnol. 176(5): 1237-1250.
Xu, X., Wu, P., Wang, T., Yan, L., Lin, M., and Chen, C. (2019b). Synergistic effects of surfactant-assisted biodegradation of wheat straw and production of polysaccharides by Inonotus obliquus under submerged fermentation. Bioresour. Technol. 278: 43-50.

$\mathrm{Xu}, \mathrm{X}$., Wu, Y., and Chen, H. (2011a). Comparative antioxidative characteristics of polysaccharide-enriched extracts from natural sclerotia and cultured mycelia in submerged fermentation of Inonotus obliquus. Food Chem. 127(1): 74-79.

Xu, X., Yan, H., Chen, J., and Zhang, X. (2011b). Bioactive proteins from mushrooms. Biotechnol. Adv. 29(6): 667-674.

$\mathrm{Xu}, \mathrm{X}$., Zhang, X., and Chen, C. (2016a). Stimulated production of triterpenoids of Inonotus obliquus using methyl jasmonate and fatty acids. Ind. Crops Prod. 85: 49-57.

Xu, X., Zhao, W., and Shen, M. (2016b). Antioxidant activity of liquid cultured Inonotus obliquus polyphenols using tween-20 as a stimulatory agent: Correlation of the activity and the phenolic profiles. J. Taiwan Inst. Chem. Eng. 69: 41-47.

Xu, X.-Q., Hu, Y., and Zhu, L.-H. (2014a). The capability of Inonotus obliquus for lignocellulosic biomass degradation in peanut shell and for simultaneous production of bioactive polysaccharides and polyphenols in submerged fermentation. J. Taiwan Inst. Chem. Eng. 45(6): 2851-2858.

Xue, J., Tong, S., Wang, Z., and Liu, P. (2018). Chemical characterization and hypoglycaemic activities in vitro of two polysaccharides from Inonotus obliquus by submerged culture. Molecules 23(12): 3261 .

Yang, S., and Zheng, W. (1994). Factors affecting accumulation of hydrolysable tannins in cultured mycelia of Inonotus obliquus. Zhong Cao Yao. 38(12): 1874-1878.

Yang, S.-F., Zhuang, T.-F., Si, Y.-M., Qi, K.-Y., and Zhao, J. (2015). Coriolus versicolor mushroom polysaccharides exert immunoregulatory effects on mouse $B$ cells via membrane Ig and TLR-4 to activate the MAPK and NF-KB signaling pathways. Mol. Immunol. 64(1): 144-151.

Ying, Y.M., Zhang, L.Y., Zhang, X., Bai, H.B., Liang, D.E., Ma, L.F., Shan, W.G., and Zhan, Z.J. (2014). Terpenoids with alpha-glucosidase inhibitory activity from the submerged culture of Inonotus obliquus. Phytochemistry 108: 171-176.

Yogeeswari, P., and Sriram, D. (2005). Betulinic acid and its derivatives: a review on their biological properties. Curr. Med. Chem. 12(6): 657666.

Yonei, Y., Takahashi, Y., Matsushita, K., Watanabe, M., and Yoshioka, T. (2007). Double Blind Study of Health Claims for Food Containing Extract of Kabanoanatake (Charga: Fuscoporia obliqua)(RCT: randomized controlled trial). Anti-Aging Med. 4(1): 1-10.

Yong, T., Chen, S., Liang, D., Zuo, D., Diao, X., Deng, C., Wu, Y., Hu, H., Xie, Y., and Chen, D. (2018). Actions of Inonotus obliquus against Hyperuricemia through XOD and Bioactives Screened by Molecular Modeling. Int. J. Mol. Sci. 19(10): 3222.

Youn, M.J., Kim, J.K., Park, S.Y., Kim, Y., Kim, S.J., Lee, J.S., Chai, K.Y., Kim, H.J., Cui, M.X., So, H.S., Kim, K.Y., and Park, R. (2008). Chaga mushroom (Inonotus obliquus) induces G0/G1 arrest and apoptosis in human hepatoma HepG2 cells. World J. Gastroenterol. 14(4): 511.

Youn, M.J., Kim, J.K., Park, S.Y., Kim, Y., Park, C., Kim, E.S., Park, K.I., So, H.S., and Park, R. (2009). Potential anticancer properties of the water extract of Inontus obliquus by induction of apoptosis in melanoma B16-F10 cells. J. Ethnopharmacol. 121(2): 221-228.

Yu, J., Xiang, J.-Y., Xiang, H., and Xie, Q. (2020). Cecal Butyrate (Not Propionate) Was Connected with Metabolism-Related Chemicals of Mice, Based on the Different Effects of the Two Inonotus obliquus Extracts on Obesity and Their Mechanisms. ACS Omega. 5(27): 16690-16700.

Yu, Y., Shen, M., Song, Q., and Xie, J. (2018). Biological activities and pharmaceutical applications of polysaccharide from natural resources: A review. Carbohydr. Polym. 183: 91-101.

Yun, J.S., Pahk, J.W., Lee, J.S., Shin, W.C., Lee, S.Y., and Hong, E.K. (2011). Inonotus obliquus protects against oxidative stress-induced apoptosis and premature senescence. Molecules 31(5): 423-429.

Zhang, C.J., Guo, J.Y., Cheng, H., Li, L., Liu, Y., Shi, Y., Xu, J., and Yu, H.T. (2020). Spatial structure and anti-fatigue of polysaccharide from Inonotus obliquus. Int. J. Biol. Macromol. 151: 855-860.

Zhang, F.-P., Yang, Q.-Y., and Zhang, S.-B. (2016). Dual effect of phenolic nectar on three floral visitors of Elsholtzia rugulosa (Lamiaceae) in SW China. PLoS One 11(4): e0154381. 
Zhang, L., Lin, D., Li, H., Yu, S., Bai, J., Ding, Z., and Wu, J. (2018). Immunopotentiating effect of Inonotus obliquus fermentation products administered at vaccination in chickens. Mol. Cell. Probes 41: 43-51.

Zhang, L., Zhang, H.-Q., Liang, X.-Y., Zhang, H.-F., Zhang, T., and Liu, F.-E. (2013a). Melatonin ameliorates cognitive impairment induced by sleep deprivation in rats: role of oxidative stress, BDNF and CaMKII. Behav. Brain Res. 256: 72-81.

Zhang, M., Zhang, Y., Zhang, L., and Tian, Q. (2019). Mushroom polysaccharide lentinan for treating different types of cancers: A review of 12 years clinical studies in China. Prog. Mol. Biol. Transl. Sci. 163: 297-328.

Zhang, M., Zhu, L., Cui, S.W., Wang, Q., Zhou, T., and Shen, H. (2011). Fractionation, partial characterization and bioactivity of water-soluble polysaccharides and polysaccharide-protein complexes from Pleurotus geesteranus. Int. J. Biol. Macromol. 48(1): 5-12.

Zhang, N., Chen, H., Ma, L., and Zhang, Y. (2013b). Physical modifications of polysaccharide from Inonotus obliquus and the antioxidant properties. Int. J. Biol. Macromol. 54: 209-215.

Zhao, F., Mai, Q., Ma, J., Xu, M., Wang, X., Cui, T., Qiu, F., and Han, G. (2015a). Triterpenoids from Inonotus obliquus and their antitumor activities. Fitoterapia 101: 34-40.

Zhao, F., Xia, G., Chen, L., Zhao, J., Xie, Z., Qiu, F., and Han, G. (2016a). Chemical constituents from Inonotus obliquus and their antitumor activities. J. Nat. Med. 70(4): 721-730.

Zhao, Y., He, M., Ding, J., Xi, Q., Loake, G.J., and Zheng, W. (2016b). Regulation of anticancer styrylpyrone biosynthesis in the medicinal mushroom Inonotus obliquus requires thioredoxin mediated transnitrosylation of S-nitrosoglutathione reductase. Sci. Rep. 6(1): 1-14.

Zhao, Y., Miao, K., Zhang, M., Wei, Z., and Zheng, W. (2009). Effects of nitric oxide on production of antioxidant phenolic compounds in Phaeoporus obliquus. Mycosystema 28(5): 750-754.

Zhao, Y., Xi, Q., Xu, Q., He, M., Ding, J., Dai, Y., Keller, N.P., and Zheng, W. (2015b). Correlation of nitric oxide produced by an inducible nitric oxide synthase-like protein with enhanced expression of the phenylpropanoid pathway in Inonotus obliquus cocultured with Phellinus morii. Appl. Microbiol. Biotechnol. 99(10): 4361-4372.

Zheng, W., Gu, Q., Chen, C., Yang, S., Wei, J., and Chu, C. (2007b). Aminophenols and mold-water-extracts affect the accumulation of flavonoids and their antioxidant activity in cultured mycelia of Inonotus obliquus. Mycosystema 26(3): 414-425.

Zheng, W., Liu, Y., Pan, S., Yuan, W., Dai, Y., and Wei, J. (2011a). Involvements of S-nitrosylation and denitrosylation in the production of polyphenols by Inonotus obliquus. Appl. Microbiol. Biotechnol. 90(5): 1763.

Zheng, W., Miao, K., Liu, Y., Zhao, Y., Zhang, M., Pan, S., and Dai, Y. (2010). Chemical diversity of biologically active metabolites in the sclerotia of Inonotus obliquus and submerged culture strategies for up-regulating their production. Appl. Microbiol. Biotechnol. 87(4): 1237-1254.
Zheng, W., Miao, K., Zhang, Y., Pan, S., Zhang, M., and Jiang, H. (2009a) Nitric oxide mediates the fungal-elicitor-enhanced biosynthesis of antioxidant polyphenols in submerged cultures of Inonotus obliquus. Microbiology 155(10): 3440-3448.

Zheng, W., Xiang, X., Chen, C., Wang, Y., Zhao, Y., Jiang, J., and Chu, C. (2008a). Effects of culture media and three metal ions on the accumulation of lanosterol and ergosterol in cultured mycelia of Inonotus obliquus. Mycosystema 27(1): 126-139.

Zheng, W., Zhang, M., Zhao, Y., Miao, K., Pan, S., Cao, F., and Dai, Y. (2011b) Analysis of antioxidant metabolites by solvent extraction from sclerotia of Inonotus obliquus (Chaga). Phytochem. Anal. 22(2): 95-102.

Zheng, W., Zhang, M., Zhao, Y., Wang, Y., Miao, K., and Wei, Z. (2009b) Accumulation of antioxidant phenolic constituents in submerged cultures of Inonotus obliquus. Bioresour. Technol. 100(3): 1327-1335.

Zheng, W., Zhao, Y., Zheng, X., Liu, Y., Pan, S., Dai, Y., and Liu, F. (2011c). Production of antioxidant and antitumor metabolites by submerged cultures of Inonotus obliquus cocultured with Phellinus punctatus. Appl. Microbiol. Biotechnol. 89(1): 157-167.

Zheng, W., Zhao, Y.-X., Zhang, M., Yin, Z., Chen, C., and Wei, Z. (2008b) Phenolic compounds from Inonotus obliquus and their immune stimulating effects. Mycosystema 27(4): 574-581.

Zheng, W.-F., Liu, T., Xiang, X., and Gu, Q. (2007a). Sterol composition in field-grown and cultured mycelia of Inonotus obliquus. Acta Pharm. Sin. 42(7): 750-756.

Zhong, X., Zhong, Y., Yang, S., and Zheng, Z. (2015). Effect of Inonotus obliquus Polysaccharides on physical fatigue in mice. J. Tradit. Chin. Med. 35(4): 468-472.

Zhong, X.-H., Ren, K., Lu, S.-J., Yang, S.-Y., and Sun, D.-Z. (2009). Progress of research on Inonotus obliquus. Chin. J. Integr. Med. 15(2): 156-160.

Zhong, X.-H., Wang, L.-B., and Sun, D.-Z. (2011). Effects of inotodiol extracts from Inonotus obliquus on proliferation cycle and apoptotic gene of human lung adenocarcinoma cell line A549. Chin. J. Integr. Med. 17(3): 218-223.

Zhou, L.-W., Vlasák, J., Decock, C., Assefa, A., Stenlid, J., Abate, D., Wu, S.H., and Dai, Y.-C. (2016). Global diversity and taxonomy of the Inonotus linteus complex (Hymenochaetales, Basidiomycota): Sanghuangporus gen. nov., Tropicoporus excentrodendri and T. guanacastensis gen. et spp. nov., and 17 new combinations. Fungal Divers. 77(1): 335-347.

Zhu, L., and Xu, X. (2013). Stimulatory effect of different lignocellulosic materials for phenolic compound production and antioxidant activity from Inonotus obliquus in submerged fermentation. Appl. Biochem. Biotechnol. 169(7): 2138-2152.

Zou, C.-X., Zhang, Y.-Y., Bai, M., Huang, X.-X., Wang, X.-B., and Song, S.-J. (2019). Aromatic compounds from the sclerotia of Inonotus obliquus. Nat. Prod. Res. 1-4 